\title{
Technological and Economic Potential of Options to Enhance, Maintain, and Manage Biological Carbon Reservoirs and Geo-engineering.
}

Kauppi, P.E.

Cambridge University Press

2001

Kauppi, P.E. and Sedjo, R. 2001. Technological and Economic Potential of Options to Enhance, Maintain, and Manage Biological Carbon Reservoirs and Geo-engineering. Climate Change 2001 (Mitigation): 301-343.

http://hdl.handle.net/1975/316

Downloaded from Helda, University of Helsinki institutional repository.

This is an electronic reprint of the original article.

This reprint may differ from the original in pagination and typographic detail.

Please cite the original version. 


\section{4}

\section{Technological and Economic Potential of Options to Enhance, Maintain, and Manage Biological Carbon Reservoirs and Geo-engineering}

Co-ordinating Lead Authors:

PEKKA KAUPPI (FINLAND), ROGER SEDJO (USA)

\section{Lead Authors:}

Michael Apps (Canada), Carlos Cerri (Brazil), Takao Fujimori (Japan), Henry Janzen (Canada), Olga Krankina (Russian Federation/USA), Willy Makundi (Tanzania/USA), Gregg Marland (USA), Omar Masera (Mexico), Gert-Jan Nabuurs (Netherlands), Wan Razali (Malaysia), N.H. Ravindranath (India)

Contributing Authors:

David Keith (USA), Haroon Kheshgi (USA), Jari Liski (Finland)

Review Editors:

Eduardo Calvo (Peru), Birger Solberg (Norway) 


\section{CONTENTS}

Executive Summary

\subsection{Introduction}

4.2 Land Use, Land-Use Change, and Carbon Cycling in Terrestrial Ecosystems

4.2.1 Historical Land-Use Change in the Tropics

4.2.1.1 Trends in Land Use and Changes in Carbon Stocks

4.2.1.2 Driving Forces for Land-Use Change

4.2.2 Land Use in the Temperate and Boreal

Zones

4.2.2.1 Historical and Present Land Use in the Temperate and Boreal Zones

4.2.2.2 Driving Forces for Land Use Change

4.2.3 Forest Disturbance Regimes

4.2.4 Changes in Global Climate and Other Indirect Human Effects

4.3 Processes and Practices that Can Contribute to Climate Mitigation

4.3.1 System Constraints and Considerations

4.3.2 Opportunities in Forests

4.3.2.1 Wood Products

4.3.2.2 Managing Wetlands
4.3.3 Opportunities in Agricultural Lands

324

4.4 Environmental Costs and Ancillary Benefits

326

4.4.1 Environmental Costs and Ancillary Benefits in Forests

306
4.4.2 Environmental Costs and Ancillary Benefits in Agricultural Lands

4.5.1 Economics 327

4.5.2 Institutional Structures and Equity Issues

4.6 Market and Non-market Options to Enhance, Maintain, and Manage Carbon Pools

4.6.1 Introduction, Taxes, and Quotas

4.6.2 Carbon Offsets, Tradable Permits and Leakage

4.6.3 Risks, Rights, and Practical Economics

4.7 Biological Uptake in Oceans and Fresh-water Reservoirs; and Geo-engineering

4.8 Future Research Needs

References
4.5 Social and Economic Considerations 327 


\section{EXECUTIVE SUMMARY}

Terrestrial ecosystems offer significant potential to capture and hold carbon at modest social costs. The Intergovernmental Panel on Climate Change (IPCC) Second Assessment Report estimated that about 60 to $87 \mathrm{GtC}$ could be conserved or sequestered in forests by the year 2050 and another 23 to 44 GtC could be sequestered in agricultural soils. In this chapter, we describe and assess biological mitigation measures in terrestrial ecosystems, focusing on the physical mitigation potential, ecological and environmental constraints, economics, and social considerations. Also the so-called geo-engineering options are discussed.

The mitigation costs through forestry can be quite modest, US\$0.1-US\$20/tC in some tropical developing countries, and somewhat higher (US\$20-US\$100/tC) in developed countries. The costs of biological mitigation, therefore, are low compared to those of many other alternative measures. The costs would be expected to rise, however, if large areas of land were taken from alternative uses. The technologies for preserving existing terrestrial $\mathrm{C}$ and enhancing $\mathrm{C}$ pools, while using biomass in a sustainable way, already exist and can be further improved.

Increased carbon pools from management of terrestrial ecosystems can only partially offset fossil fuel emissions. Moreover, larger $\mathrm{C}$ stocks may pose a risk for higher carbon dioxide $\left(\mathrm{CO}_{2}\right)$ emissions in the future, if the $\mathrm{C}$-conserving practices are discontinued. For example, abandoning fire control in forests or reverting to intensive tillage in agriculture may result in rapid loss of at least part of the $\mathrm{C}$ accumulated during previous years. However, using biomass as a fuel or wood to displace more energy-intensive materials in products can provide permanent carbon mitigation benefits. It is useful to evaluate terrestrial sequestration opportunities alongside emission reduction strategies as both approaches will likely be required to control atmospheric $\mathrm{CO}_{2}$ levels.

Carbon reservoirs in most ecosystems eventually approach some maximum level. Thus, an ecosystem depleted of carbon by past events may have a high potential rate of carbon accumulation, while one with a large carbon pool tends to have a low rate of carbon sequestration. As ecosystems eventually approach their maximum carbon pool, the sink (i.e., the rate of change of the pool) will diminish. Although both the sequestration rate and pool of carbon may be relatively high at some stages, they cannot be maximized simultaneously. Thus, management strategies for an ecosystem may depend on whether the goal is to enhance short-term accumulation or to maintain the carbon reservoirs through time. The ecologically achiev- able balance between the two goals is constrained by disturbance history, site productivity, and target time frame. For example, options to maximize sequestration by 2010 may not maximize sequestration by 2020 or 2050 ; in some cases, maximizing sequestration by 2010 may lead to higher emissions in later years.

The effectiveness of $\mathrm{C}$ mitigation strategies, and the security of expanded C pools, will be affected by future global changes, but the impacts of these changes will vary by geographic region, ecosystem type, and local abilities to adapt. For example, increases in atmospheric $\mathrm{CO}_{2}$, changes in climate, modified nutrient cycles, and altered disturbance regimes can each have negative or positive effects on $\mathrm{C}$ pools in terrestrial ecosystems.

In the past, land management has often resulted in reduced $\mathrm{C}$ pools, but in many regions like Western Europe, $\mathrm{C}$ pools have now stabilized and are recovering. In most countries in temperate and boreal regions forests are expanding, although current $\mathrm{C}$ pools are still smaller than those in pre-industrial or prehistoric times. While complete recovery of pre-historic $\mathrm{C}$ pools is unlikely, there is potential for substantial increases in carbon stocks. The Food and Agriculture Organization (FAO) and the UN Economic Commission for Europe (ECE)'s statistics suggest that the average net annual increment has exceeded timber fellings in managed boreal and temperate forests in the early 1990s. For example, C stocks in the live tree biomass has increased by 0.17 billion tonnes (gigatonnes $=\mathrm{Gt}$ ) $\mathrm{C} / \mathrm{yr}$ in the USA and $0.11 \mathrm{GtC} / \mathrm{yr}$ in Western Europe, absorbing about $10 \%$ of global fossil $\mathrm{CO}_{2}$ emissions for that time period. Though these estimates do not include changes in litter and soils, they illustrate that land surfaces play a significant and changing role in the atmospheric carbon budget and, hence, provide potentially powerful opportunities for climate mitigation.

In some tropical countries, however, the average net loss of forest carbon stocks continues, though rates of deforestation may have declined slightly in the last decade. In agricultural lands, options are now available to recover partially the $\mathrm{C}$ lost during the conversion from forest or grasslands.

Land is a precious and limited resource used for many purposes in every country. The relationship of climate mitigation strategies with other land uses may be competitive, neutral, or symbiotic. An analysis of the literature suggests that $\mathrm{C}$ mitigation strategies can be pursued as one element of more comprehensive strategies aimed at sustainable development, where 
increasing $\mathrm{C}$ stocks is but one of many objectives. Often, measures can be adopted within forestry, agriculture, and other land uses to provide $\mathrm{C}$ mitigation and, at the same time, also advance other social, economic, and environmental goals. Carbon mitigation can provide additional value and income to land management and rural development. Local solutions and targets can be adapted to priorities of sustainable development at national, regional, and global levels.

A key to making $\mathrm{C}$ mitigation activities effective and sustainable is to balance $\mathrm{C}$ mitigation with other ecological and/or environmental, economic, and social goals of land use. Many biological mitigation strategies may be neutral or favourable for all three goals and become accepted as "no regrets" or "win-win" solutions. In other cases, compromises may be needed. Important potential environmental impacts include effects on biodiversity, effects on amount and quality of water resources (particularly where they are already scarce), and long-term impacts on ecosystem productivity. Cumulative environmental, economic, and social impacts could be assessed within individual projects and also from broader, national and international perspectives. An important issue is "leakage" - an expanded or conserved $\mathrm{C}$ pool in one area leading to increased emissions elsewhere. Social acceptance at the local, national, and global scale may also influence how effectively mitigation policies are implemented.

In tropical regions, there are large opportunities for $\mathrm{C}$ mitigation, though they cannot be considered in isolation from broader policies in forestry, agriculture, and other sectors. Additionally, options vary by social and economic conditions: in some regions, slowing or halting deforestation is the major mitigation opportunity; in others, where deforestation rates have declined to marginal levels, improved natural forest management practices and, afforestation and reforestation of degraded forests and wastelands are the most attractive opportunities.

Non-tropical countries also have opportunities to preserve existing $\mathrm{C}$ pools, enhance $\mathrm{C}$ pools, or use biomass to offset fossil fuel use. Examples of strategies include fire or insect control, forest conservation, establishing fast-growing stands, changing silvicultural practices, planting trees in urban areas, ameliorating waste management practices, managing agricultural lands to store more $\mathrm{C}$ in soils, improving management of grazing lands, and re-planting grasses or trees on cultivated lands.

Wood and other biological products play several important roles in carbon mitigation: they act as a carbon reservoir; they can replace construction materials that require more fossil fuel input; and they can be burned in place of fossil fuels for renewable energy. Wood products already contribute somewhat to climate mitigation, but if infrastructures and incentives can be developed, wood and agricultural products may become vital elements of a sustainable economy: they are among the few renewable resources available on a large scale.
A comprehensive analysis of carbon mitigation measures would consider:

- $\quad$ potential contributions to $\mathrm{C}$ pools over time;

- sustainability, security, resilience, permanence, and robustness of the $\mathrm{C}$ pool maintained or created;

- compatibility with other land-use objectives;

- leakage and additionality issues;

- economic costs;

- environmental impacts other than climate mitigation;

- social, cultural, and cross-cutting issues as well as issues of equity; and

- the system-wide effects on $\mathrm{C}$ flows in the energy and materials sector.

Activities undertaken for other reasons may enhance mitigation. An obvious example is reduced rates of tropical deforestation. Furthermore, because wealthy countries generally have a stable forest estate, it could be argued that economic development is associated with activities that build up forest carbon reservoirs in the long run.

Marine ecosystems may also offer possibilities for removing $\mathrm{CO}_{2}$ from the atmosphere. The standing stock of $\mathrm{C}$ in the marine biosphere is very small, however, and efforts could focus not only on increasing biological C stocks, but also on using biospheric processes to remove $\mathrm{C}$ from the atmosphere and transport it to the deep ocean. Some initial experiments have been performed, but fundamental questions remain about the permanence and stability of $\mathrm{C}$ removals, and about possible unintended consequences of the large-scale manipulations required to have significant impact on the atmosphere. In addition, the economics of such approaches have not yet been determined.

Geo-engineering involves efforts to stabilize the climate system by directly managing the energy balance of the earth, thereby overcoming the enhanced greenhouse effect. Although there appear to be possibilities for engineering the terrestrial energy balance, human understanding of the system is still rudimentary. The likelihood of unanticipated consequences is large, and it may not even be possible to engineer the regional distribution of temperature, precipitation, etc. Geo-engineering raises scientific and technical questions as well as many ethical, legal, and equity issues. And yet, some basic inquiry does seem appropriate.

In practice, by the year 2010 mitigation in land use, land-use change, and forestry activities can lead to significant mitigation of $\mathrm{CO}_{2}$ emissions. Many of these activities are compatible with, or complement, other objectives in managing land. The overall effects of altering marine ecosystems to act as carbon sinks or of applying geo-engineering technology in climate change mitigation remain unresolved and are not, therefore, ready for near-term application. 


\subsection{Introduction}

Land is used to raise crops, graze animals, harvest timber and fuel, collect and store water, create the by-ways of travel and the foundations of commerce, mine minerals and materials, dispose of our wastes, recreate people's bodies and souls, house the monuments of history and culture, and provide habitat for humans and the other occupants of the earth. Can land, and water, also be managed to retain more carbon, and thereby mitigate the increasing concentration of atmospheric carbon dioxide $\left(\mathrm{CO}_{2}\right)$ ? This chapter examines the present scientific thinking on this question.

The atmosphere now contains about 760 billion tonnes (gigatonnes $=\mathrm{Gt}$ ) of carbon as $\mathrm{CO}_{2}$, an amount that has increased by an average of $3.3 \pm 0.2 \mathrm{GtC}$ each year throughout the $1990 \mathrm{~s}$, mostly from combustion of fossil fuels (IPCC, 2000a). Atmospheric $\mathrm{C}$ represents only a fraction $(\sim 30 \%)$ of the $\mathrm{C}$ in terrestrial ecosystems; vegetation contains nearly 500GtC, while soils contain another $2000 \mathrm{GtC}$ in organic matter and detritus (Schimel, 1995; WBGU, 1998) as cited in Intergovernmental Panel on Climate Change (IPCC) Special Report on Land Use, Land-Use Change and Forestry (LULUCF) (IPCC, 2000a). Table 4.1 provides estimates of the carbon stocks in terrestrial ecosystems now.

The Second Assessment Report (SAR) of the IPCC (1996) suggested that 700Mha of forestland might be available for carbon conservation globally $-138 \mathrm{Mha}$ for slowed tropical deforestation, 217Mha for regeneration of tropical forests, and 345Mha for plantations and agroforestry. The IPCC suggested that by 2050 this area could provide a cumulative mitigation impact of 60 to $87 \mathrm{GtC}$, of which 45 to $72 \mathrm{GtC}$ in the tropics. Towards the end of this time interval, the mitigation impact could approach a maximum rate of $2.2 \mathrm{GtC} / \mathrm{yr}$. The cost of mitigation (excluding land and other transaction costs) was envisioned to be about 2 to 8US\$/tC. The SAR (IPCC, 1996) further suggested

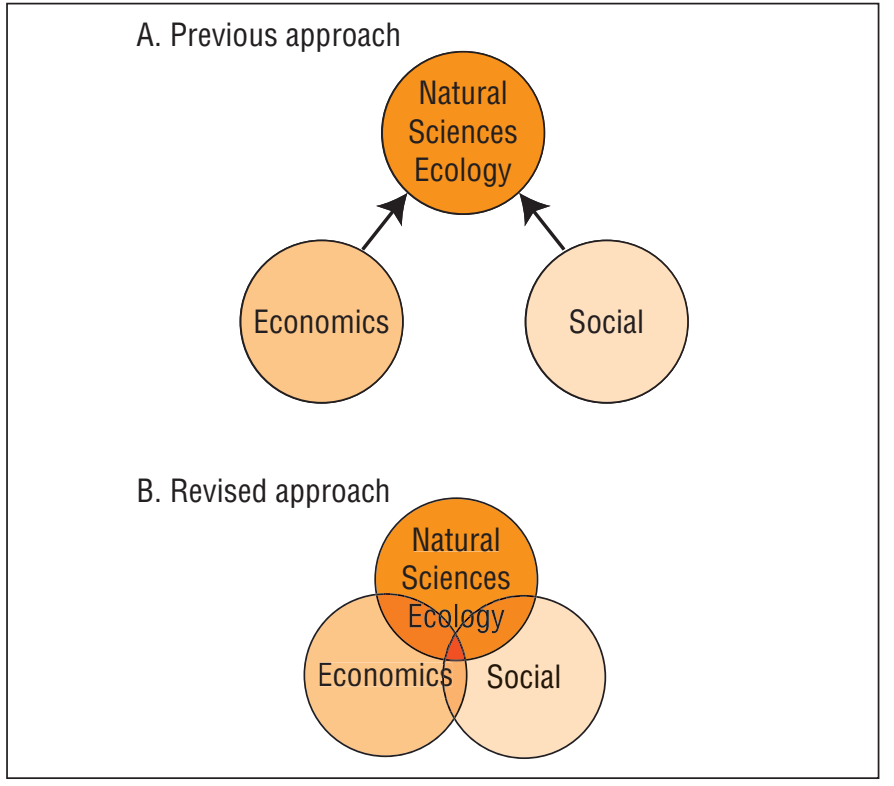

Figure 4.1: Evolution of approaches to carbon sequestration in terrestrial ecosystems. Previous assessments (e.g., IPCC, 1996) tended to focus on ecological processes and potentials, and treated economic and social factors as constraints (A). A slightly different viewpoint considers the three dimensions as mutually reinforcing and seeks to maximize the overlaps (B).

that, over the next 50 years, an additional 0.4 and $0.8 \mathrm{GtC}$ could be sequestered per year in agricultural soils, with the adoption of appropriate management practices.

The current report, while supporting many of these earlier findings, provides a broader evaluation of the potential for management of $\mathrm{C}$ stocks in the biosphere (Figure 4.1). Recent studies, for example, suggest that costs may often be higher than estimated earlier, particularly when opportunity costs of the

Table 4.1: Estimates of global carbon stocks in vegetation and soils to $1 \mathrm{~m}$ depth (from Bolin et al., 2000; based on WGBU, 1998).

\begin{tabular}{|c|c|c|c|c|}
\hline Temperate forests & 10.4 & 59 & 100 & 159 \\
\hline Boreal forests & 13.7 & 88 & 471 & 559 \\
\hline Tropical savannas & 22.5 & 66 & 264 & 330 \\
\hline Deserts and semideserts & 45.5 & 8 & 191 & 199 \\
\hline Tundra & 9.5 & 6 & 121 & 127 \\
\hline Wetlands & 3.5 & 15 & 225 & 240 \\
\hline Croplands & 16.0 & 3 & 128 & 131 \\
\hline
\end{tabular}


land are included. In addition, the issue of "leakage" (where actions at one site influence actions elsewhere, a problem not considered by the SAR) is examined. This report considers forests, grasslands, croplands, and wetlands, and, where possible, examines all $\mathrm{C}$ pools within them. Carbon mitigation is evaluated as one of many services provided by ecosystems. The objectives of this chapter are to review progress made since the IPCC-SAR, and to evaluate prospects for storing more carbon in ways that ensure the continued provision of other goods and services from the varied and finite land resources.

The aim of this chapter is not to assess specifically the implications of the Kyoto Protocol (UNFCCC, 1997), a mandate assigned to the IPCC Special Report on LULUCF (IPCC, 2000a). Rather, it seeks to provide a broader scientific view of the prospects and problems of land management for carbon sequestration, unconstrained by the limited scope of the Kyoto Protocol.

This chapter begins by describing the current state of land use, the history of land use, ongoing changes in land use, pressures driving these changes, and potential competition among demands for land (Section 4.3). It then considers opportunities for enhanced $\mathrm{C}$ stocks, especially in forestry and agriculture (Section 4.4). Having identified possible $\mathrm{C}$ conservation measures, the physical, environmental, social, and economic impacts of these measures are examined; and assessment is made of how they augment or compete with other services provided by land (Sections 4.5 - 4.7). How these options might be evaluated and, where appropriate, encouraged (Sections 4.8 and 4.9) is also considered. Finally, the prospects for managing marine ecosystems to increase carbon sequestration, and the possibility of managing the global ecosystem by 'geo-engineering' of the earth's energy balance (Section 4.10) are considered.

Land-use changes and the pressures that influence them vary widely, especially between tropical and non-tropical regions. Both of these regions are addressed.

\subsection{Land Use, Land-Use Change, and Carbon Cycling in Terrestrial Ecosystems}

Terrestrial ecosystems provide an active mechanism (photosynthesis) for biological removal of $\mathrm{CO}_{2}$ from the atmosphere. They act as reservoirs of photosynthetically-fixed $\mathrm{C}$ by storing it in various forms in plant tissues, in dead organic material, and in soils. Terrestrial ecosystems also provide a flow of harvestable products that not only contain carbon but also compete in the market place with fossil fuels, and with other materials for construction (such as cement), and for other purposes (such as plastics) that also have implications for the global carbon cycle.

Human activities have changed terrestrial carbon pools. The largest changes occurred with the conversion of natural ecosys- tems to arable lands. Such disruptions typically result in a large reduction of vegetation biomass and a loss of about $30 \%$ of the $\mathrm{C}$ in the surface 1 metre of soil (Davidson and Ackermann, 1993; Anderson, 1995; Houghton, 1995a; Kolchugina et al., 1995). Globally, conversion to arable agriculture has resulted in soil C losses of about 50GtC (Harrison et al., 1993; Scharpenseel and Becker-Heidmann, 1994; Houghton, 1995a; Cole et al., 1996; Paustian et al., 2000), and total emissions of $\mathrm{C}$ from land use change, including that from biomass loss, have amounted to about $122 \pm 40 \mathrm{GtC}$ (Houghton, 1995b; Schimel, 1995). Most of the soil C losses occur within a few years or decades of conversion, so that in temperate zones, where there is little expansion of agricultural lands now, losses of $\mathrm{C}$ have largely abated (Cole et al., 1993; Anderson, 1995; Janzen et al., 1998; Larionova et al., 1998). Tropical areas, however, remain an important source of $\mathrm{CO}_{2}$ because of widespread clearing of new lands and reduced duration of "fallow" periods in shifting agriculture systems (Paustian et al., 1997b; Scholes and van Breemen, 1997; Woomer et al., 1997; Mosier, 1998).

The competition for land varies among countries and within a country. Land-use and forestry policies for $\mathrm{C}$ management may be most successful when climate mitigation is considered alongside other needs for land, including agriculture, forestry, agroforestry, biodiversity, soil and water conservation, and recreation. Forest fires, for example, are controlled, in many parts of the world, not as a measure for carbon mitigation, but simply because fire threatens areas of human settlement and the habitats of living organisms.

Similarly, biodiversity and landscape considerations have motivated protection of old-growth stands in temperate, boreal, and tropical rain forests from commercial logging. In many cases such decisions have prevented $\mathrm{C}$ release into the atmosphere, even though $\mathrm{C}$ mitigation was not the initial intent (Harmon et al., 1990). The impact of harvest restrictions on C pool in old-growth forests may be affected by "leakage". If one ecosystem is protected but timber demand remains constant, logging may simply be shifted to another, similar ecosystem elsewhere, perhaps to a country where conservation priorities are lower.

\subsubsection{Historical Land-Use Change in the Tropics}

\subsubsection{Trends in Land Use and Changes in Carbon Stocks}

Tropical forests were largely intact until colonial times, when large tracts were removed to provide raw materials for railroads, ships, etc., in the period following the industrial revolution. The loss of tropical forests escalated in the second half of the 20th century. According to the UN Food and Agriculture Organization (FAO, 1996), about 15.4 million ha of natural tropical forests are lost each year. Of this, $42 \%$ occurs in Latin America, 31\% in Africa, and 27\% in Asia. Brunner et al. (1998) estimated tropical deforestation at 19.1 million ha/yr during the period 1990 to 1995. There has, how- 


\section{Box 4.1. Stocks and Flows}

The global carbon cycle consists of the various stocks of carbon in the earth system and the flows of carbon between these stocks. It is discussed at length in IPCC WG I (Prentice et al., 2001) and IPCC Special Report on LULUCF (IPCC, 2000a) and is illustrated in Figure 4.2.

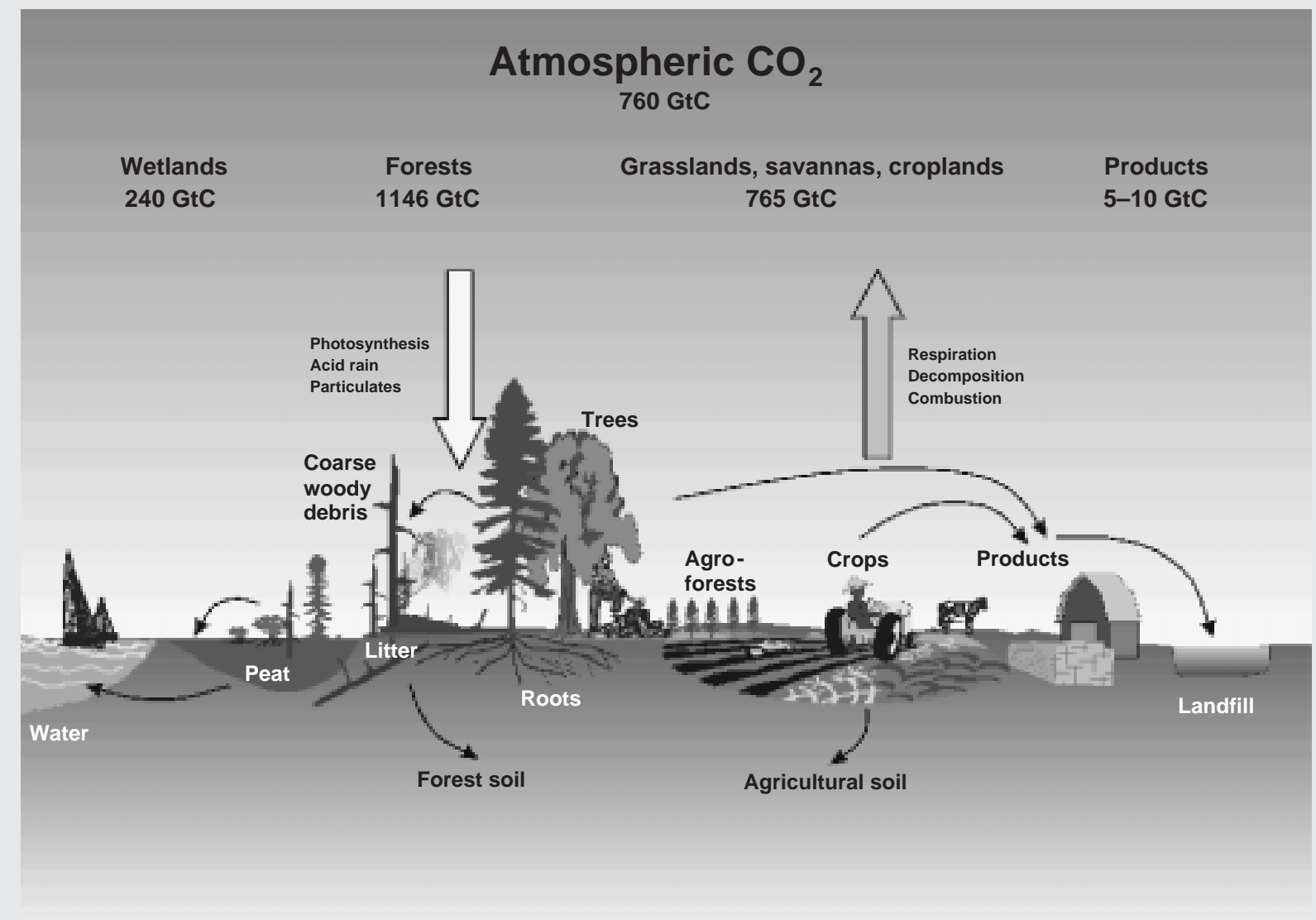

Figure 4.2: Different ecosystems, their components, and human activities. The carbon stocks associated with the different ecosystems are stored in aboveground and belowground biomass, detrital material (dead organic matter), and soils. Carbon is withdrawn from the atmosphere through photosynthesis (vertical down arrow), and returned by oxidation processes that include plant respiration, decomposition, and combustion (vertical up arrow). Carbon is also transferred within ecosystems and to other locations (horizontal arrows). Both natural processes and human activities affect carbon flows. Mitigation activities directed at one ecosystem component generally have additional effects influencing carbon accumulation in, or loss from, other components. Estimates of ecosystem and atmospheric C stocks are adapted from Bolin et al. (2000). Values for C stocks in some ecosystems are still very uncertain. Not shown are estimates of C stocks in tundra (127GtC), deserts and semi-deserts (199GtC), and oceans (approx. 39,000GtC) (numbers are taken from Special Report on LULUCF, Fig 1-1, page 30; IPCC, 2000a).

A consequence of the conservation of mass is that the net of all of the flows (measured as a rate variable in units such as tC/yr) into and out of a given reservoir or stock (measured in units such as $\mathrm{tC}$ ) during a period of time must equal the change in the stock (tC) in that period. Conversely, a change in stock of a reservoir during a given period must exactly equal the integrated net difference in $\mathrm{C}$ flows into and out of that reservoir during that period. Elsewhere in this text the word "pool" is sometimes used to represent the various reservoirs of carbon in the global carbon cycle. The word "sink" is used to indicate the net positive flow of carbon into a terrestrial carbon pool.

The maximum rate of net ecosystem carbon uptake cannot occur at the same time as the maximum ecosystem carbon stock (see Figure 4.3). An ecosystem depleted of carbon by past events may have much higher rates of carbon accumulation than a comparable one in which carbon stocks have been maintained. Ecosystems eventually approach some maximum carbon stock - a carrying capacity - at which time the flows into the carbon pool are balanced by flows out of the carbon pool. Because $\mathrm{C}$ sink and $\mathrm{C}$ stock in ecosystems cannot be maximized simultaneously, mitigation activities aimed at enhancing the sink and maintaining the biological carbon stock coincide only partially (IGBP, 1998). 


\section{Box 4.1. continued}

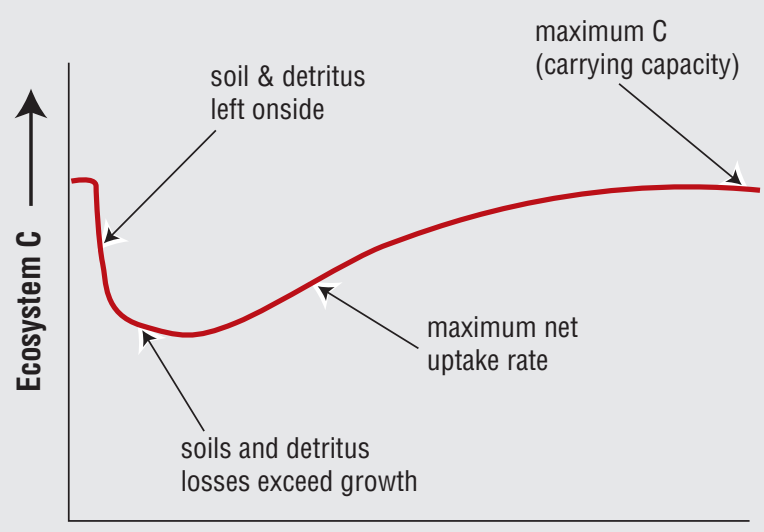

Time since disturbance (age)

Figure 4.3: An example of net changes in ecosystem carbon stocks over time. Changes in individual ecosystem components take place at different rates, but it is the net of the changes in all interconnected pools that determines the net flow to or from the atmosphere. In the example, the accumulation of biomass initially is at a lower rate than the decomposition of the dead organic matter stock so the stock of ecosystem $C$ declines. Later in the cycle, dead organic matter stocks may increase, although other components have reached a steady state. Maximum ecosystem stocks (highest value of ecosystem $C$ ) occur at a later time than the maximum rate of net carbon uptake (steepest slope of the ecosystem $C$ line).

Similarly, the maximum rate of $\mathrm{C}$ substitution cannot occur at the same time as maximum $\mathrm{C}$ conservation. High rates of carbon substitution, through use of forest products or biofuels, generally require high productivity and efficient manufacture and use of derived products.

Carbon taken up by the biosphere may also accumulate in offsite pools - as products or in landfills - but it continues to oxidize at rates that depend on the conditions of those pools. It is the net of many flows that defines the changes in carbon stocks of off-site pools as well as of on-site pools. Carbon accumulation in off-site pools is an often overlooked, but a potentially important, form of sequestration.

ever, been a large increase in area devoted to forest plantations. By 1990, there were 61.3 million ha under plantations and the rate of establishment is now about 3.2 million ha/yr (FAO, 1996).

As pointed out by the IPCC (IPCC, 1996) global estimates of $\mathrm{C}$ emissions from deforestation have remained highly uncertain and show high geographical variability. The magnitude of forest regeneration (particularly secondary forest regrowth and regrowth of abandoned lands) and forest degradation processes is not well documented. Improving the accuracy of these estimates remains an urgent and challenging task (Houghton et al., 2000).

Estimates of $\mathrm{C}$ emissions from land-use change and forestry activities in the tropics during the1990s range from 1.1 to $1.7 \mathrm{GtC} / \mathrm{yr}$, with a best estimate of $1.6 \mathrm{GtC} / \mathrm{yr}$ (Brown et al., 1996b; Melillo et al., 1993; Bolin et al., 2000). These estimates may change with improved information on biomass densities and land-use conversion. Detailed studies for major tropical countries in the early 1990s, studies that include forest regeneration and afforestation, show lower net emissions for most countries than those from aggregate estimates (Makundi et al., 1998).

A review of scenarios of future land-use changes in the tropics, and their implications for greenhouse gas (GHG) emissions, shows a wide range of estimates, particularly for the first part of the $21^{\text {st }}$ century, where estimates differ by a factor of 14 (Alcamo and Swart, 1998). These disparities reflect a lack of agreement on the definition of deforestation, and a lack of knowledge and agreement on the estimation of $\mathrm{C}$ emissions (Alcamo and Swart, 1998). These scenarios can be divided into two groups: in one group emissions decline smoothly after 1990 ; in the other group emissions increase for a few decades after 1990 .

\subsubsection{Driving Forces for Land-use Change}

The rates and causes of land-use change vary by region and scale (Kaimowitz and Angelsen, 1998). Deforestation is often considered a one way process, but the landscape is a dynamic mosaic of land uses and vegetation types, with transitions both to and away from forest (Houghton et al., 2000). Natural fac- 
tors, such as forest fires and pests, as well as socio-economic processes, many of which are not seen at the local level, interact in complex ways, complicating analysis. Understanding the causes of this mosaic of land-use and/or land-cover transitions in order to understand and predict the net effect on deforestation rates and $\mathrm{C}$ emissions remains a key research challenge.

Conversion of forests to pasture and cropland has been the most important proximal cause of tropical deforestation. Nonsustainable logging has been the leading factor in parts of Southeast Asia, whereas excessive harvest of wood fuel has been important only in specific sub-country regions and in some African countries (Kaimowitz and Angelsen, 1998). According to Bawa and Dayanandan (1997), the causes (correlates) of deforestation are many and varied, with complex interactions. Overall, Bawa and Dayanandan found that population density, cattle density, and external debt were the key factors. In Africa, the most important factors were extraction of fuelwood and charcoal and demand for cropland; in Asia, it was cropland; and in Latin America, it was cattle density.

Most analyses of land-use change and forestry have concentrated on proximal reasons for land-use and/or land-cover change; that is, on land uses such as agriculture, pasture, and timber extraction that replace forests. But Meyer and Turner (1992) have identified six "underlying" forces: (1) population, (2) level of affluence, (3) technology, (4) political economy, (5) political structure, and 6) attitudes and values. The influence of each varies by region and country.

The rate of population growth is now apparently declining, but the population, and hence the demand for food and other land services, is still growing (Roberts, 1999). Population growth has been widely cited as a major cause of deforestation (Myers, 1989), but the relationship between population and deforestation is not simple. Population growth exerts increasing pressure on resources, but whether these pressures lead to forest degradation or to positive changes (e.g., afforestation, improved forest management, and better technology) depends largely on social structure. Extensive migration may also lead to deforestation and soil erosion. Simplistic assumptions about population and deforestation also do not apply where high population densities and/or growth rates are accompanied by forest conservation and reforestation programmes. In India, for example, deforestation rates have declined since 1980, despite population growth, owing to effective forest conservation legislation (Ravindranath and Hall, 1994).

Patterns that affect land-use are changed by economic development. Affluence usually increases consumption, but it does not necessarily decrease terrestrial C stocks. The maintenance of ecosystems tends to improve with increasing and better distribution of wealth, as well as with proper institutional structures and sound development strategies. The demand for and interest in forests and their services is the driving force for the technological and economic capacity to maintain forests. Also, wealthy societies tend to be urbanized and this may reduce destructive pressures on forests. Technological development provides efficient tools for land-use change and for high-value, alternative uses. Technology can also limit encroachment. As seen by the "green revolution" in agriculture, technological development can increase productivity on intensively managed land, thereby releasing other land areas from agriculture (Waggoner, 1994). Nevertheless, there is always the risk of leakage (i.e., tendencies to transfer destructive operations from the developed to less developed areas and countries), or the possibility that technology development and transfer will have positive spillover effects (Brown et al., 2000; Noble et al., 2000)

In many countries, especially those seeking development of frontier areas, subsidies are provided for activities promoting economic development. Land clearing may be subsidized directly or by providing property rights to cleared land. Frontier development is often considered desirable for security or where there is a disputed area.

Land-use change is driven largely by efforts perceived as "best and highest" use of the land. But benefits of the land that are non-market and/or external to the direct user (e.g., watershed protection, biodiversity, and carbon mitigation) may be ignored by land managers. For example, the decision to convert forestland to agriculture may ignore the many external and non-market benefits lost. Moreover, where long-term land rights are insecure, lands may be used to generate short-term benefits, with disregard for long-term benefits.

Factors related to social structure and political economy have not been studied widely, but studies at the country and regional levels suggest that deforestation is favoured by the following factors: growing landlessness and persistent inequalities in access to land, insecure land tenure, land speculation, rising external debt, large-scale expansion in commercial agriculture, erosion of traditional systems of resource management and community control, and widespread migration of impoverished people to ecologically fragile areas (Hecht, 1985; Palo and Uusivuori, 1999; Tole, 1998).

\subsubsection{Land Use in the Temperate and Boreal Zones}

\subsubsection{Historical and Present Land Use in the Temperate and Boreal Zones}

The temperate zone is the most populated zone of the world, while the boreal zone is quite sparsely populated. For thousands of years forest area has diminished, particularly in the temperate zone, as forests were cleared for agriculture and pasture. Clearing of the European Mediterranean region began $c a$ 5000 years ago; in Central Europe and in China deforestation occurred in early Medieval times; in parts of Russia and Mongolia forest clearing occurred in late Medieval times; and in North America clearing occurred mainly in the $19^{\text {th }}$ century (Mather, 1990, see Figure 4.4). Since the mid $20^{\text {th }}$ century the 
net forest area of the temperate zone has no longer decreased but has instead increased (Kauppi et al., 1992). The inner parts of the boreal zone in Siberia, Alaska, and Canada have not been subject to significant land-use management. The opportunities present to store carbon in terrestrial ecosystems in the boreal and temperate zones are thus very much determined by historical land-use change and the associated losses of carbon (Kurz and Apps, 1999).

Understanding the historic and current net sink of $\mathrm{C}$ in the temperate and boreal zones is important to assessing the potential of present and future management options. In general, estimates of $\mathrm{C}$ flows have been based on a variety of methods and data, resulting in a wide range of reported values for $\mathrm{C}$ flows per region. The confidence level in each separate value is therefore low. For example, for European forests the estimates of the present $\mathrm{C}$ sink vary from almost 0 to $0.5 \mathrm{GtC} / \mathrm{yr}$

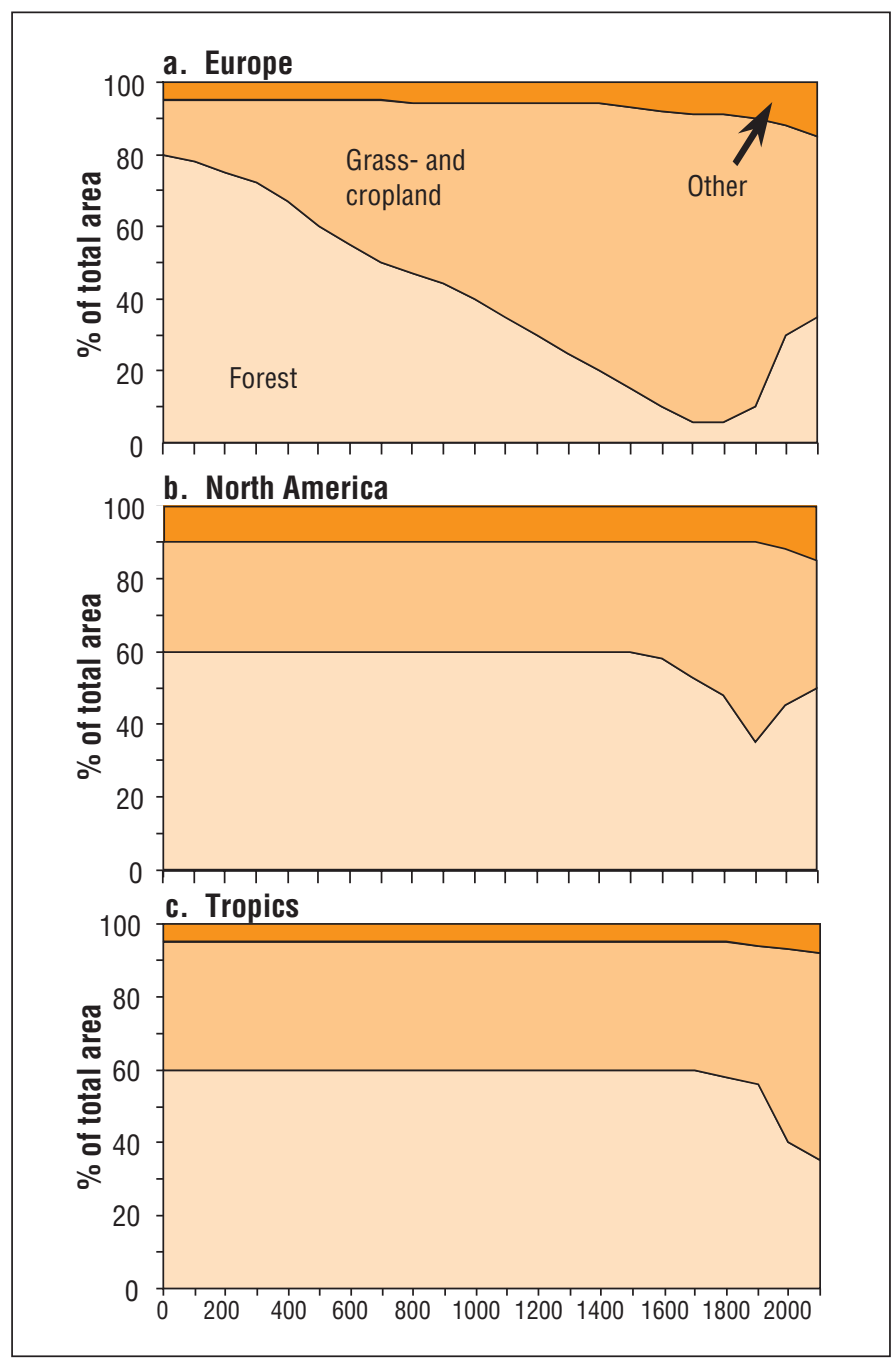

Figure 4.4: Indicative figure displaying historical changes in land use in three world regions. The presented values should not be taken as absolute, because the historical evidence is often only anecdotal (Mather, 1990; Kauppi et al., 1992; Palo and Uusivuori, 1999; Farrell et al., 2000).
(Nabuurs et al., 1997; Martin et al., 1998; Valentini et al., 2000; Schulze, 2000). For Canada, early estimates, based on a static assessment, indicated a net sink of $0.08 \mathrm{GtC} / \mathrm{yr}$ for the mid-1970s (Kurz et al., 1992); whereas subsequent analyses, accounting for changes in forest disturbances over time (see section 4.2.3), indicated that Canadian forests became a small net source of C $(-0.068 \mathrm{GtC} / \mathrm{yr})$ by the early 1990 s (Kurz and Apps, 1999). Estimates of carbon accumulation in woody biomass for the USA also show a large uncertainty. While the average rate for the USA $C$ sink ranges from 0.020 to $0.098 \mathrm{GtC} / \mathrm{yr}$ for the $1980 \mathrm{~s}$ and $1990 \mathrm{~s}$ (Birdsey and Heath, 1995; Turner et al., 1995; Houghton et al., 1999), atmospheric inversion models applied to the North American continent suggest a sink of $1.7 \pm 0.5 \mathrm{GtC} / \mathrm{yr}$, largely south of $51^{\circ} \mathrm{N}$ (Fan et al., 1998), but with very low levels of confidence (Bolin et al., 2000).

In the less intensively managed forests of Russia and Canada, changes in mortality associated with natural disturbances appear to dominate over management influences (see Section 4.2.4). In European Russia, managed forest ecosystems were estimated to be a sink of $0.051 \mathrm{GtC} / \mathrm{yr}$ between 1983 and 1992 , but the less actively managed Siberian forest was a net source of $0.081-0.12 \mathrm{GtC} / \mathrm{yr}$ (Shepashenko et al., 1998). The available estimates for Siberia differ even more than for the other regions mentioned above, and their confidence level may be "low" (Schulze et al., 1999).

Recent FAO statistics on 55 countries in the temperate and boreal zones indicate a general increase in the forest carbon stock (trees only) of $0.88 \mathrm{GtC} / \mathrm{yr}$ (UN-ECE/FAO, 2000). Changes in forest management and changes in the environment have contributed to this trend. In Europe, the trend is consistent with the observation of increased growth in individual stands noted by Spiecker et al. (1996). The FAO statistics indicate that between the 1980s and 1990s both net annual increment and timber fellings increased, but that the rate of change was lower for fellings than for growth, resulting in a substantial increase in the carbon sink from the 1980s to the 1990s (Kuusela, 1994; Kauppi et al., 1992; Sedjo, 1992; Dixon et al., 1994; UNECE/FAO, 2000). The carbon sink in live woody vegetation was on the order of $10 \%$ of the fossil fuel $\mathrm{CO}_{2}$ emissions in the USA and in western Europe, and higher in the 1990s than in the 1980s (c.f. Kauppi et al., 1992).

These relatively high sequestration rates are not a result of active policies aimed at climate mitigation, but less rather appear to be related to general trends in land use and land-use change. In the USA, Schimel et al. (2000) and Houghton et al. (1999) estimate that the observed sink is a result mainly of changes in land use and land management, rather than a response to changes in the environment. The latest observations, based on forest inventory data (UN-ECE/FAO, 2000), are reflected in the Special Report on LULUCF (IPCC, 2000a). The IPCC (2000a) estimates that the total global terrestrial biopheric sink in the $1990 \mathrm{~s}$ amounted to $0.7 \mathrm{GtC} / \mathrm{yr}$, despite a source from land-use change in the tropics of $0.9 \mathrm{GtC} / \mathrm{yr}$. 


\subsubsection{Driving Forces for Land-Use Change}

Land management decisions are influenced by many factors. In the temperate zone, and in the European parts of the boreal zone, these are mainly technological and economic. Agricultural production is, for example, heavily influenced by evolving technologies, economic opportunities, subsidies, and restrictions on international trade. Forestry practices are similarly influenced by economic returns, trade, and pressures from society (Clawson, 1979; Waggoner, 1994; Wernick et al., 1998). It is within these pressures and opportunities that carbon mitigation possibilities may be found, and preferably they would be region specific. Table 4.2 gives an overview of some of the specific issues of importance in the temperate and boreal zone of the world.

Competition for land between forestry and agriculture has become less severe. Forest area is increasing in many regions of the boreal and temperate zone, partly because agricultural yields have improved or because the profitability of marginal agriculture has declined. The ability to produce agricultural goods has grown faster than demand, resulting in a downwards trend in prices (Alig et al., 1990; Waggoner, 1994). Much abandoned agricultural land has reverted to forest, either naturally or through deliberate planting. Superimposed over these land conversions is a transition in forestry from a foraging and gathering operation, dependent upon primary forest, through a stage of more intensively managed forest, to total forest ecosystem management. The latter occurs when urbanized societies press for nature-oriented forest management. Continuously improving technologies allow low-cost establishment and higher productivity from planted and plantation forests (Sedjo, 1983; 1999a). In agriculture, also, practices are changing towards maintaining site fertility or decreasing the risk of erosion.

Silvicultural practices have increased forest growth in many boreal and temperate regions. The increasing concentration of atmospheric $\mathrm{CO}_{2}$ may also have contributed to the enhanced growth of forests.

Incentives for planting forests are provided by a combination of market factors and public policy. Remaining wild forests, such as the public forests in the US National Forest System and in British Columbia, are becoming less accessible and have increased harvesting restrictions. Subsidies to harvesting of natural forests are also being withdrawn elsewhere. For example, large subsidies for harvesting Russian forests were prevalent during the Soviet era, largely through subsidized transportation, but have now disappeared. The economic structures are in transition and industrial production has declined. As a result, harvests have fallen dramatically in Russia since the 1990s (Nilsson and Shvidenko 1998).

Market forces, reflecting industrial needs for wood, have provided financial incentives for expansion of commercial forests (Sedjo and Lyon, 1990). This is a trend expected to continue, because of growing demand for industrial wood and low profitability in agriculture (Sohngen et al., 1999). Early analyses suggested that economic returns from plantations (in the tropics as well as in the temperate and boreal zone) justify investment in a number of regions (Sedjo, 1983). Recent studies confirm that forest plantations are being established at a rate of 600,000ha/yr (Pandey, 1992; Postel and Heise, 1988; UN$\mathrm{ECE} / \mathrm{FAO}, 2000)$. However, industrial plantation forestry is new in many tropical areas and yields vary considerably across ecosystems. In many locations where plantations have only recently been established, little is known about the potential capabilities for increasing productivity as well as the potential problems that may limit yields.

\subsubsection{Forest Disturbance Regimes}

The concept of "forest disturbance" refers to events such as forest fire, harvesting, wind-throw, insect and disease outbreak (epidemics), and forest flooding that cause large pulses of $\mathrm{CO}_{2}$ to be released into the atmosphere through combustion or decomposition of resulting dead organic matter. Stand-replacing disturbances, such as crown fires and wind-throw, are associated with the sudden death of large cohorts of trees near one another (Pickett and White, 1985; Kurz et al., 1995a, 1995b; Kurz and Apps, 1999, see Box 4.2). Some disturbance agents, such as pollution and some insects and disease outbreaks, may result in large areas with productivity decline but only local mortality (Hall and Moody, 1994). Disturbances play an important natural part in the lifecycle and succession dynamics of many forest systems. In boreal systems large-scale, natural, stochastic forces tend to dominate the ecosystem dynamics, even when direct human influences are considered (Kurz et al., 1995b). The return interval of these disturbances, their intensity, and their specific impacts are referred to as the disturbance regime (Weber and Flanigan, 1997). Kurz et al. (1995b) and Price et al. (1998) (having compiled insect, fire, and harvest data) showed that the disturbance regime of Canadian forests changed over the last quarter of the 20th century from about 2.5Mha/yr prior to 1970 to $4 \mathrm{Mha} / \mathrm{yr}$ between 1970 and 1990. Using these data, Kurz and Apps (1999) showed that these changes in the disturbance regime resulted in a switch of Canadian forests from being a net sink of $\mathrm{C}$ to a small net source of $\mathrm{C}$ to the atmosphere.

Disturbances, both human-induced and natural, are major driving forces that determine the transition of forest stands, landscapes, and regions from carbon sink to source and back. The current pattern of forest vegetation and its role in carbon cycling reflects the combined effects of anthropogenic and natural disturbances over a range of time scales. For $\mathrm{C}$ stocks with very slow turnover rates (such as soils and peat) the effects of past disturbances on carbon cycling may reverberate for centuries and millennia (Figure 4.5). For example, carbon continues to accumulate in young soils (such as those associated with the isostatic uplift following deglaciation in Canada and Finland), which appear to be actively accruing carbon (Harden 
Table 4.2: Overview of biological carbon mitigation issues and opportunities in selected countries/regions (Based, in part, on Sedjo and Lyon, 1990; Fujimori, 1997; Nilsson and Shvidenko, 1998; De Camino et al., 1999; Sohngen et al. 1999; Zhang, 1996)

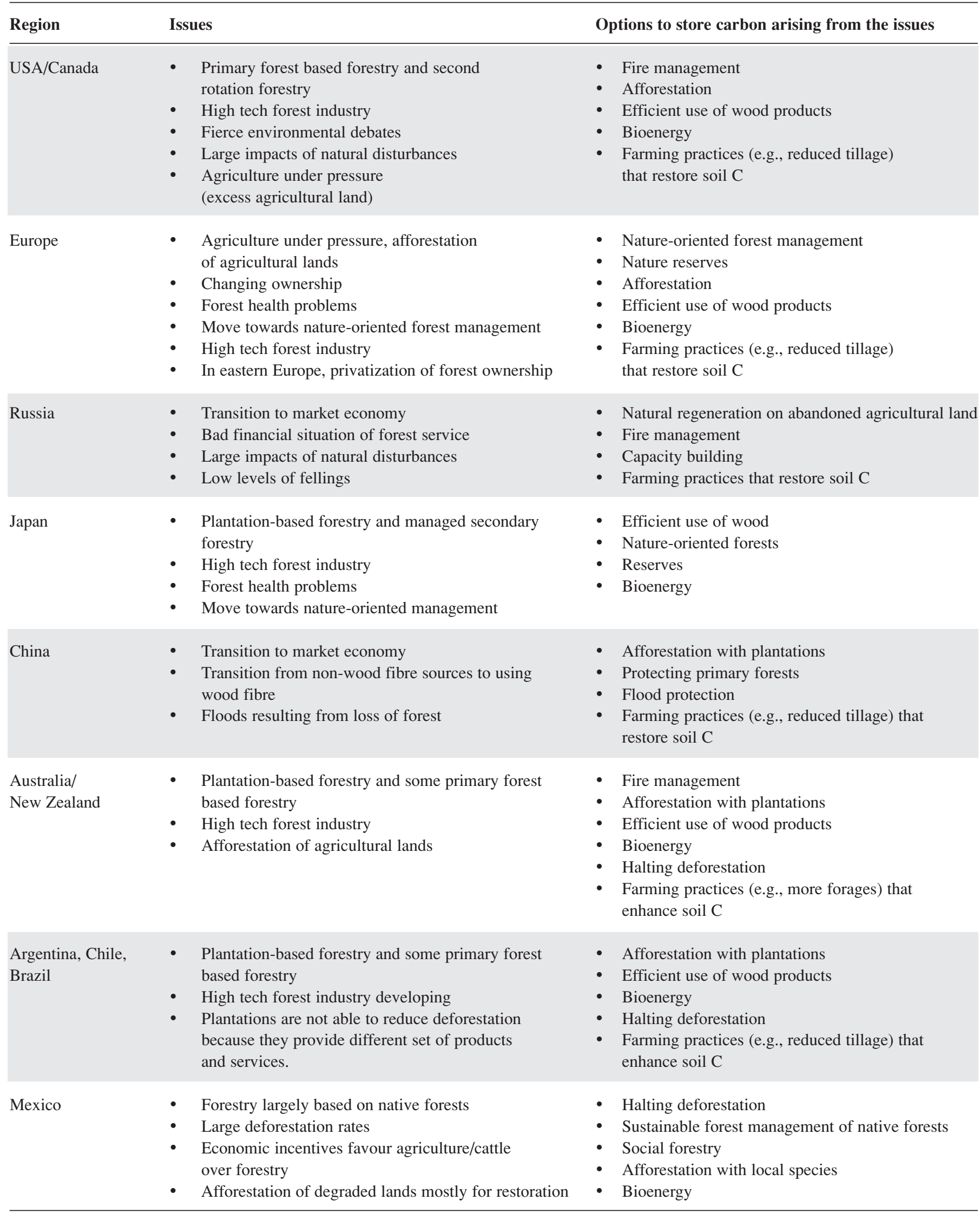




\section{Box 4.2. Disturbance, Age-class Distribution, and their Implications for Forest Carbon Dynamics}

At the stand scale, disturbance events (both natural and anthropogenic) have three main impacts on the carbon budget (Apps and Kurz, 1993). First, they redistribute the existing carbon by transferring carbon from living material, above and below ground, to the dead organic matter pools. Second, they transfer some of the carbon out of the ecosystem (e.g., into the atmosphere as combustion products, in the case of fire, and/or into the forest product sector as raw feedstock, in the case of harvest). Third, by opening the forest canopy, the disturbance changes the site micro-environment and restarts the successional cycle for new stand development.

At the scale of forests (typically comprising many stands), the disturbance regime determines the age-class structure (e.g., the evenage structure associated with stand-replacing disturbance regimes or the uneven-age structures associated with individual tree mortality and gap-phase replacement), and age-class structure of stands and trees making up the forest. The C stocks in a forest landscape, and the changes in these stocks over time, are strongly influenced by the age-class distribution (Kurz et al., 1995b; Turner et al., 1995; MacLaren, 1996; Apps et al., 2000; Bhatti et al., 2001). In managed plantation forests, the age-class distribution is controlled by the management regime and harvest cycle (Heath and Birdsey, 1993; MacLaren, 1996), while in natural forests other mortality agents play a major role. See Heath et al. (1996) and Kurz et al. (1995a) for examples.

\section{Box 4.3. The Reduced Impact Logging Project, Carbon Sequestration Through Reduced Impact Logging}

The RIL (reduced impact logging) project developed by Innoprise, a Malaysian company with forestry activities, and the New England Power Company, USA, aims to save $\mathrm{CO}_{2}$ already stored in forest biomass by reducing damage to vegetation and soils during harvesting. The hope is to reduce damage by $50 \%$ compared to that of conventional harvesting. The techniques employed are modifications of conventional bulldozer harvesting techniques; including pre-felling climber cutting, directional felling, skid trail design, and post harvest operations such as rehabilitation of log landings. Today the total project area amounts to 2,400 ha. The pilot research project has quantified the carbon implications and costs on 1,415ha. They found that avoided emissions amounted to 65-90MgC/ha and that the associated costs were US\$3.55/MgC (Wan Razali and Tay, 2000).

et al., 1992). In these soils, losses from decomposition of accumulated organic matter are exceeded by the inputs of fresh organic debris (Liski et al., 1999). Human influences on the disturbance regime include both direct effects, such as harvesting or inducing and/or suppressing natural disturbances (fires, insects, flooding, etc.), and indirect influences from altering the forest environment. Indirect influences include both climate change and atmospheric pollution, and their effects on tree health and survival.

The different types of disturbances are often linked. For example, in some forest types the probability of fire may increase following insect outbreaks because of increases in available fuel (litter). In some cases salvage logging (recovering the usable timber following a disturbance) can reduce the total area of living forest that is disturbed in a given year by all agents combined. It is common to try to replace natural disturbances (such as wildfires) with commercial harvesting, using a combination of protection and scheduled logging. In Sweden and Finland, for example, logging has become the main disturbance type; and large-scale natural disturbances resulting from wildfire, insect outbreaks, or storms have been almost nonexistent for half a century (Lähde et al., 1999).

Disturbances affect the carbon stocks of all components of forested ecosystems. During and following a disturbance, carbon is transferred from living material, above and below ground, to the dead organic matter pools (Figure 4.2). In the

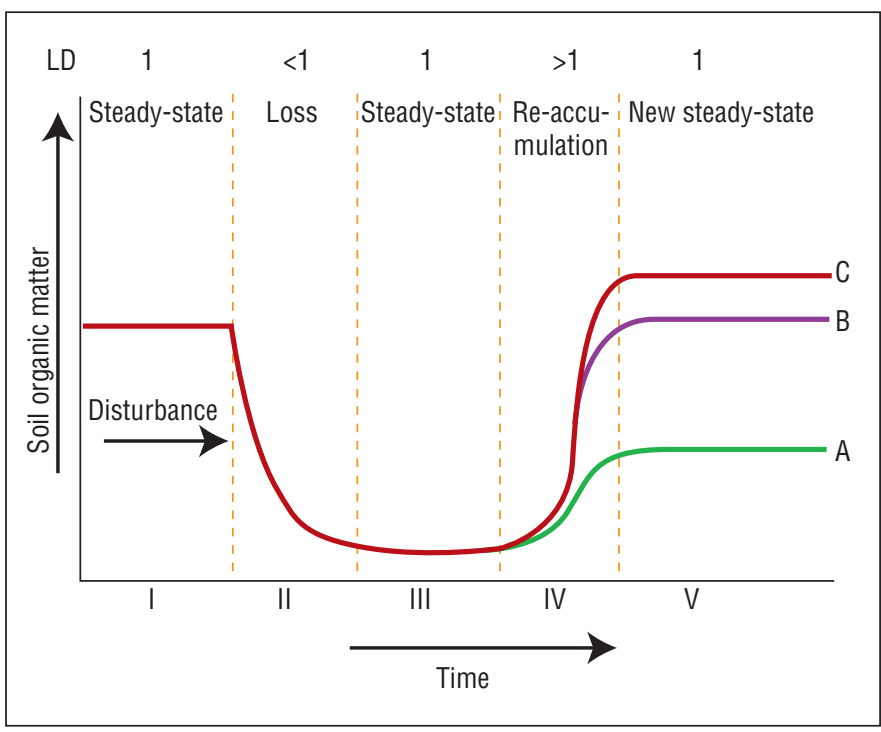

Figure 4.5: Conceptual model of soil organic matter decomposition and accumulation following disturbance (after Johnson, 1995; IPCC, 2000a). At steady state (I), carbon (C) inputs from litter $(L)$ equal $C$ losses via decomposition $(D)$ (i.e., $L / D=1)$. After a disturbance, $D$ often exceeds $L$ resulting in loss of C (II), until a new, lower steady state is reached (III). Adoption of new management, where $L$ exceeds $D$ results in a re-accumulation of $C(I V)$ until a new, higher steady state is reached $(V)$. The eventual steady state $(A, B$, or $C)$ depends on the new management adopted. 
case of a forest fire, part of the ecosystem carbon is released immediately into the atmosphere as combustion products. Disturbed forest stands continue to release carbon into the atmosphere as the enlarged pools of dead organic matter tend towards a new steady-state condition (Bhatti et al., 2001). Regrowth follows, but maximum uptake may not be achieved for some time (decades or more), and during much of this period decomposition of dead organic matter may exceed vegetative uptake. The corresponding re-sequestration of carbon through regrowth can last 50 to 200 years or more.

Management of natural disturbance regimes can provide significant $\mathrm{C}$ mitigation opportunities, e.g., through activities to prevent or suppress disturbances. Such measures can significantly enhance the strength of C sinks (Kurz et al., 1995a; Apps et al., 2000; Bhatti et al., 2001) and maintain existing C stocks, but only as long as the programmes are maintained. Other factors being equal, during periods of reduced disturbance (e.g., with increasing suppression effort), C stocks tend to increase as biomass accumulates and litter production (in all forms) increases: forests act as a sink for atmospheric C (Bhatti et al., 2001). In contrast, with increasing disturbance (e.g., with reduction in suppression effort), the net losses of $\mathrm{C}$ from forest ecosystems can exceed inputs from photosynthesis (Figures 4.2 and 4.3) and the forests could become a net source of $\mathrm{C}$. We note that all forms of disturbance, not just highly visible fires, play a role in these dynamics. In a changing climate, the control of new pathogens and immigrant herbivores (especially insects and disease), to which local forest ecosystems may be maladapted, may be critical to avoid emissions and maintain existing forest $\mathrm{C}$ stocks.

Disturbances affect the carbon stocks in vegetation, in soil, and in dead organic matter. All these stocks vary over time as a function of the history of disturbances (MacLaren, 1996; Bhatti et al., 2001; Kurz and Apps, 1999). With an increase of widespread disturbance events the carbon stocks of living vegetation decrease and the age-class distribution of the forest shifts to younger stands containing less carbon. If forests are disturbed at regular intervals (i.e., an unchanging, disturbance regime), the carbon stock of large tracts of forest can be relatively stable.

\subsubsection{Changes in Global Climate and Other Indirect Human Effects}

Evaluating the long-term outcome of carbon mitigation activities will require estimating how carbon reservoirs will change in the future. Carbon stocks sequestered through mitigation activities today may be more or less secure, depending on how the environment changes and how society adapts to those changes. Estimating future $\mathrm{C}$ stocks in ecosystems is complicated by our inability to predict the magnitude and impact of impending changes in the environment. Some of the possible changes favour larger $\mathrm{C}$ stocks; others would lead to smaller stocks. The impact of global climate change on future $\mathrm{C}$ stocks is particularly complex. These changes may result in both positive and negative feedbacks on $\mathrm{C}$ stocks (Houghton et al., 1998). For example, increases in atmospheric $\mathrm{CO}_{2}$ are known to stimulate plant yields, either directly or via enhanced wateruse efficiency, and thereby to enhance the amount of $\mathrm{C}$ added to soils (Schimel, 1995; Woodwell et al., 1998). Higher $\mathrm{CO}_{2}$ concentrations may also suppress decomposition of stored $\mathrm{C}$, because $\mathrm{C} / \mathrm{N}$ ratios in residues may increase and because more C may be allocated below ground (Owensby, 1993; Morgan et al., 1994; Van Ginkel et al., 1996; Torbert et al., 1997). Predicting the long-term influence of elevated $\mathrm{CO}_{2}$ concentrations on the $\mathrm{C}$ stocks of forest ecosystems remains a research challenge (Bolin et al., 2000; Prentice et al., 2001).

Where plant growth is now limited by nitrogen $(\mathrm{N})$ deficiencies, increased deposition of $\mathrm{N}$ associated with intensified production of bio-available N (Schindler and Bayley, 1993; Vitousek et al., 1997) may accelerate plant growth. This may, eventually, enhance the carbon stock of the soil (Wedin and Tilman 1996). Nadelhoffer et al. (1999) caution, however, that the global impact of $\mathrm{N}$ deposition may be comparatively small. Moreover, where the $\mathrm{N}$ fertilization effect increases growth, especially in the $\mathrm{N}$-deficient northern forests, it also delays the hardening-off process, resulting in increased winter damage, and thus negating some of the growth enhancement (Makipaa et al., 1999).

Increased soil temperatures associated with increased atmospheric $\mathrm{CO}_{2}$ have long been expected to result in increased soil respiration (Schimel, 1995; Townsend and Rastetter, 1996; Woodwell et al., 1998). Data recently reported by Giardina and Ryan (2000), however, suggest that decomposition of organic carbon in mineral soil layers is relatively insensitive to changes in air temperature. Modelling studies by Liski et al. (1998) suggest similar results. Nevertheless, IPCC reviews (Bolin et al., 2000; Prentice et al., 2001) conclude that existing terrestrial $\mathrm{C}$ sinks may gradually diminish over time, in part because of increasing losses via respiration.

Over the long term, as climate gradually changes, the time scales for adaptation of ecosystems to climatic conditions will become important. Vegetation types (and other organisms) have adapted to the combination of site conditions, including climate, where they now occur. It cannot be assumed that tree growth will increase with climate change, or that the plant populations will remain optimally adapted to their current sites. Analysis of provenance (seed source) data, in the light of global change, indicates either no net increase in growth rate as a result of warming or small decreases in growth rate. Trees may be under more stress in a changed climate, leaving them more susceptible to insects and diseases.

The various processes of environmental change may occur over different time periods and with varying intensity at different locations. Ecosystems that initially absorb $\mathrm{C}$ in response to higher atmospheric $\mathrm{CO}_{2}$ will become "saturated" or even later release $\mathrm{CO}_{2}$ if increasing temperatures lead to enhanced 
decomposition and respiration (Cao and Woodward, 1998; Scholes et al., 1999). Fires and other disturbances could increase in frequency and intensity if temperatures increase and precipitation patterns change. The net impact of these, and other global changes, is an area of active research (e.g., Hungate et al., 1997; Kauppi et al., 1997; Norby and Cotrufo, 1998; Woodwell et al., 1998).

The effects of climate change on mitigation activities in the terrestrial biosphere are difficult to anticipate, as they are dependent on the timing and the specific spatial character and distribution of changes. Present climate scenarios are neither spatially nor temporally very precise, and averages over the scale of typical global circulation climate models are inadequate for estimating impacts on very specific, localized mitigation activities. Moreover, the responses of ecosystems are dependent on the ecological mechanisms, the climate change imposed, and the management responses to these factors. For example, planting of species adapted to present conditions may be inappropriate for future conditions and the species might grow more slowly under chronic climate change. Conversely, species planted for an anticipated future climate may not be able to survive current variations.

Climate change can also affect the economic and social dimensions of land use and forestry. Currently, productive lands may become less productive and less attractive for food and fibre production. The current patterns of land use and disturbance could change. Model results reported by Darwin et al. (1995, 1996) and others suggest, for example, that conversion from forestland to cropland is a significant adaptive response to climate change in some regions. Protection from fire or insect and/or disease predation, in boreal regions especially, may become increasingly hard to maintain. Reliable estimates of risks to, or enhancements of, mitigation activities carried out today will require increased understanding of the interactions between the important ecological, economic, and social impacts of climate change. As described in this chapter, the carbon stocks in terrestrial ecosystems respond to a combination of ecological, economic, and social drivers. That will not change even if the global environment changes.

\subsection{Processes and Practices that Can Contribute to Climate Mitigation}

\subsubsection{System Constraints and Considerations}

In terrestrial ecosystems the carbon cycle exhibits natural cyclic behaviour on a range of time scales. Most ecosystems, for example, have a diurnal and seasonal cycle. Often this means that the ecosystem functions as a source of $\mathrm{C}$ in the winter and a sink for $\mathrm{C}$ in the summer, and this shows up in fluctuations at the global scale, as shown by the annual oscillations in the global atmospheric $\mathrm{CO}_{2}$ concentration. Large-scale fluctuations occur at other temporal scales as well, ranging from decades (Braswell et al., 1997; Turner et al., 1997; Karjalainen et al., 1998; Kurz and Apps, 1999; Bhatti et al., 2001) to several centuries (Campbell et al., 2000) and longer (Harden et al., 1992).

The net balance of $\mathrm{C}$ flows between the atmosphere and the terrestrial biosphere also undergoes management-induced cycles that occur over long time scales (decades to millennia), and that can cause the transition of terrestrial systems from sink to source and back (Harden et al., 1992). Of relevance for $\mathrm{C}$ mitigation are the human-induced changes that occur on an annual to centennial time scale. This would include the harvest cycle of managed, production forests.

The intent of any mitigation option is to reduce atmospheric $\mathrm{CO}_{2}$ relative to that which would occur without implementation of that option. Biological approaches to curb the increase of atmospheric $\mathrm{CO}_{2}$ can occur by one of three strategies (IPCC, 1996):

- conservation: conserving an existing $\mathrm{C}$ pool, thereby preventing emissions to the atmosphere;

- sequestration: increasing the size of existing carbon pools, thereby extracting $\mathrm{CO}_{2}$ from the atmosphere; and

- substitution: substituting biological products for fossil fuels or energy-intensive products, thereby reducing $\mathrm{CO}_{2}$ emissions.

The benefits of these strategies show contrasting temporal patterns. Conservation offers immediate benefits via prevented emissions. Sequestration impacts often follow an S-curve: accrual rates are often highest after an initial lag phase and then decline towards zero as $\mathrm{C}$ stocks approach a maximum (e.g., Figure 4.3). Substitution benefits often occur after an initial period of net emission, but these benefits can continue almost indefinitely into the future (Figure 4.6).

This section deals primarily with carbon conservation and sequestration in the terrestrial biosphere, but acknowledges the complementarity and trade-offs among the three strategies. Carbon sequestration in forest products is included here and the substitution benefits of forest products are treated briefly. The role of energy cropping is treated in greater depth in Chapter 3 (Section 3.6.4.3) and in the IPCC Special Report on LULUCF (IPCC, 2000a). Here the discussion is restricted to the secondary use of biomass products for energy (e.g., waste products) and non-commercial uses (e.g., domestic heating, cooking, etc.).

The general goal of sequestration activities is to maintain ecosystems in the sink phase. However, if the system is disturbed (a forest burns or is harvested, or land is cultivated), a large fraction of previously accumulated $\mathrm{C}$ may be released into the atmosphere through combustion or decomposition (Figure 4.2). When the system recovers from the disturbance, it reenters a phase of active carbon accumulation. Thus, the disturbance history of terrestrial ecosystems involves in large $\mathrm{C}$ loss- 


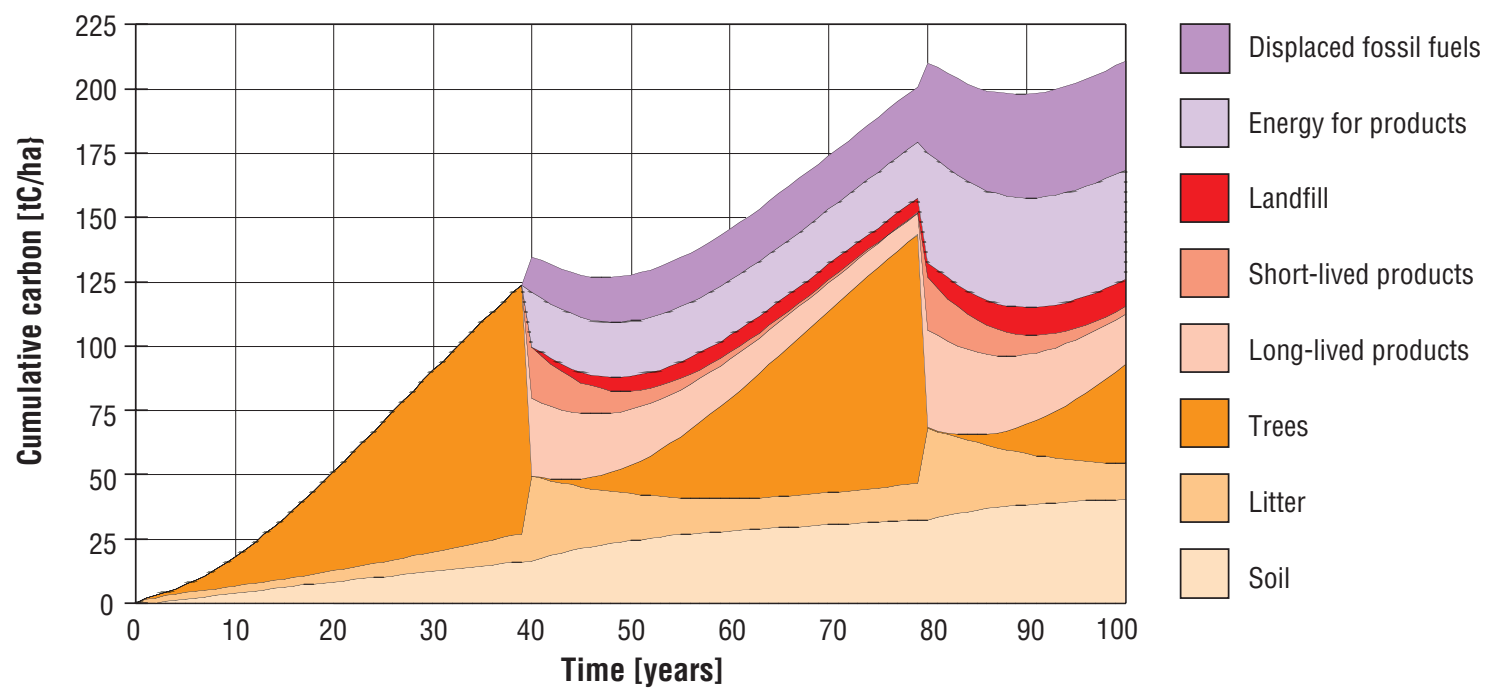

Figure 4.6: Cumulative carbon changes for a scenario involving afforestation and harvest. These are net changes in that, for example, the diagram shows savings in fossil fuel emissions with respect to an alternative scenario that uses fossil fuels and alternative, more energy-intensive products to provide the same services (adapted from Marland and Schlamadinger, 1999).

es in the past (Houghton et al., 1999; Kurz and Apps, 1999), but opportunities for $\mathrm{C}$ sequestration in the present.

A comprehensive systems analysis is useful to fully evaluate mitigation options. Factors to be considered may include: ecosystem C stocks and sinks; sustainability, security, resilience, and robustness of the $\mathrm{C}$ stock maintained or created; temporal patterns of $\mathrm{C}$ accumulation; other land-use goals and related $\mathrm{C}$ flows in the energy and materials sector; and effects on other non- $\mathrm{CO}_{2} \mathrm{GHGs}$. For example, one option might have both a high maximum $\mathrm{C}$ stock and a high or more sustained rate of sequestration, yet be incompatible with other demands placed on the land. A second option may have a high maximum C stock, but reach that level only very slowly. Still another option may offer high short-term sequestration, but reach maximum $\mathrm{C}$ stocks very quickly. Yet another option might manage production systems to maximize the flow of harvested carbon into products, thus maximizing the displacement of alternate, energy-intensive products. Thus, while a wide array of practices may be technically possible, options that meet all criteria may be much fewer, and a combination of complementary options may best accomplish C mitigation goals. Although scientists now recognize the value of system-wide analyses (Cohen et al., 1996; Alig et al., 1997), rarely have mitigation options been subjected to such comprehensive evaluations.

An upper bound for the technical potential for global C mitigation in the terrestrial biosphere, a physical upper limit, can be estimated for conservation, sequestration, and substitution measures. The technical potential for conservation measures would equal the current existing $\mathrm{C}$ stock of the world's ecosystems. This assumes that all ecosystems are threatened, but all could be conserved by implementing protection measures. The technical potential for sequestration would roughly equal the carbon stocks lost in deforestation, desertification, and other human-induced changes in land cover and land use over centuries and millennia. The theoretical upper limit would thus correspond to the full recovery of lost biomass in ecosystems, and to a steady state at the natural carrying capacity for biomass on earth. The technical potential for substitution is related to the sustainable production of harvestable biomass and its substitution for fossil fuels and energy-intensive products. Clearly, each of these upper limits violates in practice the ideals of development, equity, and sustainability. And yet, they help to appreciate that there are bounds on the role that managing the biosphere might play in carbon mitigation.

\subsubsection{Opportunities in Forests}

Many silvicultural and forest management practices have been reported to enhance carbon mitigation (Lunnan et al., 1991; Hoen and Solberg, 1994; Karjalainen, 1996; Row, 1996; Binkley et al., 1997; Price et al. 1998; Birdsey et al., 2000; Fearnside, 1999; Anonymous, 1999; Nabuurs et al., 2000). Measures suggested for forests include: protecting against fires; protecting from disease, pests, insects, and other herbivores; changing rotations; controlling stand density; enhancing available nutrients; controlling the water table; selecting useful species and genotypes; using biotechnology; reducing regeneration delays; selecting appropriate harvest methods such as reduced-impact logging; managing logging residues; recycling wood products; increasing the efficiency with which forest products are manufactured and used; and establishing, maintaining, and managing reserves.

Sampson et al. (2000) provide an overview of the potential impacts of some different management alternatives on carbon 
mitigation, and examine both additional benefits and some possible unintended, negative effects of these practices. They estimate that $10 \%$ of the global forest area could be technically available by the year 2010 , and that the global potential of forest management practices could be $0.17 \mathrm{GtC} / \mathrm{yr}$. These opportunities rise to $50 \%$ of the global forest area and $0.7 \mathrm{GtC} / \mathrm{yr}$ by the year 2040. Sampson et al. (2000) emphasize win-win situations, but also indicate the low level of certainty associated with their estimates and the possibility for certain negative impacts.

Nabuurs et al. (2000) also estimate the potential of a broad range of forest-related activities (including protection from natural disturbance, improved silviculture, savannah thickening, restoration of degraded lands, and management of forest products) at $0.6 \mathrm{GtC} / \mathrm{yr}$ over six regions in the temperate and boreal zone (Canada, USA, Australia, Iceland, Japan, and EU, Figure 4.7). According to their estimates, alternative forest management for $\mathrm{C}$ sequestration is technically feasible on $10 \%$ (on average) of the forest area in each region examined. Figure 4.8 shows that the relative importance of the different practices for the various regions depends on the current situation in the respective regions.

The analyses of Sampson et al. (2000) and Nabuurs et al. (2000) estimate that the hectare-scale effectiveness of these activities ranges from $0.02 \mathrm{tC} / \mathrm{ha} / \mathrm{yr}$ for forest fertilization to $1.2 \mathrm{tC} / \mathrm{ha} / \mathrm{yr}$ for several practices combined in Loblolly pine stands. However, they show that the impact of most practices is in the range of $0.3-0.7 \mathrm{tC} / \mathrm{ha} / \mathrm{yr}$.

Forest management and protection offer high mitigation potential in some countries. For example, additional pools of 40$160 \mathrm{tC} /$ ha and $215 \mathrm{tC} /$ ha may be possible in Cameroon and the Philippines, respectively (Sathaye and Ravindranath, 1998). Afforestation or plantation forest options have the potential to increase carbon stocks by 70-100tC/ha in many places, and the potentials for some commercial plantations may be even higher: $165 \mathrm{tC} /$ ha for timber estates in Indonesia, $120 \mathrm{tC} / \mathrm{ha}$ for timber forestry in India, and $236 \mathrm{tC} /$ ha for long rotation forestry in the Philippines (Sathaye and Ravindranath, 1998). The suggested opportunities for mitigation potential in 12 developing countries are summarized in Table 4.3.

The study of Sathaye and Ravindranath (1998) suggests that, in 10 tropical and temperate countries in Asia, about 300Mha may be available for mitigation options: 40Mha for conservation, protection, and management; 79Mha of degraded forest land for regeneration; and 181Mha of degraded land for plantation forestry and, hence, for C sequestration (Sathaye and Ravindranath, 1998). A further 172Mha was estimated to be available in these countries for agroforestry. These esti-

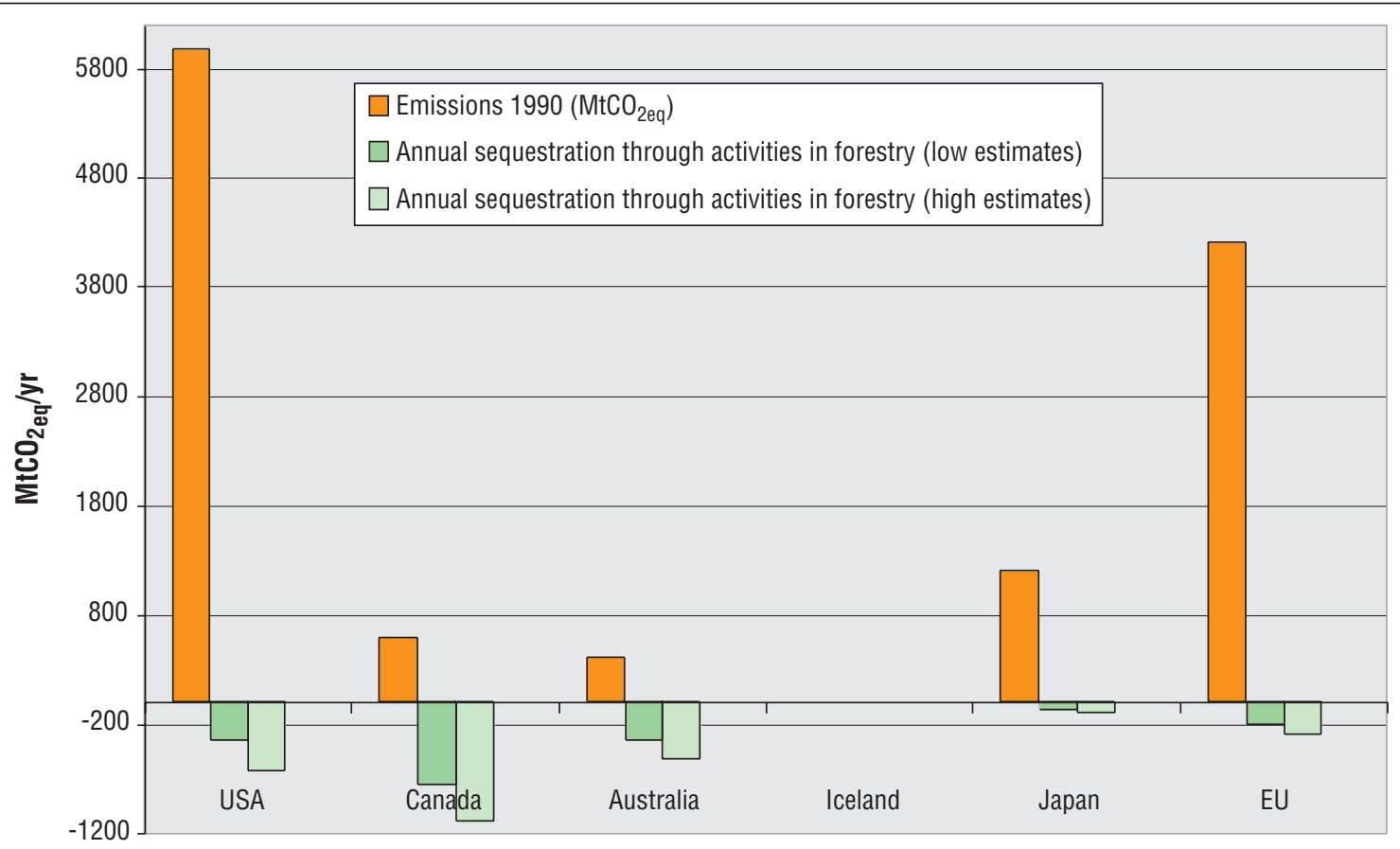

Figure 4.7: Indications of the magnitude of the carbon sink in case study countries for a set of forest management measures $\left(\mathrm{MtCO}_{2 e q}\right.$, adapted after Nabuurs et al. 2000). The values for the three bars for Iceland are 2.6, 2.8, and 2.9, respectively. The figure is based on the forest part of the model "Access to Country Specific Data" (ACSD). It was designed to provide insight into the potential magnitude of carbon sequestration that may be achieved when alternative sets of management measures are adopted. Therefore, the exact numbers provided in this figure result from the assumptions chosen for a certain set of measures. The estimates in this figure are tentative and only illustrative. In these studies all forestry activities under discussion were included, but applied on average on some $10 \%$ of mostly the exploitable forest area. 
Table 4.3: Mitigation options, mitigation potential, and investment cost per tonne of carbon (US\$/tC) abated in selected countries (Sathaye and Ravindranath, 1998)

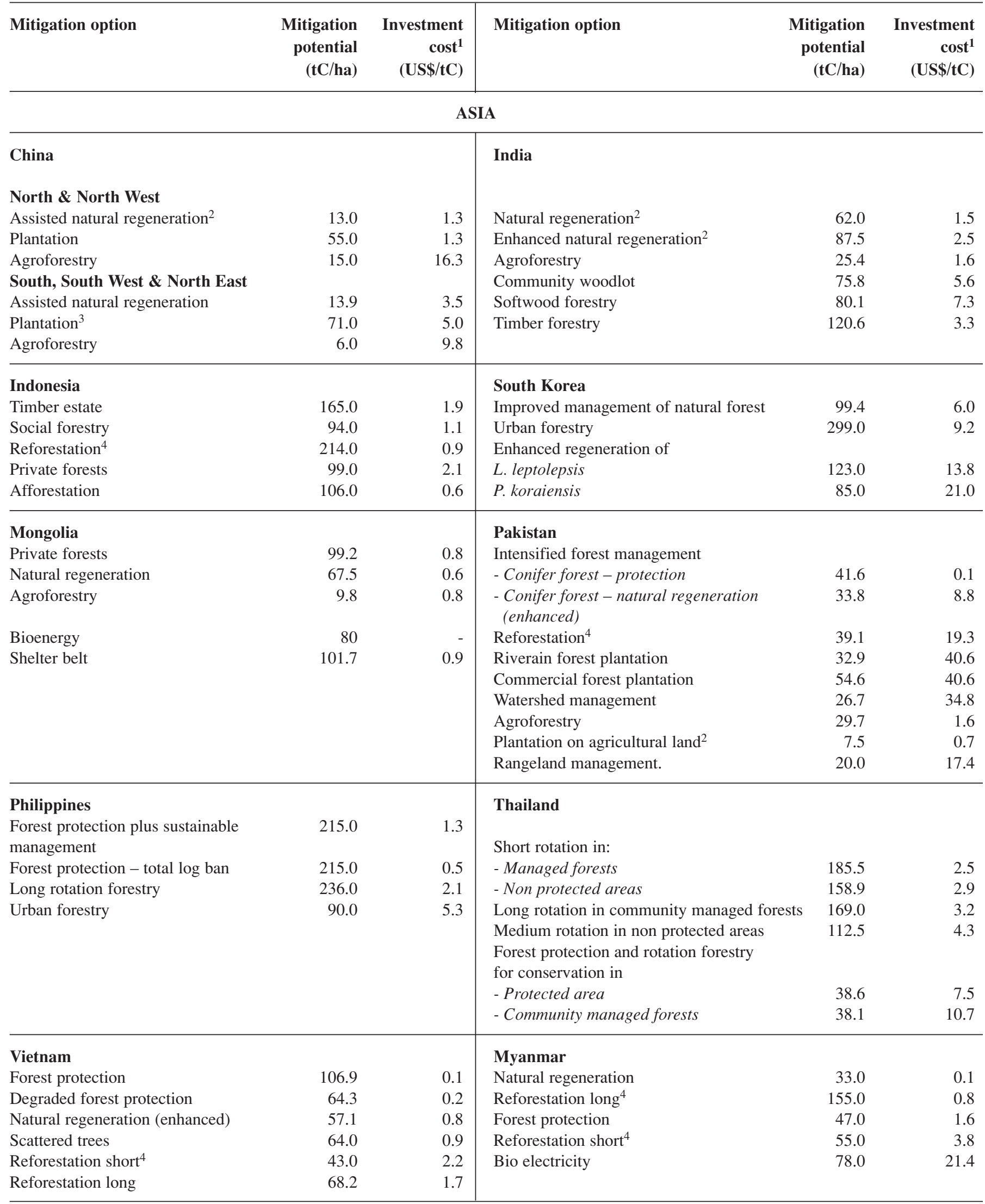


Tabel 4.3: continued

\begin{tabular}{|c|c|c|c|c|c|}
\hline Mitigation option & $\begin{array}{r}\text { Mitigation } \\
\text { potential } \\
(\mathrm{tC} / \mathrm{ha})\end{array}$ & $\begin{array}{r}\text { Investment } \\
\operatorname{cost}^{1} \\
(\mathrm{US} \$ / \mathbf{t} \mathbf{C})\end{array}$ & Mitigation option & $\begin{array}{r}\text { Mitigation } \\
\text { potential } \\
(\mathrm{tC} / \mathrm{ha})\end{array}$ & $\begin{array}{r}\text { Investment } \\
\operatorname{cost}^{1} \\
(\mathrm{US} \$ / \mathbf{t} \mathbf{C})\end{array}$ \\
\hline
\end{tabular}

AFRICA

\section{Ghana}

Evergreen forest

- agroforestry

- slowing deforestation

Deciduous forest

-slowing deforestation

- forestation 5

Savannah

- agroforestry

Cameroon

13-88

$35-140$

35-140

31-154

29-61

\section{Evergreen forest}

1-6 - agroforestry

1-2 - slowing deforestation.

- forestation ${ }^{5}$

1-2 Deciduous forest

1-27 - forestation 5

Savannah

4-12 -forestation 5
16-58

40-160

73-195

27-169

36-170
$1-5$

$1-2$

1-19

21-19

$1-31$

1 Investment costs (US\$/tC):This largely includes forest or plantation establishment costs incurred during the initial 2-3 years; discounted for only the initial 23 year period. For forest protection, the costs include expenditure on erecting barriers for protection, training, and other organizational costs incurred during the initial 2-3 year period. Mitigation potential is in pertuity, assuming one full cycle; rotation length for mitigation option subject to harvesting (such as short and long rotation) and for others 40 years.

2 Natural regeneration of forest is increasing the biomass density to that of closed forests on partially degraded open forest areas; assisted or enhanced natural regeneration would involve planting a (few) trees and/soil and water conservation activity to assist or enhance natural regeneration.

3 Plantations involve planting of one or more species at high densities.

4 Reforestation in a short rotation has a 5 to 15 year harvest cycle, reforestation in a long rotation has a 30-100 year harvest cycle.

5 Forestation includes both afforestation and reforestation.



Figure 4.8: Relative importance of each of the 10 forest management alternatives in the total potential sequestration as given in Figure 4.7. These data give an indication of opportunities and do not necessarily represent national plans. For example, silvicultural practices in Japan generally do not accompany fertilization and the figure for Japan is probably an overestimate. Nevertheless it shows that opportunities vary among countries because of both the national situation, the mix of current forestry practices, and/or the historic management. One common recommendation of which measures would yield the largest carbon sequestration can therefore not be given (adapted from Nabuurs et al., 2000). 
Table 4.4: Land categories and extent of availability for mitigation in selected developing countries (Sathaye and Ravindranath, 1998)

\begin{tabular}{|c|c|c|c|c|c|c|c|}
\hline \multicolumn{8}{|l|}{ Asia } \\
\hline India & & 36.9 & 41.3 & 96.0 & & 329.0 & 63.3 \\
\hline Indonesia & & & 30.5 & & & 193.0 & 144.7 \\
\hline Mongolia & & 2.4 & 1.6 & & & 156.6 & 17.5 \\
\hline Myanmar & 3.3 & 6.9 & & & & 65.8 & 49.3 \\
\hline Pakistan & 0.5 & 0.3 & 2.6 & 1. 2 & & 77.1 & 3.7 \\
\hline Philippines & 6.6 & 2.5 & & & 0.60 & 29.8 & 6.5 \\
\hline Total & 39.4 & 78.9 & 181.2 & 171.9 & 3.15 & 1877.4 & 458.5 \\
\hline \multicolumn{8}{|l|}{ Africa } \\
\hline Cameroon & 1.6 & & 7.3 & 1.6 & & 46.0 & 36.0 \\
\hline Ghana & 0.9 & & 0.3 & 2.5 & & 23.0 & 18.0 \\
\hline Total & 2.5 & 0 & 7.6 & 4.1 & 0 & 69.0 & 54.0 \\
\hline Total (12 countries) & 41.9 & 78.9 & 188.8 & 176 & 3.15 & 1946.4 & 512.5 \\
\hline
\end{tabular}

mates are much larger than those in IPCC (1996) (Table 4.4).

Current estimates suggest that the cumulative $\mathrm{C}$ mitigation potential of forests in 10 Asian countries is about $26.5 \mathrm{GtC}$, suggesting that the SAR estimates for the tropical region were conservative. China $(9.7 \mathrm{GtC})$ and India $(8.7 \mathrm{GtC})$ have particularly large mitigation potentials in the forestry sector (Sathaye and Ravindranath, 1998).

Latin America, which accounts for $51 \%$ of the global area of tropical forests (FAO, 1997), has an estimated mitigation potential of at least $9.7 \mathrm{GtC}$, an estimate based on analyses of Mexico, Venezuela, and partly Brazil (Table 4.5). This total includes native forest management, protected areas, commercial plantations, agroforestry, and restoration plantations. The technical potential $\mathrm{C}$ mitigation in forestry is estimated at about 4.8GtC for Mexico, 1.4GtC for Venezuela, and 3.5GtC for Brazil (Da Motta et al., 1999, Table 4.5). The feasible mitigation potential, which is largely constrained by land tenure policies and socio-economic pressures (land availability), is, however, often much lower than this technical potential. The feasible socio-economic mitigation potential is about $50 \%$ less than the technical potential in Mexico and about $44 \%$ lower than the technical potential in India (Ravindranath and Somashekar, 1995).
Deforestation in the Brazilian Amazon is a significant source of $\mathrm{CO}_{2}$ and, with $90 \%$ of the originally forested area still uncleared, Brazil remains a large potential source of future emissions. The deforestation rate in Amazonia was estimated to be $1.38 \mathrm{million} \mathrm{ha} / \mathrm{yr}$ in 1990 , corresponding to an emission of $251 \mathrm{MtC} / \mathrm{yr}$ (Fearnside, 1997). The rate of deforestation has increased in recent years, to $2.91 \mathrm{Mha} / \mathrm{yr}$ in 1995 and $1.82 \mathrm{Mha} / \mathrm{yr}$ in 1996 (Fearnside, 1998). Reducing the deforestation rate by $50 \%$ would conserve $125 \mathrm{MtC} / \mathrm{yr}$. Thus, Brazil alone offers a large potential for mitigation through slowing of deforestation.

What is the permanence of $\mathrm{C}$ sequestered by forest management activities? Clearly, tree plantations that are harvested and not re-established do not contribute to long-term carbon sequestration, though they may reduce atmospheric $\mathrm{C}$ in the short term. But, if a new forest is maintained so that harvest equals net growth, the forest can both be a source of wood products and still retain the captured C. In other words, the sequestration phase may be finite, lasting only a few decades, but the conservation phase need not be finite. Although there is an exchange of carbon between the atmosphere and the biomass, a considerable pool of carbon can be permanently stored in the steady-state biomass while wood products continue to be produced. This $\mathrm{C}$ pool remains withdrawn from the atmosphere as long as the forest exists. The substitution phase, which 
Table 4.5: Biological GHG mitigation potential in Latin America

\begin{tabular}{|c|c|c|c|c|c|c|c|c|}
\hline \multirow[t]{2}{*}{ Option } & \multicolumn{2}{|c|}{$\begin{array}{l}\text { Land available in } \\
2030 \text { (Mha) }\end{array}$} & \multirow{2}{*}{$\begin{array}{c}\text { Unit C } \\
\text { seques- } \\
\text { tration } \\
\text { (tC/ha) }\end{array}$} & \multicolumn{2}{|c|}{$\begin{array}{c}\text { Total C } \\
\text { sequestration(MtC) }\end{array}$} & \multirow{2}{*}{$\begin{array}{r}\text { Unit } \\
\text { cost }^{\mathbf{b}} \\
(\mathrm{US} \$ / \mathbf{t C})\end{array}$} & \multirow[t]{2}{*}{$\begin{array}{r}\text { Total } \\
\text { cost }\end{array}$} & \multirow[t]{2}{*}{ Reference } \\
\hline & $\begin{array}{r}\text { Technical } \\
\text { potential }\end{array}$ & $\begin{array}{r}\text { Economic } \\
\text { potential }\end{array}$ & & $\begin{array}{r}\text { Technical } \\
\text { potential }\end{array}$ & $\begin{array}{r}\text { Economic } \\
\text { potential }\end{array}$ & & & \\
\hline
\end{tabular}

\begin{tabular}{|c|c|c|c|c|c|c|c|c|}
\hline \multicolumn{9}{|c|}{ Native forest management } \\
\hline Mexico & 18.7 & 13.2 & 132 & 2465 & 1550 & $0.1-4$ & 4930 & $\begin{array}{l}\text { Masera, 1995; } \\
\text { Masera et al., 1997a; } \\
\text { Masera and Ordóñez, } \\
1997\end{array}$ \\
\hline Venezuela & 9.8 & & 75 & 735 & & 9 & 6615 & $\begin{array}{l}\text { Bonduki and } \\
\text { Swisher, } 1995\end{array}$ \\
\hline Brazil & 60 & & 18 & 735 & & 1.8 & 1323 & Da Motta et al., 1999 \\
\hline \multicolumn{9}{|c|}{ Protected areas } \\
\hline Mexico & 6 & 4.9 & 89 & 535 & 470 & $1-6$ & 1872.5 & $\begin{array}{l}\text { Masera, 1995; } \\
\text { Masera et al., } 1997 \mathrm{a} \text {, } \\
\text { Masera et al. } 1995 \\
\text { and } 1997 \mathrm{~b}\end{array}$ \\
\hline Venezuela & 4 & & 94 & 376 & & 4 & 1504 & $\begin{array}{l}\text { Bonduki and } \\
\text { Swisher, } 1995\end{array}$ \\
\hline \multicolumn{9}{|c|}{ Restoration plantations } \\
\hline Mexico & 4.2 & 2.5 & 76 & 320 & 200 & 7 & 2240 & $\begin{array}{l}\text { Masera, 1995; } \\
\text { Masera et al., 1997a, } \\
\text { Masera and Ordóñez, } \\
1997\end{array}$ \\
\hline
\end{tabular}

\begin{tabular}{|c|c|c|c|c|c|c|c|c|}
\hline \multicolumn{9}{|c|}{ Commercial plantations (includes energy plantations) } \\
\hline Mexico & 6.6 & 2.4 & 208 & 1375 & 1075 & $5-7$ & 8250 & $\begin{array}{l}\text { Masera, 1995; } \\
\text { Masera et al., } 1997 \mathrm{a} \text {, } \\
\text { Masera et al. } 1995 \\
\text { and } 1997 \mathrm{~b}\end{array}$ \\
\hline Venezuela & 4.9 & & $52-62$ & 295 & & 17 & 5015 & $\begin{array}{l}\text { Bonduki and } \\
\text { Swisher, } 1995\end{array}$ \\
\hline $\begin{array}{l}\text { Brazil } \\
\text { degraded la } \\
\text { - Pulp } \\
\text { - Charcoal } \\
\text { - Timber }\end{array}$ & & & $\begin{array}{r}24 \\
180 \\
43\end{array}$ & & & $\begin{array}{r}1.4 \\
0.7 \\
-9.5\end{array}$ & & $\begin{array}{l}\text { Da Motta et al., } 1999 \\
\text { Da Motta et al., } 1999 \\
\text { Da Motta et al., } 1999 \\
\text { '-' means profitable }\end{array}$ \\
\hline \multicolumn{9}{|c|}{ Agroforestry } \\
\hline Venezuela & 1 & & 27 & 27 & & 20 & 540 & $\begin{array}{l}\text { Bonduki and } \\
\text { Swisher, } 1995\end{array}$ \\
\hline
\end{tabular}

\begin{tabular}{|c|c|c|c|c|c|}
\hline \multicolumn{6}{|c|}{ Total } \\
\hline Mexico & 37.4 & 24.5 & 4795 & 3375 & 17943 \\
\hline Brazil $^{\mathrm{a}}$ & 211 & & 3453 & & 8973 \\
\hline
\end{tabular}

a Unit carbon sequestration considers the difference between sustainable and unsustainable logging. Unit price is NPV(net of present value of benefits minus present value of costs)

b Unit cost US\$/tC is NPV. 
begins at the onset of the first harvest, can be sustained. Each timber crop, in a cumulative manner, can substitute for fossilfuel resources. The forest thus offers a sustainable alternative to the unsustainable use of fossil-fuel resources (Schlamadinger and Marland, 1996).

Land owners are unlikely to manage their forest resources for $\mathrm{C}$ sequestration alone. In the absence of financial incentives, any $\mathrm{C}$ sequestration will likely be incidental, or have the role of a by-product in the management of forests to produce valued goods and services (ITTA, 1983, 1994). In the tropical biome, the optimal mix of management strategies will likely reflect a balance between various forest management systems and agricultural production. Existing policies for forest and agricultural land management, however, do not yet reflect economic incentives for $\mathrm{C}$ management and probably are not optimal (see for example Poore et al., 1989).

The effectiveness of various strategies for $\mathrm{C}$ sequestration will depend on the initial status of the forest ecosystems. For lands without tree cover, afforestation permits large $\mathrm{C}$ gains per hectare (Dyson, 1977; Sedjo and Solomon, 1989). Industrial plantation forests are already being created on a large scale and expansion of this area for $\mathrm{C}$ sequestration is possible (Sedjo and Sohngen, 2000). The establishment of forest plantations is generally the most reliable silvicultural method for afforestation, reforestation, and sustainable regeneration (regeneration soon after cutting). Plantation establishment can enhance productivity if desired species are planted on suitable sites. Plantations can reduce the pressures to degrade natural forests (Sedjo and Botkin, 1997). However, following the harvest of a mature or old-growth forest, the land can remain a source of carbon for many decades, even when it is regenerated (Hoen and Solberg, 1994; Cohen et al., 1996; Schlamadinger and Marland, 1996; Bhatti et al., 2001). Therefore, for primary and mature forests, conserving and protecting the existing $\mathrm{C}$ pools is often the only mitigation option that yields near-term benefits.

Because of the diversity in the current global forest status and socio-economic situation, the optimal mix of mitigation strategies will vary with country and region, in both the tropics and the non-tropics. For many countries, slowing or halting deforestation is a major opportunity for mitigation (e.g., Brazil: Fearnside, 1998, and Mexico: Masera, 1995). In countries such as India, where deforestation rates have declined to marginal levels, afforestation and reforestation in the degraded forest and non-forest lands offer large mitigation opportunities (Ravindranath and Hall, 1995). Ravindranath and Hall (1995) have shown the potential of using this degraded land and small biomass gasifiers to sustainably produce electricity from woody biomass and displace 40 million tonnes of $\mathrm{C}$ annually. In Africa an important opportunity for mitigation is in conserving wood fuel and charcoal through improved efficiencies of stoves and charcoal kilns (Makundi, 1998). The selection of mitigation strategies or projects in tropical countries, particularly, will be determined by economic development priorities, changing pressures on land use, and resource constraints. In many industrialized countries, adjusting forest management regimes and material flows in the forest products sector (including substitution) appears most promising (Hoen and Solberg, 1994; Binkley et al., 1997).

To quantify accurately the effects of changes in forest management on the net transfer of $\mathrm{C}$ to the atmosphere, the whole system could be considered (see Box. 4.1). Many earlier studies focused on the immediate results of forest management measures, e.g. the higher biomass growth rate following a silvicultural treatment or the protected stock of $\mathrm{C}$ if wildfire or logging is prevented. Global assessments based on these studies (e.g., Dixon et al., 1994; Brown et al., 1996b) have limitations. Estimates, in terms of $\mathrm{tC} / \mathrm{ha}$ or $\mathrm{tC} / \mathrm{ha} / \mathrm{yr}$, leave unanswered the critical questions of the timing, security, and sustainability of these effects. Also, recent, more comprehensive studies indicate the importance of complete accounting for all the $\mathrm{C}$ flows in and out of the system and the analysis of long-term patterns. For example, Schlamadinger and Marland (1996) showed that the positive effect of short-rotation plantations for fossil fuel substitution is less than implied by the simple substitution of fossil fuels, because of the continued input of fossil fuels needed to operate the system. While the limitations of earlier studies are now evident, data for comprehensive analysis at the global scale are not yet available. This, in part, explains why global-level estimates of the potential for $\mathrm{C}$ mitigation in forestry remain unchanged from those in SAR.

\subsubsection{Wood Products}

Wood products are an integral part of the managed forest ecosystem and the forest sector $\mathrm{C}$ cycle. They play three roles in the forest sector carbon cycle: (1) a physical pool of carbon, (2) a substitute for more energy-intensive materials and, (3) a raw material to generate energy (Burschel et al., 1993; Nabuurs and Sikkema, 1998; Harmon et al., 1996; Karjalainen, 1996; Matthews et al., 1996; Marland and Schlamadinger, 1997; Apps et al., 1999).

Wood removed from a forest by harvest, whether by thinning or clear-cut, can be viewed as a replacement for the natural mortality that would otherwise occur eventually (albeit at a faster rate). Harvested wood provides renewable raw material for use as fuel, fibre, and building materials; as well as income and employment for rural populations (Glück and Weiss, 1996). Globally, about 3.4 billion $\mathrm{m}^{3}$ of wood are harvested per year, excluding wood that is burned on site (FAO, 1997). Harvest rates are expected to increase at $0.5 \%$ per year (Solberg et al., 1996). Of the total harvest, about 1.8 billion $\mathrm{m}^{3}$ is for fuelwood, used mainly in the tropics. The total fuelwood consumption in tropical countries increased from 1.3 to 1.7 billion $\mathrm{m}^{3}$ during the period 1990 to 1995 (FAO, 1997; Nogueira et al., 1998).

If the fossil fuel based energy required to produce and transport forest products is less than that needed for alternative products, 
then $\mathrm{CO}_{2}$ emissions will be avoided by the use of forest products. Buchanan and Levine (1999) show, for example, that when wood is used for building construction in place of brick, aluminium, steel, and concrete, there can be net savings in $\mathrm{CO}_{2}$ emissions. For construction of small buildings in New Zealand, the carbon substitution effect was larger than the direct carbon storage in wood building products (Buchanan and Levine, 1999). Forest products can also substitute in the marketplace for alternative materials, such as cement, that involve carbon emissions in their manufacture.

A systems approach has been used recently to recognize interdependencies among products and sectors. For example, Adams (1992) and Alig et al. (1997) examined the effects of sequestering $\mathrm{C}$ in forests in the USA on the availability of agricultural land, and Sedjo and Sohngen (2000) used a sectoral approach that explicitly recognized interrelations among various wood investment decisions, and between wood investment and $\mathrm{C}$ sequestration activities. The systems approach also recognizes the joint product nature of industrial wood and carbon sequestration. In a study in Argentina, for example, Sedjo (1999b) found that timber alone does not generate sufficient returns to justify plantation investment, but the simultaneous sequestration of $\mathrm{C}$ can justify investment above some threshold $\mathrm{C}$ price. The models do not yet incorporate a potential increase in demand for wood as a fuel to displace fossil fuels.

In the developing world most fuelwood and charcoal use is devoted to satisfying energy needs for cooking (Makundi, 1998). The potential for conservation of fuelwood is significant, both through improved cooking stoves and by substitution with liquefied or gasified biofuels. India, China, and some African countries have large programmes for the distribution of more efficient wood stoves. In India alone 28 million improved stoves have been disseminated (Ravindranath and Hall, 1995). The carbon mitigation costs of improved wood stoves in India range from US\$0.10/tC abated (Luo and Hulscher, 1999) to US\$12/tC abated (Ravindranath and Somashekar, 1995). A review of case studies in Asia showed an average mitigation cost of US $\$ 0.8 / \mathrm{tC}$ abated in Thailand to US $\$ 1.7 / \mathrm{tC}$ in India, through programmes to encourage use of improved wood stoves (Hulscher et al., 1999). The experience with wood stoves shows that - when appropriately designed, implemented, and monitored - efficient stove programmes can provide substantial benefits to local residents. There are no estimates of the global potential for carbon conservation via this option, however, in India alone it is estimated that $20 \mathrm{MtC}$ could be saved annually (Ravindranath and Hall, 1995).

There is also a significant potential for saving fuelwood and charcoal in a large number of small industries. Charcoal making, brick making, pottery making, bakeries, etc. use fuelwood as their primary energy source in many areas. Fuelwood and charcoal consumption in tropical countries is projected to increase from 1.34 billion $\mathrm{m}^{3}$ in 1991 to 1.81 billion $\mathrm{m}^{3}$ in 2010 (FAO, 1993).
Most of the forest harvest in the boreal and temperate zone is for industrial roundwood (i.e., cut logs). About one-half to two thirds of the roundwood finds its way into final products, and the rest is used for energy or ends up as decomposing residues (e.g., Apps et al., 1999). The annual production of roundwood, according to FAO (1997) statistics, corresponds to a harvest flux of about 1.6 billion $\mathrm{m}^{3}$, resulting in about 0.9 billion $\mathrm{m}^{3}$ in final products. This represents a $\mathrm{C}$ flux of about $0.3 \mathrm{GtC} / \mathrm{yr}$ into the product pool.

According to the SAR (IPCC, 1996), the current global stock of $\mathrm{C}$ in forest products is about $4.2 \mathrm{GtC}$ and the net sink is $0.026 \mathrm{GtC} / \mathrm{yr}$. Other sources suggest a stock of $10-20 \mathrm{GtC}$ (Sampson et al., 1993; Brown et al., 1996b) and a global sink of $0.139 \mathrm{GtC} / \mathrm{yr}$ (Winjum et al., 1998). There is a large uncertainty in the estimates. Even if the high end of the range is correct, the $\mathrm{C}$ sink in wood products appears small compared to the current rate of $\mathrm{C}$ sequestration in boreal and temperate forest ecosystems. Whether the physical pool of carbon in wood products in use acts as a sink depends on the relative rates of input and output from the product pool, i.e., the difference between the production of new products and the decay of the $\mathrm{C}$ stock in existing products (Apps et al., 1999).

Options to increase physical sequestration of carbon in wood products include:

- Increasing consumption and production of wood products;

- Improving the quality of wood products;

- Improving processing efficiency; and

- Enhancing recycling and re-use of wood and wood products.

Several studies have been carried out on the impacts of these measures on the amount of carbon sequestered in wood products. These studies generally conclude that the sink potential is quite small at the national or global level (Karjalainen, 1996; Nabuurs, 1996; Marland and Schlamadinger, 1997).

Use of wood as a fuel reduces $\mathrm{CO}_{2}$ emissions from fossil fuels (Hall et al., 1991; Brown et al., 1996a; Nabuurs, 1996; Marland and Schlamadinger, 1997). Where the costs of growing biofuels on agricultural lands are higher than the costs of using fossil fuel, some form of incentive may be required to generate significant shifts to biofuels (Sedjo, 1997). The use of abandoned forest products for energy rather than disposal as waste can provide additional opportunities for displacing use of fossil fuels (Apps et al, 1999). Chapters 3 and 6 provide further discussion of the use of bioenergy within the energy sector.

Micales and Skog (1997) estimate that of the total amount of carbon-based products disposed of in the USA in 1993, as either paper or wood products, $28 \mathrm{TgC}$ (out of a total domestic harvest of approximately $123 \mathrm{TgC} / \mathrm{yr}$ ) will remain stored in landfills. Heath et al. (1996) and Karjalainen et al. (1994) emphasize the increasing role of landfills as a store of $\mathrm{C}$. 
Production of methane through anaerobic decomposition deserves to be considered when evaluating the mitigation potential.

While $\mathrm{C}$ sequestration in wood products can reach saturation, the $\mathrm{C}$ benefits of materials substitution can be sustained. Assuming a material substitution effect of $0.28 \mathrm{tC} / \mathrm{m}^{3}$ of final wood product (Burschel et al., 1993), and a flux corresponding to a roundwood volume of 0.9 billion $\mathrm{m}^{3}$ annually, the substitution impact of industrial wood products may be as large as $0.25 \mathrm{GtC} / \mathrm{yr}$. Although this estimate is highly uncertain, it is possible that for wood products the substitution impact is larger than the sequestration impact. This substitution is additional to the sinks in wood products mentioned before.

\subsubsection{Managing Wetlands}

Globally, wetlands contain large reserves of organic carbon about 300 to 600GtC (Gorham, 1991; Eswaren et al., 1993; Scharpenseel, 1993; Kauppi et al., 1997). A major portion of this carbon is found in peat-forming wetlands (peatlands), often associated with forests, in both northern (302Mha, $397 \mathrm{GtC}$ ) and tropical (50Mha, 144GtC) biomes (Zoltai and Martikainen, 1996). Over the long term, peatlands gradually accumulate additional carbon, because decomposition is suppressed under flooded conditions (Harden et al., 1992; Mitsch and Wu, 1995; Rabenhorst, 1995; Zoltai and Martikainen, 1996; Kasimir-Klemedtsson et al., 1997). The beneficial effect of this carbon accumulation, however, is at least partially offset by release of methane, which is also a GHG (Gorham, 1995).

There are few opportunities to augment the accumulation of carbon in wetlands by improved management. Drainage of forested peatlands, largely concentrated in boreal regions, can enhance tree growth significantly, but the net ecosystem carbon changes are less clear - some studies report large net gains while others indicate large net losses of carbon to the atmosphere (see review by Zoltai and Martikainen, 1996). A more important mitigation measure, from the perspective of atmospheric $\mathrm{CO}_{2}$, is the preservation of the vast carbon reserves already present (van Noordwijk et al., 1997) in peatlands. Drainage of wetlands for agricultural or other uses results in rapid depletion of stored C (Kasimir-Klemedtsson et al., 1997).

\subsubsection{Opportunities in Agricultural Lands}

Most ecosystems, under constant conditions, eventually approach a steady-state $\mathrm{C}$ stock that is dictated by management, climate, and soil properties. But changes imposed on the ecosystem can alter the balance of $\mathrm{C}$ inputs and losses, shifting the ecosystem, eventually, to a new steady state (Paustian $e t$ al., 1997c). For example, after conversion of forests or grasslands to arable agriculture, losses of $\mathrm{C}$ often exceed inputs temporarily, resulting in a net loss of $\mathrm{C}$ to the atmosphere until a new, lower equilibrium level is reached (Balesdent et al., 1998;
Huggins et al., 1998; Solomon et al., 2000). At least a portion of $\mathrm{C}$ lost, however, can often be recovered by adopting management practices that again favour higher $\mathrm{C}$ stocks (Cole et al., 1997). The accumulation of $\mathrm{C}$ in soil can continue until a new steady state is reached, often after several or more decades. Most of the additional $\mathrm{C}$ is stored in the soil as organic matter. Apart from agroforests, agricultural lands store very little carbon in plant biomass (Table 4.1).

There are two general ways of increasing $\mathrm{C}$ stocks in agricultural lands: by changing management within a given land use (e.g., cropland, rice land, grazing land, or agroforests) or by changing from one land use to another (e.g., cropland to grassland or cropland to forest) (Sampson et al., 2000). In this section, we review briefly the possible ways of increasing $\mathrm{C}$ stocks in agricultural lands, first within a land use and then by a change in land use. We then review recent estimates of the potential for increasing $\mathrm{C}$ stocks in agricultural lands globally. A more detailed assessment of management practices and corresponding rates of C accrual is reported in the IPCC Special Report on LULUCF (IPCC, 2000a).

Croplands, as referred to here, are lands devoted, at least periodically, to the production of arable crops (wetland rice, because of its unique features, is discussed separately). Soil C in these lands can often be preserved or enhanced by using farming systems with reduced tillage intensity, thus slowing the rate at which soil organic matter decomposes (Bajracharya et al., 1997; Feller and Beare, 1997; Rasmussen and Albrecht, 1997; Dick et al., 1998). Another way to promote higher soil C is to increase crop yields. This can be done by applying organic amendments, by effective use of fertilizers, by using improved crop varieties, or by irrigating. These practices help replenish soil organic matter by increasing the amount of crop residues returned to the soil (Raun et al., 1998; Huggins et al., 1998; Paustian et al., 1997b; Lal et al., 1998; Smith et al., 1997; Fernandes et al. 1997; Izac 1997). Further, soil C can often be increased by using practices that extend the duration of $\mathrm{C}$ fixation by photosynthesis; for example, cover crops, perennial forages in rotation, and avoiding bare fallow tend to increase organic C returns to soil (Lal et al., 1997; Singh et al., 1997a; Smith et al., 1997; Carter et al. 1998; Tiessen et al., 1998; Tian et al., 1999; Paustian et al., 1997a, 2000). Farming techniques that reduce erosion (e.g., terracing, windbreaks, and residue management) maintain productivity and also prevent loss of $\mathrm{C}$ from agricultural soils. The net effect of soil erosion on atmospheric $\mathrm{CO}_{2}$ is still uncertain, however, because the $\mathrm{C}$ removed may be deposited elsewhere and at least partially stabilized (van Noordwijk et al., 1997; Lal et al., 1998; Stallard, 1998).

Rice land, as the term is used here, refers to areas that are at least periodically flooded for wetland rice production. Carbon stocks in these systems can be preserved or enhanced by the addition of organic amendments (Singh et al., 1997b; Kumar et al., 1999) and nutrient management (Yadav et al., 1998). Rice lands, however, are an important source of methane and, from the standpoint of overall radiative forcing, management effects on 
methane emissions may be more important than effects on $\mathrm{C}$ storage (Greenland, 1995; Sampson et al., 2000). Methane emissions can be suppressed to some extent by soil amendments, altered tillage practices, water management, crop rotation, and cultivar selection (Minami, 1995; Kern et al., 1997; Neue, 1997; Yagi et al., 1997; Van der Gon, 2000). For more information on $\mathrm{CH}_{4}$ and $\mathrm{N}_{2} \mathrm{O}$ emissions from land use, see Section 3.6.

Grazing lands refer to natural grasslands, intensively managed pastures, savannas, and shrublands used, at least periodically, to graze livestock. One way to increase $\mathrm{C}$ stocks in these lands is to introduce new plant species. For example, the introduction of $\mathrm{N}$-fixing legumes increases productivity, thereby favouring C storage (Fisher et al., 1997; Conant et al., 2001). Large increases in soil $\mathrm{C}$ have been also reported from the introduction of deep-rooted grasses in South American savannas (e.g., Fisher et al., 1994), though the area over which these findings apply is still uncertain (Davidson et al., 1995). Other management practices that can affect $\mathrm{C}$ storage include: changing grazing intensity and frequency (Manley et al., 1995; Ash et al., 1996; Burke et al., 1997, 1998); adding nutrients, especially phosphorus (Barrett and Gifford, 1999); controlling fire (Burke et al., 1997; Kauffman et al., 1998); and irrigation (Conant et al., 2001).

Agroforests include trees on farms as part of the agricultural landscape (Sampson et al., 2000). Unlike most other agricultural systems, agroforests store $\mathrm{C}$ in the above and below ground vegetation as well as in soil organic matter (Fernandes et al., 1997; Woomer et al., 1997). Examples of practices that can enhance $\mathrm{C}$ stocks include: integrated pest management, optimum tree densities, superior tree or crop cultivars, and better nutrient management (Sampson et al., 2000).

Land-use conversion involves transferring a given land area from one use to another. Where the shift is to a land use with higher potential $\mathrm{C}$ storage, the conversion can result in increased $\mathrm{C}$ stocks. For example, conversion of cropland to grassland often increases soil C (e.g., Paustian et al., 1997b; Reeder et al., 1998; Potter et al., 1999; Post and Kwon, 2000). Carbon stocks may also be enhanced by conversion of cropland to forests (reforestation, afforestation) or to agroforests (e.g., Fernandes et al., 1997; Woomer et al., 1997; Falloon et al., 1998; Post and Kwon, 2000). In some cases, cultivated lands can be restored as wetlands (Paustian et al., 1998; Lal et al., 1999), resulting in carbon gains, though this practice may also result in higher net $\mathrm{CH}_{4}$ emissions (Willison et al., 1998; Batjes, 1999; Sampson et al., 2000).

Another form of land-use conversion is the rehabilitation of severely degraded lands. Severely degraded lands are those where previous management has caused a drastic decline or disruption of productivity. Large areas of degraded lands occur on lands previously used for agriculture; lands abandoned after excessive erosion, over-grazing, desertification, or salinization (Oldeman, 1994; Lal and Bruce, 1999). Often the degradation was caused by social and economic pressures, and land reha- bilitation may depend on the amelioration of the underlying causes of degradation. Specific rehabilitation practices include: introduction of new species (e.g., reforestation), addition of nutrients, and organic amendments (e.g., Lal and Bruce, 1999; Lal et al., 1998; Izaurralde et al., 1997).

Various attempts have been made to estimate potential C storage by improved management of agricultural lands. In the IPCC Second Assessment Report, Cole et al. (1996) estimated the potential for $\mathrm{C}$ storage in agricultural soils from improved management of existing croplands, restoration of degraded lands, and conversion to grass or forestlands. By assuming that one-half to two-thirds of the estimated historic $\mathrm{C}$ loss from cultivated soils could be recovered in 50 years, they proposed potential soil $\mathrm{C}$ increases of about 0.4 to $0.6 \mathrm{GtC} / \mathrm{yr}$ from better management of existing agricultural soils. According to their estimates, additional $\mathrm{C}$ could be stored by set-aside of surplus upland soils $(0.015$ to $0.03 \mathrm{GtC} / \mathrm{yr})$, restoration of wetlands (0.006 to $0.012 \mathrm{GtC} / \mathrm{yr})$, and restoration of degraded lands ( 0.024 to $0.24 \mathrm{GtC} / \mathrm{yr}$ ), yielding a combined potential of about 0.44 to $0.88 \mathrm{GtC} / \mathrm{yr}$ over a 50 -year period. Later studies have provided similar estimates. Lal and Bruce (1999), using rates of soil $\mathrm{C}$ gain from the literature, estimated global $\mathrm{C}$ storage potentials of 0.43 to $0.57 \mathrm{GtC} / \mathrm{yr}$ in the next $20-50$ years, from erosion control, soil restoration, conservation tillage and residue management, and improved cropping practices. Batjes (1999), based partly on C gains estimated by Bruce et al. (1999), proposed that an additional $14 \mathrm{GtC}( \pm 7)$ could be stored in agricultural soils over the next 25 years by improved management of "degraded" and "stable" agricultural lands. Including "extensive grasslands" and "regrowth forests" increased the estimate to $20 \mathrm{GtC}( \pm 10)$, corresponding to an average rate of 0.58 to $0.80 \mathrm{GtC} / \mathrm{yr}$.

Sampson et al. (2000) recently completed a comprehensive assessment of potential net $\mathrm{C}$ storage from land management as part of the IPCC Special Report on LULUCF (IPCC, 2000a). According to their estimate, improved management within a land use could result in global rates of $\mathrm{C}$ gain, in 2010, of $0.125 \mathrm{GtC} / \mathrm{yr}$ for cropland, $<0.008 \mathrm{GtC} / \mathrm{yr}$ for rice paddies, $0.026 \mathrm{GtC} / \mathrm{yr}$ for agroforestry, and $0.237 \mathrm{GtC} / \mathrm{yr}$ for grazing land. Potential rates of $\mathrm{C}$ gain in 2010 for land use conversion were $0.391 \mathrm{GtC} / \mathrm{yr}$ for conversion of unproductive cropland and grasslands to agroforests, $<0.004 \mathrm{GtC} / \mathrm{yr}$ for restoring severely degraded land, $0.038 \mathrm{GtC} / \mathrm{yr}$ for conversion of cropland to grassland, and $0.004 \mathrm{GtC} / \mathrm{yr}$ for conversion of drained land back to wetland. Corresponding rates of potential $\mathrm{C}$ gains for 2040 were consistently higher than those for 2010, often by a factor of about 2, though confidence in these values was lower. Sampson et al. (2000) cautioned that their estimates "are approximations, based on interpretation of available data" and that, "for some estimates of potential carbon storage, the uncertainty may be as high as $\pm 50 \%$ ".

Most of these estimates assume widespread, concerted adoption of C-conserving practices, and all have high uncertainty, stemming in part from the difficulty of predicting adoption of 
C-conserving practices. The various estimates, furthermore, cannot always be compared directly because of differences in practices, scope, time-frame, and underlying assumptions. Most of the more recent estimates, however, are within the same order of magnitude as those presented in the SAR (Cole et al., 1996).

Increases in soil carbon content in response to improved practices cannot continue indefinitely. Eventually, soil C storage will approach a new equilibrium where $\mathrm{C}$ gains equal $\mathrm{C}$ losses (Paustian et al., 2000). This new equilibrium will depend on the management practices adopted, as well as on soil type and climatic conditions. Consequently, rates of $\mathrm{C}$ gain will diminish with time, and estimates for a given year cannot be extrapolated far into the future.

Once soils reach a new equilibrium, there is little further accumulation of $\mathrm{C}$. And if the $\mathrm{C}$-conserving practice is discontinued (e.g., reversion from no-tillage to intensive tillage), much of the previously gained $\mathrm{C}$ may be lost back to the atmosphere as $\mathrm{CO}_{2}$ (Dick et al., 1998; Stockfisch et al., 1999). Consequently, the $\mathrm{C}$ stocks stored in soils are not necessarily permanent and irreversible.

\subsection{Environmental Costs and Ancillary Benefits}

\subsubsection{Environmental Costs and Ancillary Benefits in Forests}

Forests serve many environmental functions aside from carbon mitigation. Natural forests with various stages of stand development, including old-growth forests with snags and fallen logs, provide diverse habitats necessary for biodiversity (Harris, 1984; Franklin and Spies, 1991). Stopping or slowing deforestation and forest degradation, therefore, not only maintains carbon stocks but also preserves biodiversity, as shown by studies in Belize (EPA/USIJI, 1998) and Paraguay (Dixon et al., 1993).

Although plantations usually have lower biodiversity than natural forests (Yoshida, 1983: Kurz et al., 1997; Frumhoff and Losos, 1998), they can reduce pressure on natural forests, leaving greater areas to provide for biodiversity and other environmental services (Sedjo and Botkin, 1997). Plantations can negatively affect biodiversity if they replace biologically rich native grassland or wetland habitat, but non-permanent plantations of exotic or native species can be designed to enhance biodiversity by stimulating restoration of natural forests (Keenan et al., 1997; Lugo, 1997; Parrotta et al., 1997a, 1997b). Measures to promote biodiversity of intensively managed plantations include the adoption of longer rotation times, reduced or eliminated clearing of understory vegetation, use of native tree species, and reduced chemical inputs (Allen et al., 1995; Da Silva Jr et al., 1995; Fujimori, 1997).

Preserving forests conserves water resources and prevents flooding. For example, the flood damage in Central America following hurricane Mitch was apparently enhanced by loss of forest cover. By reducing runoff, forests control erosion and salinity. Consequently, maintaining forest cover can reduce siltation of rivers, protecting fisheries and investment in hydroelectric power facilities (Chomitz and Kumari, 1996).

Afforestation and reforestation, like forest protection, may also have beneficial hydrological effects. After afforestation in wet areas, the amount of direct runoff initially decreases rapidly, then gradually becomes constant, and baseflow increases slowly as stand age increases towards a mature stage (Kobayashi, 1987; Fukushima, 1987), suggesting that reforestation and afforestation help reduce flooding and enhance water conservation. In water-limited areas, afforestation, especially plantations of species with high water demand, can cause significant reduction of streamflow, affecting inhabitants in the basin (Le Maitre and Versfeld, 1997). The hydrological benefits of afforestation may need to be evaluated site by site.

Forest protection may, however, have negative social effects, such as displacement of local populations, reduced income, and reduced flow of subsistence products from forests. Conflicts between protection of natural ecosystems and their other functions, such as production of food, fuelwood, and roundwood, can be minimized by appropriate land use on the landscape (Boyce, 1995; Forman, 1995) and appropriate stand management.

In arid and semi-arid regions, where deforestation is advancing (Kharin, 1996) and leading to carbon loss (Duan et al., 1995), restoring forests by afforestation and proper management of existing secondary forests can help combat desertification (Cony, 1995; Kuliev, 1996). Afforestation of desertified lands may be limited, however, by costs and insufficient knowledge of ecology, genetics, and physiology (Cony, 1995). In relatively arid regions, fuelwood plantations may reduce pressure on natural woodlands, thereby retarding deforestation (Kanowski et al., 1992).

Agroforestry can both sequester carbon and produce a range of economic, environmental, and socioeconomic benefits. For example, trees in agroforestry farms improve soil fertility through control of erosion, maintenance of soil organic matter and physical properties, increased $\mathrm{N}$, extraction of nutrients from deep soil horizons, and promotion of more closed nutrient cycling (Young, 1997). Thus, agroforestry systems improve and conserve soil properties (Nair, 1989; MacDicken and Vergara, 1990; Wang and Feng, 1995). Examples of mitigation projects that promote soil conservation through agroforestry include the AES Thames Guatemala project, and the Profator project in Ecuador (Dixon et al., 1993; FACE Foundation, 1997).

We note that decisions to protect or enlarge forest cover on a large scale could also have secondary climate consequences through their feedbacks on the earth's albedo, the hydrological cycle, cloud cover, and the effect of surface roughness on air 
movements (see, for example, Pielke and Avissar, 1990; Nobre et al., 1991; Garratt, 1993). Analyses by Bonan and Shugart (1992) suggest that large-scale changes in vegetative cover in the boreal zone may be especially important, with potentially global-scale impacts. In the boreal zone the albedo contrast between forested and unforested land during the winter is particularly large (differences as large as $40 \%$ ). Indications are that the nature, magnitude, and even direction of climate changes driven by changes in surface vegetative cover will depend on the nature, location, hydrological setting, etc. of the vegetative change.

\subsubsection{Environmental Costs and Ancillary Benefits in Agricultural Lands}

Management strategies that conserve $\mathrm{C}$ in agricultural soils may have ancillary benefits quite apart from atmospheric $\mathrm{CO}_{2}$ removal. Foremost among these is a favourable effect on soil productivity. Numerous studies have shown a strong link between the organic $\mathrm{C}$ content of a soil and its quality for crop production (e.g., Carter et al., 1997; Christensen and Johnston, 1997; Herrick and Wander, 1997). Consequently, a gain in soil $\mathrm{C}$ may promote crop yields, and preserve or enhance future soil productivity (Cole et al., 1997; Rosenzweig and Hillel, 2000). For example, application of fertilizers to agro-pastoral systems in parts of South America may not only induce soil C accumulation, but also enhance agricultural productivity (Fisher $e t$ al., 1997). Many of the practices advocated for soil C conservation - reduced tillage, more vegetative cover, greater use of perennial crops - also prevent erosion, yielding possible benefits for improved water and air quality (Cole et al., 1993). As a result of these benefits, adoption of practices that promote $\mathrm{C}$ conservation in agricultural lands is often justified even without the additional benefits arising from $\mathrm{CO}_{2}$ mitigation.

Soil carbon sequestration, however, may sometimes have some potential adverse effects on the emission of other GHGs, notably nitrous oxide $\left(\mathrm{N}_{2} \mathrm{O}\right)$. Where the $\mathrm{C}$ accumulation requires addition of higher amounts of $\mathrm{N}$ as fertilizer or manure, it carries the risk of increased $\mathrm{N}_{2} \mathrm{O}$ emissions (Cole $e t$ al., 1993; Batjes, 1998). Furthermore, some C-conserving practices like reduced tillage may increase $\mathrm{N}_{2} \mathrm{O}$ emissions by favouring higher soil moisture content (Cole et al., 1993; MacKenzie et al., 1997; Ball et al., 1999), though this effect is not always observed (e.g., Jacinthe and Dick, 1997; Lemke et al., 1999). Because the radiative forcing of $\mathrm{N}_{2} \mathrm{O}$ is about 310 times that of $\mathrm{CO}_{2}(\mathrm{~kg}$ per $\mathrm{kg})$, when calculated over a 100 -year time frame (IPCC, 1996), even a small increase in $\mathrm{N}_{2} \mathrm{O}$ emissions, if confirmed, can significantly offset gains from $\mathrm{C}$ sequestration.

Carbon sequestration strategies may also have an effect on energy use and, hence, $\mathrm{CO}_{2}$ emission from fossil fuel use. Changes in fertilizer use, pesticides, and agricultural machinery may enhance or offset any gains in soil $\mathrm{C}$ because of $\mathrm{CO}_{2}$ released from fossil fuel. For example, roughly $1 \mathrm{kgC}$ (or more) is released into the atmosphere as $\mathrm{CO}_{2}$ per $\mathrm{kgN}$ used (Flach et al., 1997; Janzen el al., 1998; Schlesinger, 1999). In tropical areas where shifting cultivation is now practiced, intensification of crop production may maintain higher $\mathrm{C}$ stocks, by leaving more land under natural forest, but additional fossil fuel may have to be used to compensate for the fuelwood previously collected from the fallow period (van Noordwijk et al., 1997). In some cases, the adoption of C-conserving practices may reduce energy use. For example, using less intensive tillage may not only favour soil $\mathrm{C}$ gains, but also permits savings in $\mathrm{CO}_{2}$ emission from fossil fuel combustion (Kern and Johnson, 1993). An evaluation of the net benefit of a $\mathrm{C}$-sequestering practice, therefore, must consider energy use in addition to changes in $\mathrm{C}$ stocks. Whereas the duration of soil $\mathrm{C}$ gain in response to improved management may be finite, savings in $\mathrm{CO}_{2}$ emissions from energy use continue indefinitely (Cole et al., 1997).

Aside from their secondary effects on GHG emissions, practices that sequester soil $\mathrm{C}$ may also have other potential adverse effects, at least in some regions or conditions. Possible effects include enhanced contamination of groundwater with nutrients or pesticides via leaching under reduced tillage (Cole et al., 1993; Isensee and Sadeghi, 1996), and possible environmental effects from widespread application of manures or sludges (Batjes, 1998). These possible negative effects, however, have not been widely confirmed nor quantified, and the extent to which they may offset the environmental benefits of $\mathrm{C}$ sequestration is uncertain.

\subsection{Social and Economic Considerations}

\subsubsection{Economics}

The method of calculating costs for forestry and agricultural projects differs. Forestry almost always looks at private market costs. However, many, if not most, forestry projects have positive externalities (or ancillary benefits) in the form of erosion control, water protection, flora and fauna habitat, non-timber forest products, water protection, and so forth (Makundi, 1997; Frumhoff et al., 1998; Trexler and Associates, 1998). For agricultural projects the approach is typically tied to the idea that the carbon-sequestering projects are essentially productivity enhancing and therefore can be viewed as "no regrets" activities; these are actions that have benefits in themselves aside from climate mitigation, which make the project socially desirable even without its carbon benefits. Such "no regrets" activities generally take the form of soil management activities, which both generate increased sequestered carbon and improve agricultural productivity.

There are basically three different ways of estimating the costs of sequestration of forestry projects - point estimates, i.e., cost for a particular level of output; partial equilibrium estimates, e.g., a cost function construction with the prices of inputs being held constant; and more general equilibrium types of approach- 
es, e.g., a market equilibrium model in which some other prices, such as the prices of land inputs and the relative price of all other goods, are allowed to change owing to market forces. Additionally, economic models can incorporate changing climate conditions to estimate changes in economic variables as the climate and ecosystem change. Early studies tended to look at individual projects, relating the private costs of establishing a project to the cumulative carbon sequestered over the life of the project (see Sedjo et al., 1995). Many of the point estimate type studies provide undiscounted private market cost point estimates of the carbon sequestration in afforestation projects. However, this approach usually reveals little about how costs might change if the project were expanded to involve truly large land areas, as they do not recognize rising costs required to increasingly bid land away from alternative uses. These types of estimates tended to be biased downwards, partly because the opportunity costs of the land (land rents) were often ignored.

Point Estimates: The cost estimates of actually sequestering carbon obtained in point estimate type of studies tend to be quite low; in the SAR (IPCC, 1996) a range was given of US\$3-US\$7 per tonne of carbon. Additionally, a large number of more recent point estimate country studies reported most unit abatement costs in this low range, or lower. The earlier IPCC estimates for SAR were that of an investment of US\$ 168-220 billion required to mitigate $45-72 \mathrm{GtC}$ in the tropical regions. More recent work provides estimates that the cumulative investment required for mitigating $26.53 \mathrm{GtC}$ to be US\$63.6 billion at an overall cost of US\$2.4/tC (Sathaye and Ravindranath, 1998). The unit cost given in Table 4.3 shows that the investment cost of mitigation is generally quite low for carbon conservation options in selected developing countries and South Korea (e.g., US $\$ 0.10 / \mathrm{tC}$ in Vietnam, and US\$1- 2/tC in Cameroon and Ghana). The mitigation cost is lower than $\mathrm{US} \$ 2 / \mathrm{tC}$ for the majority of the options in Indonesia, the Philippines, Vietnam, and Mongolia.

Partial Equilibrium: Partial equilibrium involves a more complete estimation of a static cost function that estimates rising costs (e.g., as a result of land price increases as one moves to lands with higher opportunity costs) associated with increased sequestration activities. These studies generate marginal cost functions that tend to suggest most costs are higher than those of the simple point estimates. This is because, for example, they include in the cost estimates the opportunity costs of the land, and they recognize rising costs associated with additional planning activity and, for some, because they apply a discount rate to future physical carbon sequestered. The costs for modest amounts of carbon sequestered in specific areas are generally in the US\$20-US\$100/tC range (Moulton and Richards, 1990; Adams et al., 1995; Parks and Hardie, 1997;Stavins, 1999; Plantinga et al., 1999). Costs tend to depend on the forest growth rates anticipated and the opportunity costs of the land. Where projects are small, land prices would be expected to be stable. However, in regions where projects are large, land prices, and hence sequestration costs, will tend to rise.
Market Equilibrium Models: This approach incorporates sectoral and general equilibrium interrelationships. It recognizes that expanding the forest for carbon sequestration purposes has implications for current and future industrial forest production and prices, and for agricultural production and prices. These price and production changes then generate feedbacks through the market to the forest and agricultural sector behaviour. Alig et al. (1997), for example, examine the effects on welfare costs of meeting alternative carbon sequestration targets by land re-allocations between agriculture and forestry in the USA. This model explicitly treats agriculture and wood production as interrelated. Allocating more land to trees to capture carbon has implications on the price and quantity of agricultural products, as well as on timber. Thus, the costs of carbon plantations are found both in the price of establishing the plantations and in the higher agricultural prices, and thus involve welfare shifts across sectors. A different approach, also recognizing sectoral interrelationships, is that of Sedjo and Sohngen (2000). This approach expands on earlier global timber supply models by explicitly incorporating the interrelations between the industrial wood sector and carbon plantations by recognizing the joint product nature of industrial wood and carbon. This approach finds that tree planting carbon sequestration activities tend to have a somewhat more modest effect than anticipated, since the tree planting for carbon purposes leads to an expected increase in future timber supplies and a corresponding decrease in expected future prices. Through the effects of price expectations on the timber market, carbon activities may discourage industrial timber investments and thereby lose some of the carbon gains made from the initial project. This is a form of leakage not often recognized.

Climate Feedback Models: These market equilibrium models incorporate the impact of the climate-driven changing ecology into their assessment of the potential and costs. Perez-Garcia $e t$ al. (1997) examine the effects of climate change, using a global trade model (CGTM). This approach imposes a global circulation model (GCM) and a terrestrial ecosystem model on the world's industrial wood economy, and estimates the welfare effects on forest owners and forest consumers of such changes. Sohngen and Mendelsohn (1998) use a timber model of the USA to estimate the changes in the forest market sector that would be expected to occur with a climate warming using GCM and terrestrial ecosystem models. However, neither study considers the impacts of increased fuelwood demand to replace fossil fuels.

In summary, most studies, of all methodologies, suggest that there are many opportunities for relatively low-cost carbon sequestration through forestry. Estimates of the private costs of sequestration range from about US\$0.10-US\$100/tC, which are modest compared with many of the energy alternatives (see Table 3.9 and Figure 4.9). Additionally, it should be noted that most forest projects have positive non-market benefits, thus increasing their social worth. However, as the studies have become more sophisticated, incorporating both the full private 

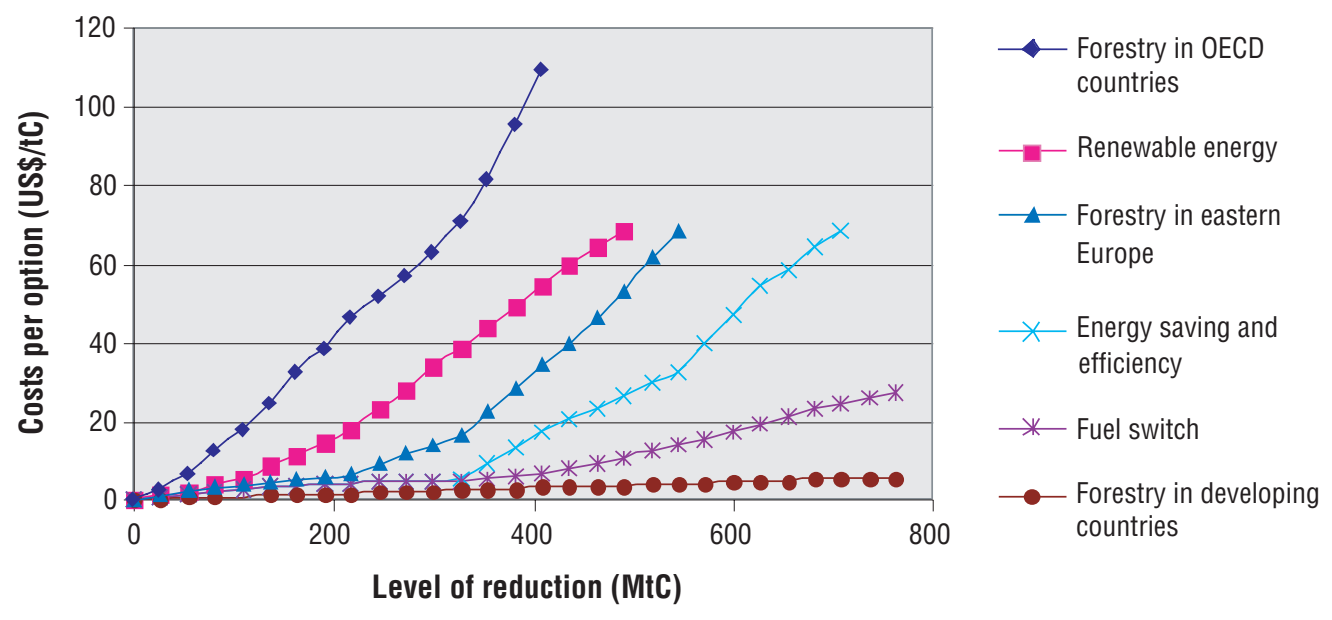

Figure 4.9: Indicative curves of costs (US\$/tC, cost of US\$28/tC is equivalent to US\$100 per tonne of $C \mathrm{O}_{2}$ ) of emission reduction or carbon sequestration by level of total reduction. The curves display how comparable options vary in costs between world regions. However, costs per option are also reported to vary widely at comparable total levels of reduction. This is mainly because cost studies have not been carried out in the same way. In some options net monetary profit may occur as well (i.e., costs may be negative as well) (Brown et al., 1996a, Hol et al., 1999; Jepma et al., 1997; Sedjo et al., 1995).

opportunity costs of the land and market effects on land and resource prices, estimates of carbon sequestration costs have tended to rise. The cost estimates tend to vary for regions, with high costs generally associated with high opportunity costs for land. In the many regions that have low opportunity costs for land, including many subtropical regions, the costs tend to remain low.

\subsubsection{Institutional Structures and Equity Issues}

In order to realize the mitigation potential in part or in full, it would be helpful to have a set of institutions to translate the policies and measures into avoided emissions or carbon sequestration. In the United Nations Conference on Environment and Development (UNCED) held in 1992, the importance of sustainable forest management was emphasized under the "Forest Principles." Subsequently, the formulation of criteria and indicators was worked out under the Helsinki and Montreal Processes, in which the maintenance and enhancement of forest resources to contribute to the global carbon cycle is described. The same is a criterion under the United Nations (UN-ECE/FAO, 2000). The three main types of necessary institutions are global and/or regional, national and local, and/or community based (IPCC, 2000b). At the global level, there exist government-based multilateral institutions such as the United Nations Food and Agriculture Organization (FAO), United Nations Environment Programme (UNEP), the World Bank, and the International Tropical Timber Organization (ITTO). All of these institutions are involved in natural resource management, and can play a significant role in integrating mitigation objectives in tropical forest management. Also, a wide array of non-governmental organizations (NGOs) active in resource conservation and sustainable utilization, as well as bilateral aid organizations, could play a more important role in incorporating mitigation in their policy objectives. For example, investment promotion agencies could be created to assist in the co-ordination of investment into carbon projects (e.g., see Moura-Costa et al., 1999). Additionally, global private enterprises could be encouraged to include climate mitigation measures in their plans. Financial incentives may be required to achieve broad participation.

In tropical countries, forestry is dominated by governmentbased institutions, mostly the departments of forestry and agriculture and/or those involved in environmental management (WRI, 1987). These departments may need support and new insight in order to effectively incorporate mitigation policies and measures in their resource management activities. At a national level, there also exist some institutions involving NGOs that focus on conservation and forest expansion, as well as those dedicated to encouraging sustainable agriculture. Such institutions may also include umbrella organizations involved in developmental activities such as gender, poverty alleviation, etc. A few institutions, including non-governmental and especially those involved in nature conservation and environmental services, e.g., game reserves, tourism companies, and largescale agricultural production, could also incorporate mitigation considerations in their efforts.

At the local level, effective institutions include community leaderships, religious institutions, schools, traditional organizations, and indeed the family. These institutions are essential with regard to natural resource management and agricultural practices, as well as for introducing mitigation-type activities that do not contravene their basic needs to use their land and natural resources for sustenance. 
Public, NGO, and private institutions, at each spatial level where they exist, can focus on including GHG mitigation as one of their considerations, while they oversee the use of forest and land resources to meet the developmental aspirations of those in tropical countries and elsewhere. For example, a recent study on sustainable livelihoods and carbon management discussed arrangements to facilitate the involvement of small-scale farmers and rural communities in carbon trading (Bass et al., 2000). An optimal mix of conservation, sequestration, and substitution will be incidental or arise from the optimal management of forest resources for producing desired goods and services as shown under various tropical forest management stipulations (ITTA, 1983, 1994). In the tropical biome, the most likely use of the optimal mix of management strategies will be based on optimal management of forestry and agricultural resources in each country. For example, balance between forest conservation, afforestation, reforestation, and multiple land use of the forest and agricultural areas will predetermine the extent of utilization of the land-use sectors for mitigation activities. However, the existing policies in managing forest and agricultural resources have been criticized as non-optimal (see, for example, Poore et al., 1989). Optimal levels of substitution will be determined by the energy and industrial policies of these countries, rather than by carbon sequestration criteria.

The so-called "no regrets options" can be identified and pursued (see Chapters 7 and 8 for a discussion of no regrets options). Analysis has suggested that adequately designed and implemented GHG mitigation options in forestry and agriculture could help advance the countries' own development priorities, at the same time providing significant carbon sequestration (see Sheinbaum and Masera (2000) for analysis at the country level).

\subsection{Market and Non-market Options to Enhance, Maintain, and Manage Carbon Pools}

\subsubsection{Introduction, Taxes, and Quotas}

There are a host of market and non-market options to manage carbon pools in the terrestrial biosphere. Some of the most relevant questions related to carbon sequestration deal with the types of instruments, policies, and mechanisms that could play a role in promoting increased sequestration and how the various arrangements would actually affect outcomes. Market mechanisms could be important in promoting or discouraging carbon sequestration. Potential mechanisms might include taxes or subsidies for activities that affect carbon directly or that affect activities with large carbon implications. The UK, for example, has proposed a "Climate Change Levy" to be adopted by the UK's 2001 Budget. The Kyoto Protocol introduces flexible mechanisms allowing joint implementation, emissions trading, and the clean development mechanism. When dealing with terrestrial systems any policies that influence land use can affect carbon sequestration. Finally, there is the question of how the various instruments and policies are likely to influence leakage of carbon flows outside the targetted system.

Agricultural subsidies are common in many, if not most, countries. Agricultural subsidies and absent forestry subsidy policies can often be viewed as discouraging forest production and thus, inadvertently, discouraging some possibilities for carbon sequestration. Similarly, tax policies can promote or discourage certain types of land use. In some countries, however, subsidies do promote afforestation and reforestation. The movement of land from agriculture to forests generally leads to gains in the forest sector and losses in the agricultural sector. The cost of any additional carbon storage can involve a change in welfare across two sectors. Lower taxes for agricultural lands and subsidies for forest clearing may be part of the package of instruments to promote development.

To reach objectives for carbon sequestration, market mechanisms are important, but an appropriate institutional setting is also useful. In some tropical countries the profitability of maintaining forests could be improved in order to prevent conversion to alternative uses of the land. Success could entail revising policies that directly or indirectly subsidize cattle ranching (as has been historically the case in Latin America) or agriculture. Success in $\mathrm{C}$ sequestration could also entail technical and financial training and capacity building at the local level. It should be recognized, however, that in many tropical countries, particularly within Asia and Africa, forests are harvested and used according to the subsistence needs of local communities. In these cases, some have argued that approaches based on market mechanisms will not be effective. Also, non-timber forest products are an important component of the total demand for forest products and could be considered.

It is clear that some measures aimed at sequestering $\mathrm{C}$ in the biosphere have relatively low cost compared to other approaches for mitigating the atmospheric increase of $\mathrm{CO}_{2}$ (Section 4.5). However, to date only a small number of projects involving a small and varied group of stakeholders has been initiated in the terrestrial biosphere. These projects (forest expansion, forest management, soil carbon management, community forestry, and agroforestry) have covered, worldwide, an area of 3.6 to 6.4 million hectares in 1999 (for an overview see Brown et al., 2000). Incentives that would create projects aimed at carbon sequestration in the biosphere on a large scale are not yet in place.

An important change in motivating carbon sequestration has been the creation of the Kyoto Protocol, in December 1997. Although few countries have yet to ratify the Kyoto Protocol, it introduces ceilings and/or quotas for $\mathrm{CO}_{2}$ emissions for Annex B countries. In addition, the Kyoto Protocol explicitly recognizes afforestation, reforestation, and deforestation (ARD) as having carbon implications, and it provides credits (and debits) for these activities in meeting carbon-emissions targets. This arrangement has contributed to pressures to find 
ways to give sequestered carbon value in the market place. A detailed explanation of how the Kyoto Protocol might influence management of $\mathrm{C}$ stocks is given in the IPCC Special Report on LULUCF (IPCC, 2000a).

Through setting emissions targets and introducing taxes on $\mathrm{CO}_{2}$ emission in some countries, carbon gains monetary value and could become a new product for the forestry sector. From existing emissions taxes this value is estimated at US $\$ 200 / \mathrm{tCO}_{2}$ in Norway and US\$100/tCO (Solberg, 1997; Nabuurs, 1998). In the case of the Netherlands, this carbon value is equivalent to US $\$ 17.5 / \mathrm{m}^{3}$ of roundwood, more than the stumpage value of wood as a raw material. However, in the first trades of certified carbon credits, MouraCosta and Stuart (1998) found that prices ranged between US\$5-US\$10/tC. More generally, Moura-Costa and Stuart (1998) found that the average price for carbon credits for carbon sequestered in developing countries ranged from US $\$ 0.19$ to US\$12/tC, and that these differences are very much linked to uncertainty about long term policy.

The Dutch Government is considering the introduction of $\mathrm{CO}_{2}$ certificates as part of a test of $\mathrm{CO}_{2}$ emissions trading. In this system, each economic sector and each firm could achieve its targets partly through certificates. Funds generated from these certificates would be used to establish forests.

\subsubsection{Carbon Offsets, Tradable Permits, and Leakage}

Markets created for carbon credits from management of the biosphere, of course, will be heavily influenced by the many other commodities produced by the biosphere (food, wood, etc.). Food security may, for example, be a reason for a government to continue its policy of agricultural subsidies in the absence of forestry (carbon) subsidies. On the other hand, some studies (e.g., Callaway and McCarl, 1996) have shown that when diverting agricultural subsidies to carbon payments, the net impact on the national budget could be zero. In tropical countries, the institutions and subsidies for forest clearing may remain as part of the package to promote economic development. Only if the monetary value of carbon stocks and sinks is recognized and paid for will markets be efficient in encouraging $\mathrm{C}$ sequestration. Some developing countries see markets for $\mathrm{C}$ offsets as providing resources to facilitate capital inflows to finance conservation and other activities.

An emerging instrument that is likely to have a large effect on carbon sequestration is the tradable emissions permit. Tradable permits to deal with environmental pollutants have precedents in other areas. In the USA, for example, there is an active market for sulphur emissions permits (Burtraw, 2000). Firms with excess emissions permits can trade these to firms in need of additional permits. Thus, incremental emissions are no longer free, but incur additional costs to the firm. Firms that have excess permits can either sell those permits or forego the opportunity of receiving a payment - an opportunity cost. Such an approach allows the market to reallocate emission permits, and thus emissions, to the users that receive the highest return from the permits, thereby distributing carbon emissions permits to the most efficient users. This approach is beginning to be contemplated in addressing the problem of increasing atmospheric carbon and is endorsed in the Kyoto Protocol.

Currently, there are a series of brokers prepared to trade carbon credits in the USA and Europe, e.g., Natsource and Canto Fitzgerald (Stuart and Moura-Costa, 1998), and the Sydney Futures Exchange in Australia is planning to begin trading in the latter part of $2000^{1}$ ). In addition to tradable carbon emission permits, the door is open for consideration of an analogous instrument, tradable "carbon offsets". Activities, such as planting and protecting forests, could provide carbon sequestration services that could be sold or traded.

To date there is only limited experience with certified carbon offset instruments. In the USA, the electrical power industry, through the Edison Electric Institute (EEI - an association of private electrical power companies), has formed the Utility Carbon Management Tree Program whereby the various member companies invest money into a project fund to develop or purchase carbon offset credits (Sedjo, 1999a). Another market approach has been created, the Certified Tradable Offsets, issued by the Costa Rican government, and the first carbonbacked securities worldwide (Stuart and Moura-Costa, 1998). These offsets are like JI or CDM as defined in the Kyoto Protocol, but would be tradable.

A potentially serious problem with carbon offsets is that there may be carbon leakage. Leakage refers to the situation in which a carbon sequestration activity (e.g., tree planting) on one piece of land inadvertently, directly or indirectly, triggers an activity which, in whole or part, counteracts the carbon effects of the initial activity. It can be shown that most of these types of problems arise from differential treatment of carbon in different regions and circumstances, and the problem is not unique to carbon sequestration activities but pervades carbon mitigation activities in the energy sector as well.

In land use, leakage can occur from either protection or planting activities. Suppose, for example, that a forest or wetland that was to be cleared is instead protected. Protection of one such forest or wetland may simply deflect the pressure to another piece of land that is not protected and will be cleared instead. Leakage can occur across both spatial and temporal boundaries. Additionally, a forest protected in one year is subject to the possibility of clearing in subsequent years.

A similar situation may also exist with activities such as tree planting. Trees provide at least two services: producing industrial wood and sequestering carbon. Trees planted for carbon sequestration, because they may eventually be used for wood,

${ }^{1}$ See International Herald Tribune, 31/08/1999. 
can affect expectations about future industrial wood prices, thereby influencing the planting decisions of forest products companies. If carbon credits are provided to carbon forests but not to industrial forests, and if some carbon forests are anticipated to enter future timber markets, then forest industrial firms may reduce investments in new forests. Such a reduction would partly offset carbon sequestered in the newly planted carbon forest, thereby reducing the net total carbon that would have accumulated by both industrial and carbon forests (Sedjo and Sohngen, 2000). This leakage effect would not occur if both industrial and carbon forests could expect to receive payment for both their carbon and their wood.

Leakage from industrial forests, resulting from forests established for carbon purposes, has been estimated by Sohngen and Sedjo (1999) to be about $40 \%$, globally, assuming that all carbon forests are made available to the timber market. This compares with estimated leakages in the energy sector of about $5 \%-20 \%$. No estimates of leakage generated from protection activities are available, but it is suggested that it may vary by country and site, unlike planted forests that are linked through the global timber market.

The leakage problem may be addressed reasonably well within nations by caps imposed on total emissions, but leakage of emissions across national boundaries may still occur in the absence of global coverage.

Conceptually, a permanent net carbon offset should be equivalent to a tradable emissions permit. If a new activity permanently reduces net atmospheric carbon by one tonne, the climatic implications are the same as if the tonne of carbon was never released. Thus, a carbon-offset credit would be equivalent to a tradable emission credit. However, since carbon offset can quickly be liquidated, offset credits have greater liability problems. One approach might be treated on an annual (or decadal) basis as the rental of (perhaps temporary) carbon sequestering services. Although different from carbon emissions permits, they nevertheless would expand the number of "credits" available, and thus have a mitigating effect on the market price of the credits. A discussion of some of the options is presented in IPCC (2000a).

\subsubsection{Risks, Rights, and Practical Economics}

Protecting forestlands, grasslands, and other natural ecosystems is often proposed as the best way to maintain large carbon reservoirs at lowest cost. The cost of such an approach, however, may in fact be significant, although low in comparison with many of the options in the energy sector and attempts at forest protection have failed in many parts of the world. The incentives to convert often far outweigh the incentives to protect. This problem is often exacerbated by the absence of welldefined, enforceable property rights, either private or public, and the absence of other necessary institutions. In an open access situation the incentives are to "use it or lose it", since there are no certain claims on the future use of the resource. Because there is no long-term claim on the resource in the future, the result is that resources may be used wastefully in excess of their economic optimum. Thus, deforestation and land clearing are a form of the open access problem (Hardin, 1968).

The costs of carbon management may not be distributed in the same way as the benefits. Carbon management options in developing countries may have low market costs but high local social costs in land commitments, and the benefits that arise may not be shared with local peoples. Analysis of a forest protection project in Madagascar suggests that there are financial benefits for local inhabitants and social benefits for the global community, but short-term debits at the national level (Kremen et al., 2000). Formal adoption of markets for forest carbon could increase incentives for forest protection, especially if mechanisms assure that local peoples share in the benefits. Similarly, costs and benefits may be realized at different times; future benefits are often weighted against current costs. How communities value present and future costs depends on wealth, culture, and economic and environmental priorities.

International consensus on carbon management begins to have important implications for national sovereignty and personal property rights, an issue brought to prominence by recent turmoil regarding international trade agreements (see Chapter 6 for a detailed discussion on policies, measures and instruments).

\subsection{Biological Uptake in Oceans and Freshwater Reservoirs, and Geo-engineering}

The net primary production of marine ecosystems is roughly the same as for terrestrial ecosystems $(50 \mathrm{GtC} / \mathrm{yr}$ for marine ecosystems and $60 \mathrm{GtC} / \mathrm{yr}$ for terrestrial ecosystems), and there are opportunities to increase the net carbon flow into the marine biosphere. There are fundamental differences between the two systems, however, as the marine biosphere does not include large stores of carbon in the living and dead biomass. There are some $3 \mathrm{GtC}$ in marine biota versus nearly $2500 \mathrm{GtC}$ in terrestrial vegetation and soils (Table 4.1). The key to increasing the carbon stocks in ocean ecosystems is thus to move carbon through the small reservoir of the marine biota to the larger reservoirs of dissolved inorganic carbon (the "biological pump") in ways that will isolate the carbon and prevent its prompt return to the atmosphere. The biological pump serves to move carbon from the atmosphere to the deep oceans, as organisms take up $\mathrm{CO}_{2}$ by photosynthesis in the surface ocean, and release the carbon when the organic material sinks and is oxidized at depth.

Several researchers have suggested that ocean productivity in major geographical regions is limited by the availability of primary or micronutrients, and that productivity could be increased substantially by artificially providing the limiting 
nutrients. This might involve providing nitrogen or phosphorus in large quantities, but the quantities to be supplied would be much smaller if growth were limited by a micronutrient. In particular, there is evidence that in large areas of the Southern Ocean productivity is limited by availability of the micronutrient iron. Martin $(1990,1991)$ suggested that the ocean could be stimulated to take up additional $\mathrm{CO}_{2}$ from the atmosphere by providing additional iron, and that 300,000 tonnes of iron could result in the removal of $0.8 \mathrm{GtC}$ from the atmosphere. Other analyses have suggested that the effect may be more limited. Peng and Broecker (1991) examined the dynamic aspects of this proposal and concluded that, even if the iron hypothesis was completely correct, the dynamic issues of mixing the excess carbon into the deep ocean would limit the magnitude of the impact on the atmosphere. Joos et al. (1991) reported on a similar model experiment and found the ocean dynamics to be less important, the time path of anthropogenic $\mathrm{CO}_{2}$ emissions to be very important, and the maximum potential effect of iron fertilization to be somewhat greater than reported by Peng and Broecker (1991).

Some of the concepts of iron fertilization have now been tested with 2 small-scale experiments in the equatorial Pacific Ocean. In experiment IronEX 1 (November, 1993) $480 \mathrm{~kg}$ of iron were added over 24 hours to a $64 \mathrm{~km}^{2}$ area of the equatorial Pacific. In IronEX 2 (May/June, 1995) a similar $450 \mathrm{~kg}$ of iron (as acidic iron sulphate) were added over a $72 \mathrm{~km}^{2}$ area, but the addition occurred in 3 doses over a period of one week.

The IronEx 1 experiment showed unequivocally that there was a biological response to the addition of iron. However, although plant biomass doubled and phytoplankton production increased fourfold, the decrease in $\mathrm{CO}_{2}$ fugacity (in effect the partial pressure of $\mathrm{CO}_{2}$ decreased by 10 micro atm) was only about a tenth of that expected (Martin et al., 1994; Watson et al., 1994; Wells, 1994). In the IronEX 2 experiment the abundance and growth rate of phytoplankton increased dramatically (by greater than 20 and twice, respectively), nitrate decreased by half, and $\mathrm{CO}_{2}$ concentrations were significantly reduced (the fugacity of $\mathrm{CO}_{2}$ was down $90 \mu \mathrm{atm}$ on day 9). Within a week of the last fertilization, however, the phytoplankton bloom had waned, the iron concentration had decreased below ambient, and there was no sign that the iron was retained and recycled in the surface waters (Monastersky, 1995; Coale et al., 1996; Cooper et al., 1996; Frost, 1996).

These two experiments have demonstrated that week-long, sustained additions of iron to nutrient-rich, but iron-poor, regions of the ocean can produce massive phytoplankton blooms and large drawdowns of $\mathrm{CO}_{2}$ and nutrients. While the results of these two experiments cannot be uncritically extrapolated, they suggest a very important role for iron in the cycling of carbon (Cooper et al., 1996). The consequences of larger, longer-term introductions of iron remain uncertain. Concerns that have been expressed relate to the differential impact on different algal species, the impact on concentrations of dimethyl sulphide in surface waters, and the potential for creating anoxic regions at depth (Coale et al., 1996; Frost, 1996; Turner et al., 1996). There is much to be learned of the ecological consequences of large-scale fertilization of the ocean.

Jones and Young (1998) suggest that the addition of reactive nitrogen in appropriate areas, perhaps in conjunction with trace nutrients, would increase production of phytoplankton and could both increase $\mathrm{CO}_{2}$ uptake and provide a sustainable fishery with greater yield than at present.

Chemical buffering of the oceans to decreases in $\mathrm{pH}$ associated with uptake of $\mathrm{CO}_{2}$ leads to an increase in dissolved inorganic carbon that does not rely on alteration of the biological pump. Buffering of the oceans is enhanced by dissolution of alkaline minerals. Dissolution of alkaline materials in ocean sediments with rising $\mathrm{pH}$ occurs in nature, but does so on a time-scale of thousands of years or more (Archer et al., 1997). Intentional dissolution of mined minerals has been considered, but the quantity (in moles) of dissolved minerals would be comparable to the quantity of additional carbon taken up by the oceans (Kheshgi, 1995).

Stallard (1998) has shown that human modifications of the earth's surface may be leading to increased carbon stocks in lakes, water reservoirs, paddy fields, and flood plains as deposited sediments. Burial of 0.6 to $1.5 \mathrm{GtC} / \mathrm{yr}$ may be possible theoretically. Although Stallard (1998) does not suggest intentional manipulation for the purpose of increasing carbon stocks, it is clear that human activities are likely leading to carbon sequestration in these environments already, that there are opportunities to manage carbon via these processes, and that the rate of carbon sequestration could be either increased or decreased as a consequence of human decisions on how to manage the hydrological cycle and sedimentation processes.

The term "geo-engineering" has been used to characterize large-scale, deliberate manipulations of earth environments (NAS, 1992; Marland, 1996; Flannery et al., 1997). Keith (2001) emphasizes that it is the deliberateness that distinguishes geo-engineering from other large-scale, human impacts on the global environment; impacts such as those that result from large-scale agriculture, global forestry activities, or fossil fuel combustion. Management of the biosphere, as discussed in this chapter, has sometimes been included under the heading of geo-engineering (e.g., NAS, 1992) although the original usage of the term geo-engineering was in reference to a proposal to collect $\mathrm{CO}_{2}$ at power plants and inject it into deep ocean waters (Marchetti, 1976). The concept of geo-engineering also includes the possibility of engineering the earth's climate system by large-scale manipulation of the global energy balance. It has been estimated, for example, that the mean effect on the earth surface energy balance from a doubling of $\mathrm{CO}_{2}$ could be offset by an increase of $1.5 \%$ to $2 \%$ in the earth's albedo, i.e. by reflecting additional incoming solar radiation back into space. Because these later concepts offer a potential approach for mitigating changes in the global climate, and because they 
are treated nowhere else in this volume, these additional geoengineering concepts are introduced briefly here.

Summaries by Early (1989), NAS (1992), and Flannery et al. (1997) consider a variety of ways by which the albedo of the earth might be increased to try to compensate for an increase in the concentration of infrared absorbing gases in the atmosphere (see also Dickinson, 1996). The possibilities include atmospheric aerosols, reflective balloons, and space mirrors. Most recently, work by Teller et al. (1997) has re-examined the possibility of optical scattering, either in space or in the stratosphere, to alter the earth's albedo and thus to modulate climate. The latter work captures the essence of the concept and is summarized briefly here to provide an example of what is envisioned. In agreement with the 1992 NAS study, Teller et al. (1997) found that $\sim 10^{7} \mathrm{t}$ of dielectric aerosols of $\sim 100 \mathrm{~nm}$ diameter would be sufficient to increase the albedo of the earth by $\sim 1 \%$. They showed that the required mass of a system based on alumina particles would be similar to that of a system based on sulphuric acid aerosol, but the alumina particles offer different environmental impact. In addition, Teller et al. (1997) demonstrate that use of metallic or optically resonant scatterers can, in principle, greatly reduce the required total mass of scattering particles required. Two configurations of metal scatterers that were analyzed in detail are mesh microstructures and micro-balloons. Conductive metal mesh is the most mass-efficient configuration. The thickness of the mesh wires is determined by the skin-depth of optical radiation in the metal, about $20 \mathrm{~nm}$, and the spacing of wires is determined by the wavelength of scattered light, about $300 \mathrm{~nm}$. In principle, only $\sim 10^{5} \mathrm{t}$ of such mesh structures are required to achieve the benchmark $1 \%$ increase in albedo. The proposed metal balloons have diameters of $\sim 4 \mathrm{~mm}$ and a skin thickness of $\sim 20 \mathrm{~nm}$. They are hydrogen filled and are designed to float at altitudes of $\sim 25 \mathrm{~km}$. The total mass of the balloon system would be $\sim 10^{6} \mathrm{t}$. Because of the much longer stratospheric residence time of the balloon system, the required mass flux (e.g., tonnes replaced per year) to sustain the two systems would be comparable. Finally, Teller et al. (1997) show that either system, if fabricated in aluminium, can be designed to have long stratospheric lifetimes yet oxidize rapidly in the troposphere, ensuring that few particles are deposited on the surface.

One of the perennial concerns about possibilities for modifying the earth's radiation balance has been that even if these methods could compensate for increased GHGs in the global and annual mean, they might have very different spatial and temporal effects and impact the regional and seasonal climates in a very different way than GHGs. Recent analyses using the CCM3 climate model (Govindasamy and Caldeira, 2000) suggest, however, that a $1.7 \%$ decrease in solar luminosity would closely counterbalance a doubling of $\mathrm{CO}_{2}$ at the regional and seasonal scale (in addition to that at the global and annual scale) despite differences in radiative forcing patterns.

It is unclear whether the cost of these novel scattering systems would be less than that of the older proposals, as is claimed by
Teller et al. (1997), because although the system mass would be less, the scatterers may be much more costly to fabricate. However, it is unlikely that cost would play an important role in the decision to deploy such a system. Even if we accept the higher cost estimates of the NAS (1992) study, the cost may be very small compared to the cost of other mitigation options (Schelling, 1996). It is likely that issues of risk, politics (Bodansky, 1996), and environmental ethics (Jamieson, 1996) will prove to be the decisive factors in real choices about implementation. The importance of the novel scattering systems is not in minimizing cost, but in their potential to minimize risk. Two of the key problems with earlier proposals were the potential impact on atmospheric chemistry, and the change in the ratio of direct to diffuse solar radiation, and the associated whitening of the visual appearance of the sky. The proposals of Teller el al. (1997) suggest that the location, scattering properties, and chemical reactivity of the scatterers could, in principle, be tuned to minimize both of these impacts. Nonetheless, most papers on geo-engineering contain expressions of concern about unexpected environmental impacts, our lack of complete understanding of the systems involved, and concerns with the legal and ethical implications (NAS, 1992; Flannery et al., 1997; Keith, 2000). Unlike other strategies, geo-engineering addresses the symptoms rather than the causes of climate change.

\subsection{Future Research Needs}

This chapter suggests a host of future research needs. A combination of statistical, ecological, and socio-economic research would be helpful to better understand the situation of the land, the forces of land-use change and the dynamic of forest carbon pools in relation to human activities and natural disturbance. More precise information is needed about degradation or improvement of secondary and natural forests throughout the world, but particularly in developing countries.

\section{Some specific examples are:}

- assessment of land available for mitigation options based on socio-economic pressures and land tenure policies. Furthermore, it would be beneficial if the impact of market price of carbon mitigated on land available for mitigation opportunities in different countries was understood;

- implications of financial incentives and mechanisms on LULUCF sector mitigation potential in different countries;

- comparative advantage (mitigation cost, ancillary benefits, etc.) of LULUCF sector mitigation options over energy sector opportunities;

- development and assessment of different approaches to developing baselines for LULUCF activities and comparison with other sectors; and

- socio-economic and environmental costs and benefits of implementing LULUCF sector mitigation options in developing countries, including issues such as property rights and land tenure. 
Finally, an important consideration is the problem of leakages. Research would help to determine the conditions under which leakage is likely to be a serious problem and when it may be less so. Estimates of the degree of leakage under varying circumstances could be made so that appropriate adjustments in carbon credits can be made. 


\section{References}

Adams, D.M., 1992: Long-term timber supply in the United States: an analysis of resources and policies in transition. Journal of Business Administration, 20, 131-156.

Adams, D.M., R.J. Alig, J.M. Callaway, B.A. McCarl, and S.M. Winnett, 1995: The forest and agricultural sector optmization model (FASOM): Model structure and policy implications. Research paper PNW-RP USDAForest Service, Pacific Northwest Research Station, USA, 166 pp.

Alcamo, J., and R. Swart, 1998: Future trends of land use emissions of major greenhouse gases. Mitigation and Adaptation Strategies to Global Change, 3, 343-381.

Alig R., D. Adams, B. McCarl, J.M. Callaway, and S. Winnett, 1997: Assessing Effects of Mitigation Strategies for Global Climate Change with an Intertemporal Model of the U.S. Forest and Agricultural Sectors. In Economics of Carbon Sequestration in Forestry. R.A. Sedjo, R.N. Sampson and J. Wisniewski (eds.), Lewis Publishers, Boca Raton, pp. 185193.

Alig, R.J., W.G. Hohenstein, B.C. Murray, and R.G. Haight, 1990: Changes in area of timberland in the United States, 1952-2040, by ownership, forest type, region and state. General Technical Report SE 64, USDA-Forest Service, Southeastern Forest Experiment Station, 34 pp.

Allen, R.K., K. Platt, and S. Wiser, 1995: Biodiversity in New Zealand plantation. New Zealand Forestry, 26-29 February.

Anderson, D.W., 1995: Decomposition of organic matter and carbon emissions from soils. In: Soils and Global Change. R. Lal, J. Kimble, E. Levine, and B. A. Stewart (eds.), Boca Raton, CRC Lewis Publishers, pp. 165-175.

Anonymous, 1999: Land-use, land-use change and forestry in Canada and the Kyoto Protocol. Canada's National Climate Change Process. Sinks Table Options Paper, 169 pp., http://www.nccp.ca/html/index.htm

Apps, M.J., and W.A. Kurz, 1993: The Role of Canadian Forests in the Global Carbon Balance. In Carbon Balance on World's Forested Ecosystems: Towards a Global Assessment. M. Kannien (ed.), Proceedings Intergovernmental Panel on Climate Change Workshop, Joensuu, Finland, 11-15 May 1992, Publications of the Academy of Finland, Helsinki, pp. 1428.

Apps, M.J., J.S. Bhatti, D. Halliwell, H. Jiang, and C. Peng, 2000: Ch 7: Simulated carbon dynamics in the boreal forest of central Canada under uniform and random disturbance regimes. In Global Climate Change and Cold Regions Ecosystems. R. Lal, J.M. Kimble, and B.A. Stewart (eds.), Advances in Soil Science, Lewis Publishers, Boca Raton, pp. 107-121.

Apps, M.J., W.A. Kurz, S.J. Beukema, and J.S. Bhatti, 1999: Carbon budget of the Canadian forest product sector. Environmental Science and Policy, 2, 25-41.

Ash, A.J., S.M. Howden, and J.G. McIvor, 1996: Improved rangeland management and its implications for carbon sequestration. In Proceedings of the Fifth International Rangeland Congress, Salt Lake City, Utah, USA, 23-28 July 1995, 1, 19-20.

Bajracharya, R.M., R. Lal, and J.M. Kimble. 1997: Long-term tillage effects on soil organic carbon distribution in aggregates and primary particle fractions of two Ohio soils. In Management of Carbon Sequestration in Soil. R. Lal, et al. (eds.), CRC Press, Boca Raton, pp. 113-123.

Balesdent, J., E. Besnard, D. Arrouays, and C. Chenu, 1998: The dynamics of carbon in particle-size fractions of soil in a forest-cultivation sequence. Plant and Soil, 201 49-57.

Ball, B.C., A. Scott, and J.P. Parker, 1999: Field $\mathrm{N}_{2} \mathrm{O}, \mathrm{CO}_{2}$ and $\mathrm{CH}_{4}$ fluxes in relation to tillage, compaction and soil quality in Scotland. Soil and Tillage Research, 53, 29-39.

Barrett, D.J., and R.M. Gifford, 1999: Increased C-gain by an endemic Australian pasture grass at elevated atmospheric $\mathrm{CO}_{2}$ concentration when supplied with non-labile inorganic phosphorus. Australian Journal of Plant Physiology, 26, 443-451.

Bass, S., J. Ford, O. Duboois, P. Moura-Costa, C. Wilson, M. Pinard, and R. Tipper, 2000: Rural Livelihoods and Carbon Management. An Issues Paper. International Institute for Environment and Development, Forestry and Land Use, London, UK.
Batjes, N.H., 1998. Mitigation of atmospheric $\mathrm{CO}_{2}$ concentrations by increased carbon sequestration in the soil. Biology and Fertility of Soils, 27, 230-235.

Batjes, N.H., 1999: Management options for reducing $\mathrm{CO}_{2}$-concentrations in the atmosphere by increasing carbon sequestration in the soil. Report 410 200031 , Dutch National Research Programme on Global Air Pollution and Climate Change, Project executed by the International Soil Reference and Information Centre, Wageningen, The Netherlands, 114 pp.

Bawa, K.S., and S. Dayanandan, 1997: Socioeconomic factors and tropical deforestation. Nature, 386, 562-563.

Bhatti, J. S., M.J. Apps and H. Jiang, 2001: Examining the Carbon Stocks of Boreal Forest Ecosystems at Stand and Regional Scales. In Assessment of Methods for Soil C Pools. R. Lal, M. Kimble, R.F. Follett, and B.A. Stewart (eds.), Advances in Soil Science. Lewis Publishers, Boca Raton, pp. 513-532.

Binkley, C.S., M.J. Apps, R.K. Dixon, P.E. Kauppi, and L.O. Nilsson, 1997: Sequestering carbon in natural forests In Economics of carbon sequestration in Forestry. R.A. Sedjo, R.N. Sampson, and J. Wisniewski (eds.). Critical Reviews in Environmental Science and Technology, 27, 23-45.

Birdsey, R.A., and L.S. Heath, 1995: Carbon changes in US forests. Productivity of America's Forests and Climate Change, 271, 56-70.

Birdsey, R.A., R. Alig, and D. Adams, 2000: Mitigation activities in the forest sector to reduce emissions and enhance sinks of greenhouse gases. In The Impact of Climate Change on America's Forests. L. Joyce and R. Birdsey (eds.), U.S. Department of Agriculture, Rocky Mountain Research Station, Fort Collins, CO, USA, $133 \mathrm{pp}$.

Bodansky, D., 1996: May We Engineer the Climate? Climatic Change, 33, 309-321.

Bolin, B., R. Sukumar, P. Ciais, W. Cramer, P. Jarvis, H. Kheshgi, C. Nobre, S. Semenov, and W. Steffen, 2000: Global perspective. In Land Use, Land Use Change and Forestry. R.T. Watson, I.R. Noble, B. Bolin, N.H. Ravindranath, D.J. Verardo, and D.J. Dokken (eds.), A Special report of the IPCC, Cambridge University Press, pp. 23-51.

Bonan, G.B., and H.H. Shugart, 1992: Soil temperature, nitrogen mineralization and carbon source sink relationships in boreal forests. Canadian Journal of Forest Research, 22, 629-639.

Bonduki, Y., and J.N. Swisher, 1995: Options for mitigating greenhouse gas emissions in Venezuela's forest sector: A general overview. Interciencia, 20(6), 380-387.

Boyce, S.G., 1995: Landscape forestry. John Wiley \& Sons, Inc., New York, pp. 67-166.

Braswell, B.H., D.S. Schimel, E. Linder, and B. Moore III, 1997: The response of global terrestrial ecosystems to interannual temperature variability. Science, 278, 870-872.

Brown, S., J. Sathaye, M. Cannell, and P.E. Kauppi, 1996a: Mitigation of carbon emissions to the atmosphere by forest management. Commonwealth Forestry Review, 75, 80-91.

Brown, S., J. Sathaye, M. Cannell, and P.E. Kauppi, 1996b: Management of forests for mitigation of greenhouse gas emissions. In Climate Change 1995 - Impacts, Adaptations and Mitigation of Climate Change: ScientificTechnical Analyses. R.T. Watson, M.C. Zinyowera, R.H. Moss, and D.J. Dokken (eds.), Contribution of Working Group II to the Second Assessment Report of the Intergovernmental Panel on Climate Change, Cambridge University Press, Cambridge, UK, pp. 773-797.

Brown, S., O. Masera, and J. Sathaye, 2000: Project based activities. In Land Use, Land Use Change and Forestry. R.T. Watson, I.R. Noble, B. Bolin, N.H. Ravindranath, D.J. Verardo, and D.J. Dokken (eds.), A Special report of the IPCC, Cambridge University Press, pp.283-338.

Bruce, J.P., M. Frome, E. Haites, H. Janzen, R. Lal, and K. Paustian, 1999: Carbon sequestration in soils. Journal of Soil and Water Conservation, 54, 381-389.

Brunner, J., K. Talbot, and C. Elkin, 1998: Logging Burma's Frontier Forests: Resources and the Regime. The World Resources Institute, Washington DC, USA.

Buchanan, A.H., and S.B. Levine, 1999: Wood based building materials and atmospheric carbon emissions. Environmental Science and Policy, 2, $427-$ 437. 
Burke, I.C., W.K. Lauenroth, and D.G. Milchunas. 1997: Biogeochemistry of managed grasslands in central North America. In Soil Organic Matter in Temperate Agroecosystems. Long-Term Experiments in North America. E.A. Paul, E.T. Elliott, K. Paustian, and C.V. Cole (eds.), CRC Press, Boca Raton, pp. 85-102.

Burke, I.C., W.K. Lauenroth, M.A. Vinton, P.B. Hook, R.H. Kelly, H.E. Epstein, M.R. Aguiar, M.D. Robles, M.O. Aguilera, K.L. Murphy, and R.A. Gill, 1998: Plant-soil interactions in temperate grasslands. Biogeochemistry, 42, 121-143.

Burschel, P., E. Kuersten, and B.C. Larson, 1993: Die Rolle von Wald und Forstwirtschaft im Kohlenstoffhaushalt. Eine Betrachtung für die Bundesrepublik Deutschland. (Role of Forests and forestry in the carbon cycle; a try-out for Germany). Forstliche Forschungsberichte München, Schriftenreihe der Forstwissenschaftlichen Fakultät der Universität München und der Bayerischen Forstlichen Versuchs- und Forschungsanstalt, 126, 135 pp.

Burtraw, D., 2000: Innovation Under the Tradable Sulfur Dioxide Emission Permits Program in the U.S. Electricity Sector. RFF Discussion Paper 0038, Resources for the Future, Washington DC, USA, 28 pp.

Callaway, J.M., and B.A. McCarl, 1996: The economic consequences of substituting carbon payments for crop subsidies in U.S. agriculture. Environmental and Resource Economics, 7, 15-43.

Campbell, I., C. Campbell, Z. Yu, D. Vitt, and M.J. Apps, 2000:. Millennialscale rhythms in peatlands in the western interior of Canada and in the global carbon cycle. Quaternary Research, 54, 155-158.

Cao, M., and F.I. Woodward, 1998:. Dynamic reponses of terrestrial ecosystem carbon cyling to global climate change. Nature, 393, 249-252.

Carter, M.R., E.G. Gregorich, D.A. Angers, R.G. Donald, and M.A. Bolinder, 1998: Organic C and N storage, and organic C fractions, in adjacent cultivated and forested soils of eastern Canada. Soil \& Tillage Research, 47,253-261.

Carter, M.R., E.G. Gregorich, D.W. Anderson, J.W. Doran, H.H. Janzen, and F.J. Pierce, 1997: Concepts of soil quality and their signific ance. In Soil Quality for Crop Production and Ecosystem Health. E.G. Gregorich, and M.R. Carter (eds.), Elsevier, Amsterdam, The Netherlands, pp. 1-19.

Chomitz, K.M., and K. Kumari, 1996: The domestic benefits of tropical forests: a critical review emphasizing hydrological functions. Policy Research Working Paper, World-Bank, No. WPS1601, 41 pp.

Christensen, B.T., and A.E. Johnston, 1997: Soil organic matter and soil quality - Lessons learned from long-term experiments at Askov and Rothamsted. In Soil Quality for Crop Production and Ecosystem Health. E.G. Gregorich, and M.R. Carter (eds.), Elsevier, Amsterdam, The Netherlands, pp. $399-430$.

Clawson, M., 1979: Forests in the Long Sweep of American History. Science, 204, 1168-1174.

Coale, K.H., K.S. Johnson, S.E. Fitzwater, R.M. Gordon, S. Tanner, F.P. Chavez, L. Ferioli, C. Sakamoto, P. Rogers, F. Millero, P. Steinberg, P. Nightingale, D. Cooper, W.P. Cochran, M.R. Landry, J. Constantinou, R. Rollwagen, A. Trasvina, and R. Kudela, 1996: A massive Phytoplankton Bloom Induced by an Ecosystem-Scale Iron Fertilization Experiment in the Equatorial Pacific Ocean. Nature, 383, 495-501.

Cohen, W.B., M.E. Harmon, D.O. Wallin, and M. Fiorella, 1996: Two decades of carbon flux from forests of the Pacific Northwest. BioScience, 46(11), 836-844, 20-33.

Cole, C.V., J. Duxbury, J. Freney, O. Heinemeyer, K. Minami, A. Mosier, K. Paustian, N. Rosenberg, N. Sampson, D. Sauerbeck, and Q. Zhao, 1996: Agricultural options for mitigation of greenhouse gas emissions. In Climate Change 1995 - Impacts, Adaptations, and Mitigation of Climate Change: Scientific-Technical Analyses. R.T. Watson, M.C. Zinyowera, R.H. Moss, and D.J. Dokken (eds.), Cambridge University Press, pp. 745-771.

Cole, C.V., J. Duxbury, J. Freney, O. Heinemeyer, K. Minami, A. Mosier, K. Paustian, N. Rosenberg, N. Sampson, D. Sauerbeck, and Q. Zhao, 1997: Global estimates of potential mitigation of greenhouse gas emissions by agriculture. Nutrient Cycling in Agroecosystems, 49, 221-228.

Cole, C.V., K. Flach, J. Lee, D. Sauerbeck, and B. Stewart, 1993: Agricultural sources and sinks of carbon. Water Air and Soil Pollution, 70, 111-122.

Conant, R.T., K. Paustian, and E.T. Elliot, 2001: Grassland management and conversion into grassland: Effects on soil carbon. Ecological Applications (in press).
Cony, M.A., 1995: Rational afforestation of arid and semiarid lands with multipurpose trees. Interciencia, 2(5), 249-253.

Cooper, D.J., A.J. Watson, and P.D. Nightingale, 1996: Large Decrease in Ocean Surface CO2 Fugacity in Response to in situ Iron Fertilization. Nature, 382, 511-513.

Da Motta, S., C. Young, and C. Ferraz, 1999: Clean Development Mechanism and Climate Change: Cost Effectiveness and Welfare Maximization in Brazil. Report to the World Resources Institute, Institute of Economics, Federal University of Rio de Janeiro, Brazil, 42 pp.

Da Silva, F. Jr., S. Rubio, and F. de Souza, 1995: Regeneration of an Atlantic forest formation in the understory of a Eucalyptus grandis plantation in south-eastern Brazil. Journal of Tropical Ecology, 11, 147-152.

Darwin, R., M. Tsigas, J. Lewandrowski, and A. Raneses, 1995: World Agriculture and climate change: economic adaptations. Agricultrural Economic Report No. 703, US Department of Agriculture, Economic Research Service, Washington DC, USA, 86 pp.

Darwin, R., M. Tsigas, J. Lewandrowski, and A. Raneses, 1996. Land Use and Cover in Ecological Economics. Ecological Economics, 17(3), 157-181.

Davidson, E.A., D.C. Nepstad, C. Klink, and S.E. Trumbore, 1995: Pasture soils as carbon sink. Nature, 376, 472-473.

Davidson, E.A., and I.L. Ackerman, 1993: Changes in soil carbon inventories following cultivation of previously untilled soils. Biogeochemistry, 20, 161-164.

Dick, W.A., R.L. Blevins, W.W. Frye, S.E. Peters, D.R. Christenson, F.J. Pierce, and M.L. Vitosh, 1998: Impacts of agricultural management practices on $\mathrm{C}$ sequestration in forest-derived soils of the eastern Corn Belt. Soil \& Tillage Research, 47, 235-244.

Dickinson, R.E., 1996: Climate Engineering - A Review of Aerosol Approaches to Changing the Global Energy Balance. Climatic Change, 33, 279-290.

Dixon, R.K., S. Brown, R.A. Houghton, A.M. Solomon, M.C. Trexler, and J. Wisniewski, 1994: Carbon pools and flux of global forest ecosystems. Science, 263, 185-190.

Dixon, R.K., J.K. Winjum, and P.E. Schroeder, 1993: Conservation and sequestration of carbon: the potential of forest and agroforest management practices. Global Environmental Change, 3(2), 159-173.

Duan, Z., X. Liu., and J. Qu, 1995: Effect of land desertification on $\mathrm{CO}_{2}$ content of atmosphere in China. Agricultural Input and Environment 1995, 279-302.

Dyson, F.J., 1977: Can we control the carbon dioxide in the atmosphere ?. Energy, 2, 287-291.

Early, J.T., 1989: Space-based Solar Screen to Offset the Greenhouse Effect. Journal of the British Interplanetary Society, 42, 567-569.

EPA/USIJI (US Environmental Protection Agency / US Initiative on Joint Implementation), 1998: Activities Implemented Jointly: Third Report to the Secretariat of the UN Framework Convention on Climate Change. 2 volumes, EPA-report 236-R-98-004. US Environmental Protection Agency, Washington DC, USA, p.19 (Vol. I) and p. 607 (Vol. II).

FACE Foundation, 1997: Annual report 1996. Foundation FACE, Arnhem, The Netherlands.

Falloon, P.D., P. Smith, J.U. Smith, J. Szabo, K. Coleman, and S. Marshall, 1998: Regional estimates of carbon sequestration potential: linking the Rothamsted Carbon Model to GIS databases. Biology and Fertility of Soils, 27, 236-241.

Fan, S., M. Gloor, J. Mahlman, S. Pacala, J. Sarmiento, T. Takahashi, and P. Tans, 1998: A large terrestrial carbon sink in North America implied by atmospheric and oceanic carbon dioxide data and models. Science, 282, $442-446$.

FAO (Food and Agriculture Organization), 1993: Forestry Statistics Today and tomorrow. FAO, Rome, Italy.

FAO, 1996: Forest resources assessment 1990: Survey of tropical forest cover and study of change processes. FAO Forestry paper 130. Food and Agriculture Organization of the United Nations, Rome, Italy.

FAO, 1997. State of the World's Forests. Food and Agriculture Organization of the United Nations, Rome, Italy, 200 pp.

Farrell, E.P., E. Führer, D. Ryan, F. Andersson, R. Hüttl, and P. Piussi, 2000: European forest ecosystems: building the future on the legacy of the past. Forest Ecology and Management, 132, 5-20. 
Fearnside, P.M., 1997: Greenhouse gases from deforestation in Brazilian Amazonia: net committed emissions. Climatic Change, 35(3), 321-360.

Fearnside, P.M., 1998: Plantation forestry in Brazil: projections to 2050. Biomass and Bioenergy, 15, 437-450.

Fearnside, P.M., 1999: Forests and global warming mitigation in Brazil: opportunities in the Brazilian forest sector for responses to global warming under the "clean development mechanism". Biomass-and-Bioenergy, 16, 171-189.

Feller, C., and M.H. Beare, 1997. Physical control of soil organic matter dynamics in the tropics. Geoderma, 79, 69-116.

Fernandes, E.C.M., P.P. Motavalli, C. Castilla, and L. Mukurumbira, 1997: Management control of soil organic matter dynamics in tropical land-use systems. Geoderma, 79, 49-67.

Fisher, M.J., I.M. Rao, M.A. Ayarza, C.E. Lascano, J.I. Sanz, R.J. Thomas, and R.R. Vera, 1994: Carbon storage by introduced deep-rooted grasses in the South American savannas. Nature, 371, 236-238.

Fisher, M.J., R.J. Thomas, and I.M. Rao, 1997: Management of tropical pastures in acid-soil savannas of South America for carbon sequestration in the soil. In Management of Carbon Sequestration in Soil. R. Lal et al. (eds.) CRC Press, Boca Raton, pp. 405-420.

Flach, K.W., T.O. Barnwell, Jr., and P. Crosson, 1997: Impacts of agriculture on atmospheric carbon dioxide. In Soil Organic Matter in Temperate Agroecosystems. Long-Term Experiments in North America. E.A. Paul, E.T. Elliott, K. Paustian, and C.V. Cole (eds.), CRC Press, Boca Raton, pp. 3-13.

Flannery, B.P., H. Kheshgi, G. Marland, M.C. MacCracken, H. Komiyama, W. Broecker, H. Ishitani, N. Rosenberg, M. Steinberg, T. Wigley, and M. Morantine, 1997: Geoengineering Climate. In Engineering Response to Global Climate Change. R.G. Watts (ed.), CRC/Lewis Publishers, Boca Raton, Louisiana, USA, pp. 379-427.

Forman, R.T.T., 1995: Land Mosaics - The ecology of landscapes and regions. Cambridge University Press, New York, 632 pp.

Franklin, J.F., and T.A. Spies, 1991: Composition, function, and structure of old-growth Douglas-fir forests. Wildlife and vegetation of unmanaged Douglas-fir forests. USDA Forest Service General Technical Report, PNW-GTR-285, pp. 71-80.

Frost, B.W., 1996: Phytoplankton Bloom on Iron Rations. Nature, 383, 475476.

Frumhoff, P.C., and E.C. Losos, 1998: Setting Priorities for Conserving Biological Diversity in Tropical Timber Production Forests. Union of Concerned Scientists, Cambridge, MA, USA, 14 pp.

Frumhoff, P.C., D.C. Goetze, and J.J. Hardner, 1998: Linking Solutions to Climate Change and Biodiversity Loss Through the Kyoto Protocol's Clean Development Mechanism. Union of Concerned Scientists, Cambridge, MA, USA, 14 pp.

Fujimori, T., 1997: Overview of forest resources and forestation activities in Japan. Environmentally friendly tree products and their processing technology. In Proceedings of the Japanese/Australian workshop on environmental management. Japan Science and Technology Agency and Forestry and Forest Products Research Institute, pp. 21-27.

Fukushima, Y., 1987: Influence of forestation on mountainside at granite highlands. Water Science, 177, 17-34.

Garratt, J.R., 1993: Sensitivity of Climate Simulations to Land-Surface and Atmospheric Boundary-Layer Treatments - A Review. Journal of Climate, 6, 419-449.

Giardina, C.P., and M.G. Ryan, 2000: Evidence that decomposition rates of organic carbon in mineral soils do not vary with temperature. Nature, $\mathbf{4 0 4}$, 858-861.

Glück, P., and G. Weiss, 1996: Forestry in the Context of Rural Development: Future Research Needs. Proceedings of the COST seminar 'Forestry in the Context of Rural Development', Vienna, Austria, 15-17 April 1996, EFI Proceedings No. 15, European Forest Institute Joensuu, Finland, 173 pp.

Gorham, E., 1991: Northern peatlands: role in the carbon cycle and probable response to climate warming. Ecological Applications, 1(2), 182-195.

Gorham, E., 1995: The biogeochemistry of northern peatlands and its possible responses to global warming. In Biotic Feedback in the Global Climatic System. Will the Warming Feed the Warming? G.M. Woodwell and F.T. McKenzie (eds.), Oxford University Press, New York, pp. 169-187.
Govindasamy, B., and K. Caldeira, 2000: Geoengineering Earth's Radiation Balance to Mitigate $\mathrm{CO}_{2}$-Induced Climate Change. Geophysical Research Letters, 27, 2141-2144.

Greenland, D.J, 1995: Land use and soil carbon in different agroecological zones. Soils and Global Change. In Soil Management and the Greenhouse Effect. R. Lal, J. Kimble, E. Levine, and B.A. Stewart (eds.), Lewis Publishers, pp. 9-24.

Hall, P.J., and B. Moody, 1994: Forest depletions caused by insects and diseases in Canada 1982-1987. Information Report ST-X-8, Natural Resources Canada, Canadian Forest Service, Ottawa, 14 pp.

Hall, D.O., H.E. Mynick, and R.H. Williams, 1991: Cooling the Greenhouse with bioenergy. Nature, 353, 11-12.

Harden, J.W., E.T. Sundquist, R.F. Stallard, and R.K. Mark, 1992: Dynamics of soil carbon during deglaciation of the Laurentide ice sheet. Science, $\mathbf{2 5 8}$ 1921-1924.

Hardin, G., 1968: The tragedy of the commons. Science, 162, 1243-1248.

Harmon, M.E., J.M. Harmon, W.K. Ferell, and D. Brooks, 1996: Modelling carbon stores in Oregon and Washington forest products: $1900-1992$. Climatic Change, 33, 521-550.

Harmon, M.E., W.K. Ferrel, and J.F. Franklin, 1990: Effects on carbon storage of conversion of old-growth forests to young forests. Science, 247(4943), 699-703.

Harris, L.D., 1984: The fragmented forest: Island biogeography theory and the preservation of biotic diversity. The University of Chicago, 211pp.

Harrison, K.G., W.S. Broecker, and G. Bonani, 1993: The effect of changing land use on soil radiocarbon. Science, 262, 725-726.

Heath, L.S., and R.A. Birdsey, 1993: Carbon trends of productive temperate forests of the conterminous United States. Water, Air, and Soil Pollution, 70, 279-293.

Heath, L.S., R.A. Birdsey, C. Row, and A.J. Plantinga, 1996: Carbon pools and fluxes in U.S. forest products. In Forest Ecosystems, Forest Management, and the Carbon Cycle. M.J. Apps, and D.T. Price (eds.), NATO ASi Series, 140, 271-278.

Herrick, J.E., and M.M. Wander, 1997: Relationships between soil organic carbon and soil quality in cropped and rangeland soils: the importance of distribution, composition, and soil biological activity. In: Soil Processes and the Carbon Cycle. R. Lal, J.M. Kimble, R.F. Follett, and B.A. Stewart (eds.), Boca Raton, CRC Press, pp. 405-425.

Hoen, H.F., and Solberg, B. 1994: Potential and economic efficiency of carbon sequestration in forest biomass through silvicultural management. Forest Science, 40, 429-451.

Hol, P., R. Sikkema, E. Blom, P. Barendsen, and W. Veening, 1999: Private investments in sustainable forest management. I. Final Report. Form Ecology Consultants and Netherlands Committee for IUCN, The Netherlands.

Houghton, R.A., 1995a: Changes in the storage of terrestrial carbon since 1850. In Soils and Global Change. R. Lal, J. Kimble, E. Levine, and B.A. Stewart (eds.), Lewis Publishers, Boca Raton, pp. 45-65.

Houghton, R.A., 1995b: Effects of land-use change, surface temperature, and $\mathrm{CO}_{2}$ concentration on terrestrial stores of carbon. In Biotic Feedbacks in the Global Climate Systems. G.M. Woodwell, and E.T. MacKenzie (eds.), Oxford University Press, New York, pp. 333-350.

Houghton, R.A., E.A. Davidson, and G.M. Woodwell, 1998: Missing sinks, feedbacks, and understanding the role of terrestrial ecosystems in the global carbon balance. Global Biogeochemical Cycles, 12, 25-34.

Houghton, R.A., J.L. Hackler, and K.T. Lawrence, 1999: The U.S. carbon budget: Contributions from land-use change. Science, 285, 574-578.

Houghton, R.A., D.L. Skole, C.A. Nobre, J.L. Hackler, K.T. Lawrence, and W.H. Chomentowski, 2000: Annual fluxes or carbon from deforestation and regrowth in the Brazilian Amazon. Nature, 403(6767), 301-304.

Huggins, D.R., G.A. Buyanovsky, G.H. Wagner, J.R. Brown, R.G. Darmody, T.R. Peck, G.W. Lesoing, M.B. Vanotti, and L.G. Bundy, 1998: Soil organic $\mathrm{C}$ in the tallgrass prairie-derived region of the corn belt: effects of longterm crop management. Soil \& Tillage Research, 47, 219-234.

Hulscher, W.S., Z. Luo, and A. Koopmans, 1999: Stoves on the carbon market. Wood Energy News, 14(3), 20-21.

Hungate, B.A., E.A. Holland, R.B. Jackson, F.S. Chapin, H.A. Mooney, and C.B. Field, 1997: The fate of carbon in grasslands under carbon dioxide enrichment. Nature, 388, 576-579. 
IGBP, 1998. The terrestrial carbon cycle: Implications for the Kyoto Protocol. Science, 280, 1393-1394.

IPCC (Intergovernmental Panel on Climate Change), 1996: Climate Change 1995: Impacts, Adaptations and Mitigation of Climate Change: ScientificTechnical Analyses. Contribution of working group II to the Second Assessment Report of the Intergovernmental Panel on Climate Change, R. Watson, M.C. Zinyowera, and R. Moss (eds.), Cambridge University Press, Cambridge, UK, 880 pp.

IPCC, 2000a: Land Use, Land Use Change and Forestry. R.T. Watson, I.R. Noble, B. Bolin, N.H. Ravindranath, D.J. Verardo, and D.J. Dokken (eds.), A Special report of the IPCC, Cambridge University Press, Cambridge, $\mathrm{UK}, 377 \mathrm{pp}$

IPCC, 2000b: Methodological and Technological Issues in Technology Transfer. B. Metz, O.R. Davidson, J.-W. Martens, S.N.M. van Rooijen, and L. van Wie-McGrory (eds.), A Special report of the IPCC, Cambridge University Press, Cambridge, UK, 466 pp.

Isensee, A.R., and A.M. Sadeghi, 1996: Effect of tillage reversal on herbicide leaching to groundwater. Soil Science, 161, 382-389.

ITTA (International Tropical Timber Agreement), 1983: 1983 United Nation Conference on Trade and Development. Geneva.

ITTA (International Tropical Timber Agreement), 1994: 1994 United Nations Conference on Trade and Development. Geneva.

Izac, A-M.N., 1997: Developing policies for soil carbon management in tropical regions. Geoderma, 79, 261-276.

Izaurralde, R.C., M. Nyborg, E.D. Solberg, H.H. Janzen, M.A. Arshad, S.S. Malhi, and M. Molina-Ayala, 1997: Carbon storage in eroded soils after five years of reclamation techniques, In Soil Processes and the Carbon Cycle. R. Lal, J.M. Kimble, R.F. Follett, and B.A. Stewart (eds.), CRC Press, Boca Raton, pp. 369-385.

Jacinthe, P.A,. and W.A. Dick, 1997: Soil management and nitrous oxide emissions from cultivated fields in southern Ohio. Soil and Tillage Research, 41, 221-235.

Jamieson, D., 1996: Ethics and Intentional Climate Change. Climatic Change, 33, 323-336.

Janzen, H.H., C.A. Campbell, R.C. Izaurralde, B.H. Ellert, N. Juma, W.B. McGill, and R.P. Zentner, 1998: Management effects on soil C storage on the Canadian prairies. Soil and Tillage Research, 47, 181-195.

Jepma, C.J., S. Nilsson, M. Amano, Y. Bonduki, L. Lonnstedt, J. Sathaye, and T. Wilson, 1997: Carbon sequestration and sustainable forest management: common aspects and assessment goals. In Economics of cabon sequestration in Forestry. R.A. Sedjo, R.N.Sampson, and J. Wisniewski (eds.), Critical Reviews in Environmental Science and Technology, 27, 83-96.

Johnson, M.G., 1995: The role of soil management in sequestering soil carbon. In Soil Management and Greenhouse Effect. R. Lal, J. Kimble, E. Levine and B.A. Stewart, Boca Raton, CRC Lewis Publishers, pp. 351363.

Jones, I.S.F., and H.E. Young, 1998: Enhanced Oceanic Uptake of Carbon Dioxide - an AIJ Candidate. In: Greenhouse Gas Mitigation: Technologies for Activities Implemented Jointly. P.W.F. Riemer, A.Y. Smith, and K.V. Thambimuthu (eds.), Elsevier Science Ltd., Oxford, UK, pp. 267-272.

Jong, B.H.J. de, G. Montoya-Gomez, K. Nelson, and L. Soto-Pinto, 1995: Community forest management and carbon sequestration: A feasibility study from Chiapas, Mexico. Interciencia, 20, 409-416.

Joos, F., J.L. Sarmiento, and U. Siegenthaler, 1991: Estimates of the Effect of Southern Ocean Iron Fertilization on Atmospheric CO2 Concentrations. Nature, 349, 772-774.

Kaimowitz, D., and A. Anglesen, 1998: Economic Models of Tropical Deforestation: a Review. Center for International Forestry Research (CIFOR), Bogor, Indonesia, $139 \mathrm{pp}$.

Kanowski, P.J., P.S. Savill, P.G. Adlard, J. Burley, J. Evans, J.R. Palmer, and P.J. Wood, 1992: Plantation forestry. In Managing the World's Forests. N.P. Sharma (ed.), Kendall-Hunt, Dubuque, Iowa, USA, pp. 375-401.

Karjalainen, T., A. Pussinen, S. Kellomäki, and R. Mäkipää, 1998: The History and Future Carbon Dynamics of Carbon Sequestration in Finland's Forest Sector. In Carbon Mitigation in Forestry and Wood Industry. G.H. Kohlmaier, M. Weber, and R.A. Houghton (eds.), Springer-Verlag, Berlin, pp. $25-42$.
Karjalainen, T., 1996: Dynamics and potentials of carbon sequestration in managed stands and wood products in Finland under changing climatic conditions. Forest Ecology and Management, 80, 113-132.

Karjalainen, T., S. Kellomaeki, and A. Pussinen, 1994: Role of wood based products in absorbing atmospheric carbon. Silva Fennica, 28(2), 67-80.

Kasimir-Klemedtsson, A., L. Klemedtsson, K. Berglund, P. Martikainen, J. Silvola, and O. Oenema. 1997: Greenhouse gas emissions from farmed organic soils: a review. Soil Use and Management, 13, 245-250.

Kauffman, J.B., D.L. Cummings, and D.E. Ward, 1998: Fire in the Brazilian Amazon. 2. Biomass, nutrient pools and losses in cattle pastures. Oecologia, 113, 415-427.

Kauppi, P.E., K. Mielkainen, and K. Kuusela, 1992: Biomass and carbon budget of European forests, 1971-1990. Science, 256, 70-74.

Kauppi, P.E., M. Posch, P. Hänninen, H.M. Henttonen, A. Ihalainen, E. Lappalainen, M. Starr, and P. Tamminen, 1997: Carbon reservoirs in peatlands and forets in the boreal regions of Finland. Silva Fennica, 31(1), 1325.

Keenan, R., D. Lamb, O. Woldring, T. Irvine, and R. Jensen, 1997: Restoration of plant biodiversity beneath tropical tree plantations in Northern Australia. Forest Ecology and Management, 99, 117-131.

Keith, D.W., 2000: Geoengineering the climate: History and prospect. Annual Reviews Energy and the Environment, 25, 245-284.

Keith, D.W., 2001: Geoengineering. In Oxford Encyclopedia of Global Change: Environmental Change and Human Society. A.S. Goudie (ed.), Oxford University Press, New York, 1440 pp.

Kern, J.S., G. Zitong, Z. Ganlin, Z. Huizhen, and L. Guobao, 1997: Spatial analysis of methane emissions from paddy soils in China and the potential for emissions reduction. Nutrient Cycling in Agroecosystems, 49, 181-195.

Kern, J.S., and M.G. Johnson, 1993: Conservation tillage impacts on national soil and atmospheric carbon levels. Soil Science Society America Journal, 57, 200-210.

Kharin, N., 1996: Strategy to combat desertification in Central Asia. Desertification Control Bulletin, 29, 29-34.

Kheshgi, H., 1995: Sequestering Carbon Dioxide by Increasing Ocean Alkalinity. Energy, 20, 915-922.

Kobayashi, K., 1987: Hydrologic effects of rehabilitation treatment for bare mountain slops. Bulletin of the Forestry and Forest Products Research Institute, 300, 151-185.

Kolchugina, T.P., T.S. Vinson, G.G. Gaston, V.A. Rozhkov, and A.Z. Shwidenko, 1995: Carbon pools, fluxes, and sequestration potential in soils of the former Soviet Union. In Soil Management and Greenhouse Effect. R. Lal, J. Kimble, E. Levine, and B.A. Stewart (eds.), CRC Lewis Publishers, Boca Raton, pp. 25-40.

Kremen, C., J.O. Niles, M.G. Dalton, G.C. Daily, P.R. Ehrlich, J.P. Fray, D. Gerwal, and R.P. Guillery, 2000: Economic incentives for rain forest conservation across scales. Science, 288, 1828-1832.

Kuliev, A., 1996: Forests - an important factor in combatting desertification. Problems of desert development, 4, 29-31.

Kumar, V., B.C. Ghosh, and R. Bhat, 1999: Recycling of crop wastes and green manure and their impact on yield and nutrient uptake of wetland rice. Journal of Agricultural Science, 132, 149-154.

Kurz, W.A., M.J. Apps, B.J. Stocks, and W.J.A. Volney, 1995a: Global climatic change: disturbance regimes and biospheric feedbacks of temperate and boreal forests. In Biotic feedbacks in the global climatic system: Will the warming speed the warming? G.M. Woodwell, and F.T. Mackenzie (eds.), Oxford University Press, New York, pp. 119-133.

Kurz, W.A., and M.J. Apps, 1999: A 70-year retrospective analysis of carbon fluxes in the Canadian forest sector. Ecological Applications, 9, 526-547.

Kurz, W.A., M.J. Apps, S.J. Beukema, and T. Lekstrum, 1995b: Twentieth century carbon budget of Canadian forests. Tellus, 47B, 170-177.

Kurz, W.A., M.J. Apps, T. Webb, and P. MacNamee, 1992: The Carbon Budget of the Canadian Forest Sector: Phase 1. ENFOR Information Report NOR-X-326, Forestry Canada Northwest Region, Edmonton, Alberta, Canada, 93 pp.

Kurz, W.A., S.J. Beukema, and M.J. Apps, 1997: Carbon budget implications of the transition from natural to managed disturbance regimes in forest landscapes. Mitigation and Adaptation Strategies for Global Change, 2, 405-421. 
Kuusela, K., 1994: Forest resources in Europe 1950-1990. Research Report 1, European Forest Institute, Joensuu, Finland, 154 pp.

Lähde, E., O. Laiho, and Y. Norokorpi, 1999: Diversity-oriented silviculture in the boreal zone of Europe. Forest Ecology and Management, 118, 223-243.

Lal, R., and J.P. Bruce, 1999: The potential of world cropland soils to sequester $\mathrm{C}$ and mitigate the greenhouse effect. Environmental Science and Policy, 2, 177-185.

Lal, R., J. Kimble, and R. Follett, 1997: Land use and soil C pools in terrestrial ecosystems. In: Management of Carbon Sequestration in Soil. R. Lal, J.M. Kimble, R.F. Follett, and B.A. Stewart. (eds.), CRC Press, Boca Raton, pp. 1-10.

Lal, R., J.M. Kimble, R.F. Follett, and C.V. Cole, 1998: The Potential of U.S. Cropland to Sequester Carbon and Mitigate the Greenhouse Effect. Sleeping Bear Press, Inc., Ann Arbor Press, Chelsea, MI.

Lal, R., R.F. Follett, J. Kimble, and C.V. Cole, 1999: Managing U.S. cropland to sequester carbon in soil. Journal of Soil and Water Conservation, First Quarter 1999: 374-381.

Larionova, A.A., A.M. Yermolayev, S.A. Blagodatsky, L.N. Rozanova, I.V. Yevdokimov, and D.B. Orlinsky, 1998: Soil respiration and carbon balance of gray forest soils as affected by land use. Biology and Fertility of Soils, 27, 251-257.

Le Maitre, D.C., and D.B. Versfeld, 1997: Forest evaporation models: relationships between stand growth and evaporation. Journal of Hydrology, 193, 240-257.

Lemke, R.L., R.C. Izaurralde, M. Nyborg, and E.D. Solberg, 1999: Tillage and $\mathrm{N}$ source influence soil-emitted nitrous oxide in the Alberta Parkland region. Canadian Journal of Soil Science, 79, 15-24.

Liski, J., H. Ilvesniemi, A. Makela, and M. Starr, 1998: Model analysis of the effects of soil age, fires and harvesting on the carbon storage of boreal forest soils. European Journal of Soil Science, 49, 397-406.

Liski, J.; H. Ilvesniemi, A. Makela, and C.J. Westman, 1999: CO2 emissions from soil in response to climatic warming are overestimated - the decomposition of old soil organic matter is tolerant of temperature. Ambio, 28(2), 171-174.

Lugo, A., 1997: The apparent paradox of reestablishing species richness on degraded lands with tree monocultures. Forest Ecology and Management, 99, 9-19.

Lunnan, A., S. Navrud, P.K. Rorstad, K. Simensen, and B. Solberg, 1991 : Skog og skogproduksjon i norge som virkemiddel mot $\mathrm{CO}_{2}$-opphopning $i$ atmosfaeren. Forest and wood products in Norway as a mean to reduce CO2-accumulation in the atmosphere. Skogforsk 6-1991, Norsk Institut for skogforskning og institut fro skogfag, Norges Landbrukshogskole, As Norway, $86 \mathrm{pp}$.

Luo, Z., and W. Hulscher, 1999: Woodfuel emissions and costs. Wood Energy News, 14(3), 13-15.

MacDicken, K.G., and N.T. Vergara, 1990: Introduction to agroforestry. In Agroforestry: Classification and Management. K.G. Macdicken, and N.T. Vergara (eds.), John Wiley and Sons, New York, USA, pp. 1-30.

MacKenzie, A.F., M.X. Fan, and F. Cadrin, 1997: Nitrous oxide emission as affected by tillage, corn-soybean-alfalfa rotations and nitrogen fertilization. Canadian Journal of Soil Science, 77, 145-152.

MacLaren, J.P., 1996: Plantation forestry - its role as a carbon sink: conclusions from calculations based on New Zealand's planted forest estate. In Forest Ecosystems, Forest Management and the Global Carbon Cycle. M.J. Apps, and D.T. Price (eds.), NATO ASI Series I (Global Environmental Change), Vol. I 40, Springer-Verlag Academic Publishers, Heidelberg, Germany, pp. 257-270.

Makipaa, R., T. Karjalainen, A. Pussinen, and S. Kellomaki, 1999: Effects of climate change and nitrogen deposition on the carbon sequestration of a forest ecosystem in the boreal zone. Canadian Journal of Forest Research, 29, 1490-1501.

Makundi, W.R., 1997: Global Climate Change Mitigation and Sustainable Forest Management - The Challenge of Monitoring and Verification. Journal of Mitigation and Adaptation Strategies for Global Change, 2, 133-155.

Makundi, W.R., 1998: Mitigation Options in Forestry, Land-use Change and Biomass Burning in Africa. In Climate Change Mitigation in Africa. G. Mackenzie, J. Turkson, and O. Davidson (eds), Proceedings of UNEP/SCEE Workshop, Harare, May 1998.
Makundi, W.R., W. Razali, D. Jones, and C. Pinso, 1998: Tropical Forests in the Kyoto Protocol: Prospects for Carbon Offset Projects after Buenos Aires. Tropical Forestry Update, 8(4), 5-8, International Tropical Timber Organization (ITTO), Yokohama, Japan.

Manley, J.T., G.E. Schuman, J.D. Reeder, and R.H. Hart, 1995: Rangeland soil carbon and nitrogen responses to grazing. Journal of Soil and Water Conservation, 50, 294-298.

Marchetti, C., 1976: On Geoengineering and the $\mathrm{CO}_{2}$ Problem. Research Memorandum RM-76-17, International Institute for Applied Systems Analysis, Vienna, Austria

Marland, G., 1996: Geoengineering. In Encyclopedia of climate and weather, volume 1. S.H. Schneider (ed.), Oxford University Press, New York, 338339.

Marland, G., and B. Schlamadinger, 1997: Forests for carbon sequestration or fossil fuel substitution? A sensitivity analysis. Biomass and Bioenergy, 13(6), 389-397.

Marland, G., and B. Schlamadinger, 1999: The Kyoto Protocol could make a difference for the optimal forest-based $\mathrm{CO}_{2}$ mitigation strategy: some results from GORCAM. Environmental Science and Policy, 2, 111-124.

Martin, J.H., 1990: A New Iron Age, or a Ferric Fantasy. US JGOFS Newsletter, 1(4), 5-6.

Martin, J.H., 1991: Iron, Liebig's Law, and the Greenhouse. Oceanography, 4, 52-55.

Martin, J.H., K.H. Coale, K.S. Johnson, S.E. Fitzwater, 1994: Testing the Iron Hypothesis in Ecosystems of the Equatorial Pacific Ocean. Nature, 371, 123-130.

Martin, P.H., R. Valentini, P. Kennedy, and S. Folving, 1998: New estimate of the carbon sink strength of EU forests integrating flux measurements, field surveys, and space observations: 0.17-0.35 Gt(C). Ambio, 27(7), 582-584.

Masera, O.R., 1995: Carbon Mitigation Scenarios for Mexican Forests: Methodological Considerations and Results. Interciencia, 20, 388-395.

Masera, O.R., and A. Ordóñez, 1997: Forest Management Mitigation Options. In Final report to the USAID-Support to the National Climate Change Plan for Mexico. C. Sheinbaum (Coord.), Instituto de ingeniería, National University of Mexico (UNAM), Report 6133, UNAM, Mexico City, pp. 77-93.

Masera, O.R., M. Bellon, and G. Segura, 1995: Forest management options for sequestering carbon in Mexico. Biomass and Bioenergy, 8(5), 357-368.

Masera, O.R., M.R. Bellon, and G. Segura, 1997b: Forestry Options for Sequestering Carbon in Mexico: Comparative Economic Analysis of Three Case Studies. Critical Reviews in Environmental Science and Technology, 27, 227-244.

Masera, O.R., M.J. Ordoñez, and R. Dirzo, 1997a: Carbon emissions from Mexican Forests: Current Situation and Long-term Scenario. Climatic Change, 35, 265-295.

Mather, A.S., 1990: Global forest resources. Chapter 3. Historical perspectives on forest resource use. Timber Press, Portland, OR, USA, pp. 30-57.

Matthews, R., G.J. Nabuurs, V. Alexeyev, R.A. Birdsey, A. Fischlin, J.P. MacLaren, G. Marland, and D. Price, 1996: WG3 Summary: Evaluating the role of forest management and forest products in the carbon cycle. In Forest ecosystems, forest management and the global carbon cycle. M.J. Apps, and D.T. Price (eds.), NATO Advanced Science Institute Series, NATO-ASI Vol I 40, Berlin, Heidelberg, Proceedings of a workshop held in September 1994 in Banff, Canada, pp. 293-301.

Melillo, J.R., A.D. McGuire, D.W. Kicklighter, B. Moore, C. J. Vorosmarty, and A.L. Schloss, 1993: Global climate change and terrestrial net primary production. Nature, 363, 234-240.

Meyer, W.B., and B.L. Turner II, 1992: Human population growth and global land-use / cover change. Annual Review Ecology Systematics, 23, 39-61.

Micales, J.A., and K.E. Skog, 1997: The decomposition of forest products in landfills. International Biodeterioration and Biodegradation, 39, 145-158.

Minami, K., 1995: The effect of nitrogen fertilizer use and other practices on methane emission from flooded rice. Fertilizer Research, 40, 71-84.

Mitsch, W.J., and X. Wu, 1995: Wetlands and global change. In Soil Management and Greenhouse Effect. R. Lal, J. Kimble, E. Levine, and B.A. Stewart (eds.), Boca Raton, CRC Lewis Publishers, pp. 205-230.

Monastersky, R., 1995: Iron versus the Greenhouse. Science News, 148, 220222. 
Morgan, J.A., W.G. Knight, L.M. Dudley, and H.W. Hunt, 1994: Enhanced root system $\mathrm{C}$-sink activity, water relations and aspects of nutrient acquisition in mycotrophic Bouteloua gracilis subjected to $\mathrm{CO}_{2}$ enrichment. Plant and Soil, 165, 139-146.

Mosier, A.R., 1998: Soil processes and global change. Biology and Fertility of Soils, 27, 221-229.

Moulton, R., and K. Richards, 1990: Costs of Sequestrating Carbon Through Tree Planting and Forest Management in the United States. GTR WO-58, USDA Forest Service, Washington DC, USA.

Moura-Costa, P., and M. Stuart, 1998: Forestry based greenhouse gas mitigation: a story of market evolution. Commonwealth Forestry Review, 77, 191-202.

Nabuurs, G.J., 1996: Significance of wood products in forest sector carbon balances. In Forest ecosystems, forest management and the global carbon cycle. M.J. Apps, and D.T. Price (eds.), NATO Advanced Science Institute Series, Vol I 40, Berlin, Heidelberg, Proceedings of the workshop held in September 1994 in Banff, Canada, 245-256.

Nabuurs, G.J., 1998: Bos wordt meer geld waard - Dutch forests become more valuable. Nederlands Bosbouwtijdschrift, 70(2), 69.

Nabuurs, G.J., and R. Sikkema, 1998: The role of harvested wood products in national carbon balances - an evaluation of alternatives for IPCC guidelines. IBN Research report 98/3, Institute for Forestry and Nature Research, Institute for Forest and Forest Products, $53 \mathrm{pp}$.

Nabuurs, G.J., A.V. Dolman, E. Verkaik, P.J. Kuikman, C.A. van Diepen, A. Whitmore, W. Daamen, O. Oenema, P. Kabat, and G.M.J. Mohren, 2000: Article 3.3 and 3.4. of the Kyoto Protocol - consequences for industrialised countries' commitment, the monitoring needs and possible side effect. Environmental Science and Policy, 3(2/3) 123-134.

Nabuurs, G.J., R. Paeivinen, R. Sikkema, and G.M.J. Mohren, 1997: The role of European forests in the global carbon cycle - a review. Biomass and Bioenergy, 13(6), 345-358.

Nadelhoffer, K.J., B.A. Emmett, P. Gundersen, O.J. Kjønaas, C.J. Koopmans, P. Schleppi, A. Tietema, and R.F. Wright, 1999: Nitrogen deposition makes a minor contribution to carbon sequestration in temperate forests. Nature, 398, 145-148.

Nair, P.K.R., 1989: The role of trees in soil productivity and protection. In Agroforestry systems in the tropics. P.K.R. Nair (ed.), Kluwer Academic Publishers, Dordrecht, The Netherlands, pp. 567-589.

NAS (National Academy of Sciences), 1992: Policy Implications of Greenhouse Warming: Mitigation, Adaptation, and the Science Base. Panel on Policy Implications of Greenhouse Warming, U.S. National Academy of Sciences, National Academy Press, Washington DC, USA.

Neue, H.U., 1997: Fluxes of methane from rice fields and potential for mitigation. Soil Use and Management, 13, 258-267.

Nilsson, S., and A. Shvidenko, 1998: Is sustainable development of the Russian forest sector possible? IUFRO-Occasional-Paper, 1998, No. 11, 76 pp.

Noble, I., M. Apps, R. Houghton, D. Lashof, W. Makundi, D. Murdiyarso, B. Murray, W. Sombroek, and R. Valentini, 2000: Implications of different definitions and generic issues. In: Land Use, Land Use Change and Forestry. R.T. Watson, I.R. Noble, B. Bolin, N.H. Ravindranath, D.J. Verardo, and D.J. Dokken (eds.), A Special report of the IPCC, Cambridge University Press, UK, pp. 55-126.

Nobre, C.A., P.J. Sellers, and J. Shukla, 1991: Amazonian Deforestation and Regional Climate Change. Journal of Climate, 4, 957-988.

Nogueira, L.A.H., M.A. Trossero, L. Couto, 1998: A discussion of the relationship between wood fibre for energy supply and overall supply of wood fibre for industry. Unasylva, 49, 51-56.

Norby, R.J., and M.F. Cotrufo, 1998: A question of litter quality. Nature, 396, 17-18.

Oldeman, L.R., 1994: The global extent of soil degradation. In Soil Resilience and Sustainable Land Use. D.J. Greenland, and I. Szaboles (eds.), CAB International, Wallingford, UK, pp. 99-118.

Owensby, C.E., 1993: Potential impacts of elevated $\mathrm{CO}_{2}$ and above- and belowground litter quality of a tallgrass prairie. Water Air and Soil Pollution, 70, 413-424.

Palo, M., and J. Uusivuori, 1999: Globalization of Forests, Societies and Environments. In World Forests, Society and Environment. M. Palo, and J. Uusivuori (eds.), Kluwer, pp. 3- 14.
Parks, P.J., and I.W. Hardie, 1995: Least-cost forest carbon reserves: cost effective subsidies to convert marginal agricultural land to forests. Land Economics, 71, 122-136.

Paustian, K., E.T. Elliot, and K. Killian, 1997a: Modeling soil carbon in relation to management and climate change in some agroecosystems in central North America. In Soil Processes and the Carbon Cycle. R. Lal, J.M. Kimble, R.F. Follett, and B.A. Stewart (eds.), CRC Press, Boca Raton, pp. 459-471.

Paustian, K., O. Andren, H.H. Janzen, R. Lal, P. Smith, G. Tian, H. Tiessen, M. van Noordwijk, and P.L. Woomer, 1997b: Agricultural soils as a sink to mitigate $\mathrm{CO}_{2}$ emissions. Soil Use and Management, 13, 230-244.

Paustian, K., H.P. Collins, and E.A. Paul, 1997c: Management controls on soil carbon. Soil Organic Matter in Temperate Agroecosystems. In Long-Term Experiments in North America. E.A. Paul, E.T. Elliott, K. Paustian, and C.V. Cole (eds.), CRC Press, Boca Raton, pp. 15-49.

Paustian, K., C.V. Cole, D. Sauerbeck, and N. Sampson, 1998: CO mitigation by agriculture: an overview. Climatic Change, 40, 135-62.

Paustian, K., J. Six, E.T. Elliott, and H.W. Hunt, 2000: Management options for reducing $\mathrm{CO}_{2}$ emissions from agricultural soils. Biogeochemistry, 48, $147-163$.

Peng, T.H., and W.S. Broecker, 1991: Dynamical Limitations on the Antarctic Iron Fertilization Strategy. Nature, 349, 227-229.

Perez-Garcia, J., L.A. Joyce, C.S. Binkley, and A.D. McGuire, 1997: Economic Impacts of Climate Change on the Global Forest Sector. In Economics of Carbon Sequestration in Forestry. R.S. Sedjo (ed.), Lewis Publishers, Boca Raton.

Pickett, S.T.A., and P.S. White, 1985: The Ecology of Natural Disturbance and Patch Dynamics. Academic Press Inc., San Diego, USA, 472 pp.

Pielke, R.A., and R. Avissar, 1990: Influence of Landscape Structure on Local and Regional Climate. Landscape Ecology, 4, 133-155.

Plantinga, A.J., T. Mauldin, and D.J. Miller, 1999: An econometric analysis of the costs of sequestering carbon in forests. American Journal of Agricultural Economics, 81(4), 812-824.

Poore, D., P. Burges, J. Palmer, S. Rietbergen, and T. Synnott, 1989: No Timber Without Trees: Sustainability in the Tropical Forest. Earthscan Publications, London.

Post, W.M., and K.C. Kwon, 2000: Soil carbon sequestration and land-use change: processes and potential. Global Change Biology, 6, 317-327.

Postel, S., and L. Heise, 1988: Reforesting the Earth. Worldwatch Institute, Washington DC, USA, $55 \mathrm{pp}$.

Potter, K.N., H.A. Torbert, H.B. Johnson, and C.R. Tischler, 1999: Carbon storage after long-term grass establishment on degraded soils. Soil Science, 164, 718-725.

Prentice, I.C., G.D. Farquhar, M.J.R. Fasham, M.L. Goulden, M. Heimann, V.J. Jaramillo, H.S. Kheshgi, C. Le Quéré, R.J. Scholes, D.W.R. Wallace, 2001: The Carbon Cycle and Atmospheric $\mathrm{CO}_{2}$. In Climate Change 2001: The Scientific Basis. Contribution of Working Group I to the IPCC Third Assessment Report, Cambridge University Press.

Price, D.T., M.J. Apps, and W.A. Kurz, 1998: Past and possible future dynamics of Canada's Boreal Forest Ecosystems. In Carbon Dioxide Mitigation in Forestry and Wood Industry. G.H. Kohlmaier, M. Weber, and R.A. Houghton (eds.), Springer-Verlag, Berlin, Germany, pp. 63-88.

Rabenhorst, M.C. 1995: Carbon storage in tidal marsh soils. In Soils and Global Change. R. Lal, J. Kimble, E. Levine, and B.A. Stewart, CRC Lewis Publishers, Boca Raton, pp. 93-103.

Rasmussen, P.E., and S.L. Albrecht, 1997: Crop management effects on organic carbon in semi-arid Pacific Northwest soils. In Management of Carbon Sequestration in Soil. R. Lal, J.M. Kimble, R.F. Follett, and B.A. Stewart, CRC Press, Boca Raton, pp. 209-219.

Raun, W.R., G.V. Johnson, S.B. Phillips, and R.L. Westerman, 1998: Effect of long-term $\mathrm{N}$ fertilization on soil organic $\mathrm{C}$ and total $\mathrm{N}$ in continuous wheat under conventional tillage in Oklahoma. Soil and Tillage Research, 47, 323-330.

Ravindranath, N.H., and B.S. Somashekhar, 1995: Potential and Economics of Forestry Options for Carbon Sequestration in India. Biomass and Bioenergy, 8, 323-336.

Ravindranath, N.H., and D.O. Hall, 1994: Indian forest conservation and tropical deforestation. Ambio, 23(8), 521-523. 
Ravindranath, N.H., and D.O. Hall, 1995: Biomass, Energy and Environment. A Developing Country Perspective from India. Oxford University Press, Oxford, UK, $376 \mathrm{pp}$.

Reeder, J.D., G.E. Schuman, and R.A. Bowman, 1998: Soil C and N changes on conservation reserve program lands in the Central Great Plains. Soil and Tillage Research, 47, 339-349.

Roberts, L., 1999: World Resources: 1998-99. A joint publication by The World Resources Institute, The United Nations Environment Programme, The United Nations Development Programme and The World Bank, Oxford University Press, New York.

Rosenzweig, C., and D. Hillel, 2000: Soils and global climate change: Challenges and opportunities. Soil Science, 165, 47-56.

Row, C., 1996: Effects of selected forest management options on carbon storage. In Forests and Global Change. Vol. 2. Forest Management Opportunities for Mitigating Carbon Emissions. N. Sampson, and D. Hair (eds.), American Forests, Washington DC, USA, pp. 27-58.

Sampson, R.N., M. Apps, S. Brown, C.V. Cole, J. Downing, L.S. Heath, D.S. Ojima, T.M. Smith, A.M. Solomon, and J. Wisniewski, 1993: Workshop Summary Statement - Terrestrial Biospheric Carbon Fluxes Quantification of Sinks and Sources of $\mathrm{CO}_{2}$. Water Air and Soil Pollution, 70(1-4), 3-15.

Sampson, R.N., R.J. Scholes, C. Cerri, L. Erda, D.O. Hall, M. Handa, P. Hill, M. Howden, H. Janzen, J. Kimble, R. Lal, G. Marland, K. Minami, K. Paustian, P. Read, P.A. Sanchez, C. Scoppa, B. Solberg, M.A. Trossero, S. Trumbore, O. Van Cleemput, A. Whitmore, and D. Xu, 2000: Additional Human-induced Activities - Article 3.4. In Land Use, Land-use Change, and Forestry. In R.T. Watson, I.R. Noble, B. Bolin, N.H. Ravindranath, D.J. Verardo, and D.J. Dokken (eds.), A Special Report of the Intergovernmental Panel on Climate Change, Cambridge University Press, Cambridge, UK, 377 pp.

Sathaye, J., and N.H. Ravindranath, 1998: Climate change mitigation in the energy and forestry sectors of developing countries. Annual Review of Energy and Environment, 23, 387-437.

Scharpenseel, H.W., 1993: Major carbon reservoirs of the pedosphere; sourcesink relations; potential of $\mathrm{d} 14 \mathrm{C}$ and $\mathrm{d} 13 \mathrm{C}$ as supporting methodologies. Water Air and Soil Pollution, 70, 431-442.

Scharpenseel, H.W., and P. Becker-Heidmann, 1994: Sustainable land use in the light of resilience/elasticity to soil organic matter fluctuations. In Soil Resilience and Sustainable Land Use. D.J. Greenland, and I. Szabolcs (eds.), CAB International, Wallingford, pp. 249-264.

Schelling, T.C., 1996: The Economic Diplomacy of Geoengineering. Climatic Change, 33, 303-307.

Schimel, D., J. Melillo, H. Tian, A.D. McGuire, D. Kicklighter, T. Kittel, N. Rosenbloom, S. Running, P. Thornton, D. Ojima, W. Parton, R. Kelly, M. Sykes, R. Neilson, and B. Rizzo, 2000: Contribution of increasing $\mathrm{CO}_{2}$ and climate to carbon storage by ecosystems in the United States. Science, 287, 2004-2006.

Schimel, D.S., 1995: Terrestrial ecosystems and the carbon cycle. Global Change Biology, 1, 77-91.

Schindler, D.W., and S.E. Bayley, 1993: The biosphere as an increasing sink for atmospheric carbon: Estimates from increased nitrogen deposition Global Biogeochemical Cycles, 7, 717-733.

Schlamadinger, B., and G. Marland, 1996: The role of forest and bioenergy strategies in the global carbon cycle. Biomasss and Bioenergy, 10, 275300.

Schlesinger, W.H., 1999: Carbon sequestration in soils. Science, 284, 2095.

Scholes, R.J., and N. van Breemen, 1997: The effects of global change on tropical ecosystems. Geoderma, 79, 9-24.

Scholes, R.J., E.D. Schulze, L.F. Pitelka, and D.O. Hall, 1999: Biogeochemistry of terrestrial ecosystems. In The Terrestrial Biosphere and Global Change: Implications for Natural and Managed Ecosystems. B. Walker, W. Steffen, J. Canadell, and J. Ingram (eds.), Cambridge University Press, Cambridge, pp. 271-303.

Schulze, E.D., 2000: Carbon and nitrogen cycling in European forest ecosystems. Ecological Studies, Vol. 142, Springer, Heidelberg, Germany, 500 pp.
Schulze, E.D., J. Lloyd, F.M. Kelliher, C. Wirth, C. Rebmann, B. Luhker, M. Mund, A. Knohl, I.M. Milyukova, W. Schulze, W. Ziegler, A. Varlargin, A.F. Sogachev, R. Valentini, S. Dore, S. Grigoriev, O. Kolle, M.I. Panfyorov, N. Tchebokova, and N.N. Vygodskaya, 1999: Productivity of forests in the Eurosiberian boreal region and their potential to act as a carbon sink - a synthesis. Global Change Biology, 5, 703-722.

Sedjo, R.A., 1983: The Comparative Economics of Plantation Forestry. Johns Hopkins Press, Resources for the Future, Baltimore, MD, USA, 161 pp.

Sedjo, R.A., 1992: Forest Ecosystem in the Global Carbon Cycle. Ambio, 21(4), 274-277.

Sedjo, R.A., 1997: The economics of forest-based biomass supply. Energy Policy, 25(6), 559-566.

Sedjo, R.A., 1999a: Land Use Change and Innovation in U.S. Forestry. In Productivity in Natural Resources Industries: Improvement Through Innovation. David Simpson (ed.), Resources for the Future, Washington DC, USA, pp. 141-174.

Sedjo, R.A., 1999b: Potential for Carbon Forest Plantations in Marginal Timber Forests: The Case of Patagonia, Argentina. RFF Discussion Paper 99-27, Resources for the Future, Washington DC, 20 pp.

Sedjo, R.A., and D. Botkin, 1997: Using Forest Plantations to Spare natural Forests. Environment, 30(10), 14-20 and 30.

Sedjo, R.A., and K.S. Lyon: 1990: The Long-Term Adequacy of World Timber Supply. Resources for the Future, Washington DC, USA, $230 \mathrm{pp}$.

Sedjo, R.A., and B. Sohngen, 2000: Forestry Sequestration of CO2 and Markets for Timber. RFF Discussion Paper 00-35, Resources for the Future, Washington DC, USA, $83 \mathrm{pp}$.

Sedjo, R.A., and A.M. Solomon, 1989: Climate and Forests. In Greenhouse Warming : Abatement and Adaptation. N.J. Rosenberg, W.E. Easterling, P.R. Crosson, and J. Darmstadter (eds.), Resources for the Future, Washington DC, pp. 105-120.

Sedjo, R.A., J. Wisniewski, A.V. Sample, and J.D. Kinsman, 1995: The economics of managing carbon via forestry: assessment of existing studies. Environmental and Resource Economics, 6(2), 139-165.

Sheinbaum, C., and O.R. Masera, 2000: Mitigating Carbon Emissions while Advancing National Development Priorities - The Case of Mexico. Climatic Change, 47(3), 259-282.

Shepashenko, D., A. Shvidenko, and S. Nilsson, 1998: Phytomass (live biomass) and carbon of Siberian forests. Biomass and Bioenergy, 14(1), 2131.

Singh, B.R., T. Borresen, G. Uhlen, and E. Ekeberg, 1997a: Long-term effects of crop rotation, cultivation practices, and fertilizers on carbon sequestration in soils in Norway. In: Management of Carbon Sequestration in Soil. R. Lal, J.M. Kimble, R.F. Follett, and B.A. Stewart (eds.), CRC Press, Boca Raton, pp.195-208.

Singh, B., Y. Singh, M.S. Maskina, and O.P. Meelu, 1997b: The value of poultry manure for wetland rice grown in rotation with wheat. Nutrient Cycling in Agroecosystems, 47, 243-250.

Smith, P., D.S. Powlson, M.J. Glendining, and J.U. Smith, 1997: Opportunities and limitations for $\mathrm{C}$ sequestration in European agricultural soils through change in management. In Management of Carbon Sequestration in Soil. R. Lal, J.M. Kimble, R.F. Follett, and B.A. Stewart (eds.), CRC Press, Boca Raton, pp. 143-152.

Sohngen, B., and R. Mendelsohn, 1998: Valuing the impact of large-scale ecological change in a market: The effect of climate change on US timber American Economic Review, 88(4), 686-710.

Sohngen, B., and R.A. Sedjo, 1999: Carbon Sequestration by Forestry Effects of Timber Markets. Report number PH3/10, IEA Greenhouse Gas R\&D Programme, UK, $74 \mathrm{pp}$.

Sohngen, B., R. Mendelsohn, and R.A. Sedjo, 1999: Forest management, Conservation, and Global Timber Markets. American Journal of Agricultural Economics, 81, 1-13.

Solberg, B., 1997: Forest biomass as carbon sink - economic value and forest management/policy implications. Critical reviews in Environmental Science and Technology, 27, S323-333.

Solberg, B., D. Brooks, H. Pajuoja, T.J. Peck, and P.A. Wardle, 1996: Longterm trends and prospects in world supply and demand for wood and implications for sustainable forest management. EFI research report 6, European Forest Institute/Norwegian Forest Research Institute, A contribution to the CSD Ad Hoc Intergovernmental Panel on Forests, 31 pp. 
Solomon, D., J. Lehmann, and W. Zech, 2000: Land use effects on soil organic matter properties of chromic luvisols in semi-arid northern Tanzania: carbon, nitrogen, lignin and carbohydrates. Agriculture Ecosystems and Environment, 78, 203-213.

Spiecker, H., K. Mielikainen, M. Kohl, and J.P. Skovsgaard, 1996: Growth Trends in European Forests. Springer-Verlag, Heidelberg, Germany, 372 pp.

Stallard, R.F., 1998: Terrestrial sedimentation and the carbon cycle: Coupling weather and erosion to carbon burial. Global Biogeochemical Cycles, $\mathbf{1 2}$, 231-257.

Stavins, R., 1999: The Costs of Carbon Sequestration: A Revealed Preference Approach. The American Economic Review, 89, 994-1009.

Stockfisch, N., T. Forstreuter, and W. Ehlers, 1999: Ploughing effects on soil organic matter after twenty years of conservation tillage in Lower Saxony, Germany. Soil and Tillage Research, 52, 91-101.

Stuart, M.D., and P.H. Moura-Costa, 1998: Greenhouse gas mitigation: a review of international policies and initiatives. In Policies that Work for People, Series no. 8, International Institute of Environment and Development, London, UK, pp. 27-32.

Teller, E., L. Wood, and R. Hyde, 1997: Global Warming and Ice Ages: I. Prospects for Physics-Based Modulation of Global Change. UCRL-JC128715, Lawrence Livermore National Laboratory, Livermore, California, USA, $20 \mathrm{pp}$.

Tian, G., G.O. Kolawole, F.K. Salako, and B.T. Kang, 1999: An improved cover crop-fallow system for sustainable management of low activity clay soils of the tropics. Soil Science, 164, 671-682.

Tiessen, H., C. Feller, E.V.S.B. Sampaio, and P. Garin, 1998: Carbon sequestration and turnover in semiarid savannas and dry forest. Climatic Change, 40, 105-117

Tole, L., 1998: Source of deforestation in tropical developing countries. Environmental Management, 22, 19-33.

Torbert, H.A., H.H. Rogers, S.A. Prior, W.H. Schlesinger, and G.B. Runions, 1997: Effects of elevated atmospheric $\mathrm{CO}_{2}$ in agro-ecosystems on soil carbon storage. Global Change Biology, 3, 513-521.

Townsend, A.R., and E.B. Rastetter, 1996: Nutrient constraints on carbon storage in forested ecosystems. In Forest Ecosystems, Forest Management and the Global Carbon Cycle. M.J. Apps, and D.T. Price (eds.), NATO ASI Series I (Global Environmental Change), Vol. I 40, Springer-Verlag Academic publishers, Heidelberg, Germany, pp. 35-46.

Trexler and Associates, Inc., 1998: Final Report of the Biotic Offsets Assessment Workshop, Baltimore, USA. Prepared for the US Environmental Protection Agency, Washington DC, USA, 107 pp.

Turner, D.P., G.J. Koerper, M.E. Harmon, and J.L. Lee, 1995: A carbon budget for forests of the conterminous United States. Ecological Applications, 5, 421-436.

Turner, S.M., P.D. Nightingale, L.J. Spokes, M.I. Liddicoat, and P.S. Liss, 1996: Increased Dimethyl Sulphide Concentrations in Sea Water From in situ Iron Enrichment. Nature, 383, 513-517.

Turner, D.P., J.K. Winjum, T.P. Kolchugina, and M.A. Cairns, 1997: Accounting for biological and anthropogenic factors in national land-based carbon budgets. Ambio, 26, 220-226.

UN-ECE/FAO (UN Economic Committee for Europe / Food and Agricultural Organisation), 2000: Forest resources of Europe, CIS, North America, Australia, Japan and New Zealand. Geneva Timber and Forest Study papers No 17, United Nations Economic Committee for Europe, Food and Agricultural Organisation, Geneva, Switzerland, 445 pp.

UNFCCC (UN Framework Convention on Climate Change), 1997: The Kyoto Protocol to the United Nations Framework Convention on Climate Change. Document FCCC/CP/1997/7/Add.1. http://www.unfccc.de/

Valentini, R., A. Matteucci, A.J. Dolman, and E.D. Schulze, 2000: Respiration as the main determinant of carbon balance of European forests. Nature, 404, 861-865.

Van der Gon, H.D., 2000: Changes in $\mathrm{CH}_{4}$ emission from rice fields from 1960 to 1990s. 1- Impacts of modern rice technology. Global Biogeochemical Cycles, 14, 61-72.

Van Ginkel, J.H., A. Gorissen, and J.A. van Veen, 1996: Long-term decomposition of grass roots as affected by elevated atmospheric carbon dioxide. Journal of Environmental Quality, 25, 1122-1128.
Van Noordwijk, M., C. Cerri, P.L. Woomer, K. Nugroho, and M. Bernoux, 1997: Soil carbon dynamics in the humid tropical forest zone. Geoderma, 79, 187-225.

Vitousek, P.M., H.A. Mooney, J. Lubchenco, and J.M. Melillo, 1997: Human domination of earth's ecosystems. Science, 277, 494-499.

Waggoner, P., 1994: How Much Land Can Ten Billion People Spare for Nature? Task Force Report No. 121, Council for Agricultural Science and Technology, Ames, IA, 64 pp.

Wan Razali, W.M., and J. Tay, 2000: Forestry Carbon Emission Offset and Carbon Sinks Project: Examples of Opportunity in Carbon Sequestration and its Implications from Kyoto Protocol. International Workshop on The response of tropical forest ecosystems to long term cyclic climate change, Science and Technology Agency, Japan, National Research Council of Thailand, 24-27 January, 2000, Kanchanaburi, Thailand, 10 pp.

Wang, X., and Z. Feng, 1995: Atmospheric carbon sequestration through agroforestry in China. Energy, 20(2), 117-121.

Watson, A.J., C.S. Law, K.A. Van Scoy, F.L. Millero, W. Yao, G.E. Friedrich, M.I. Liddcoat, R.H. Wanninkhof, R.T. Barber, and K.H. Coale, 1994: Minimal Effect of Iron Fertilization on Sea-Surface Carbon Dioxide Concentrations. Nature, 371, 143-145.

WBGU (Wissenschaftlicher Beirat der Bundesregierung Globale Umweltveränderungen), 1998: Die Anrechnung biologischer Quellen und Senken im Kyoto-Protokoll: Fortschritt oder Rückschlag für den globalen Umweltschutz? Sondergutachten 1998, WBGU, Bremerhaven, Germany, 76 pp., (available in English).

Weber, M.G., and M.D. Flanningan, 1997: Canadian boreal forest ecosystem structure and function in a changing climate: impact on fire regimes. Environmental Reviews, 5, 145-166.

Wedin, D.A., and D. Tilman, 1996: Influence of Nitrogen Loading and Species Composition on the Carbon Balance of Grasslands. Science, 274, 1720 1723 .

Wells, M.L., 1994: Pumping Iron in the Pacific. Nature, 368, 295-296.

Wernick, I.K., P.E. Waggoner, and J.H. Ausubel, 1998: Searching for Leverage to Conserve Forests. The Industrial Ecology of Wood Products in the United States. Journal of Industrial Ecology, 1, 125-145.

Willison, T.W., J.C. Baker, and D.V. Murphy, 1998: Methane fluxes and nitrogen dynamics from a drained fenland peat. Biology and Fertility of Soils, 27, 279-283.

Winjum, J.K., S. Brown, and B. Schlamadinger, 1998: Forest harvests and wood products: sources and sinks of atmospheric carbon dioxide. Forest Science, 44(2), 272-284.

Woodwell, G.M., F.T. Mackenzie, R.A. Houghton, M. Apps, E. Gorham, and E. Davidson, 1998: Biotic Feedbacks in the Warming of the Earth. Climatic Change, 40, 495-518.

Woomer, P.L., C.A. Palm, J.N. Qureshi, and J. Kotto-Same, 1997: Carbon sequestration organic and resource management in African smallholder agriculture. In Management of Carbon Sequestration in Soil. R. Lal, J.M. Kimble, R.F. Follett, and B.A. Stewart (eds.), CRC Press, Boca Raton, pp. 153-173.

WRI (World Resources Institute), 1987: Tropical Forestry Action Plan: Recent Developments. The World Resources Institute, Washington DC, USA.

Yadav, R.L., D.S. Yadav, R.M. Singh, and A. Kumar, 1998: Long term effects of inorganic fertilizer inputs on crop productivity in a rice-wheat cropping system. Nutrient Cycling in Agroecosystems, 51, 193-200.

Yagi, K., H. Tsuruta, and K. Minami, 1997: Possible options for mitigating methane emission from rice cultivation. Nutrient Cycling in Agroecosystems, 49, 213-220.

Yoshida, K., 1983: Heterogeneous environmental structure in a moth community of Tomakomai Experiment Forest, Hokkaido University. Japan Journal of Ecology, 33, 445-451.

Young, A., 1997: Agroforestry for Soil Management ( $2^{\text {nd }}$ edition). CAB International, Oxford, UK, 320 pp.

Zhang, Z.X., 1996: Some economic aspects of climate change. International Journal Environment and Pollution, 6, 185-195.

Zoltai, S.T., and P.J. Martikainen, 1996: Estimated extent of forested peatlands and their role in the global carbon cycle. In Forest Ecosystems, Forest Management and the Global Carbon Cycle. M.J. Apps, and D.T. Price (eds.), NATO ASI Series, Series I: Global Environmental Change, Vol. 40, pp. 47-58. 
